SÉRGIO TONZAR RISTORI OZAKI

DETECÇÃO DE ADULTERAÇÃO DE COMBUSTÍVEIS COM SENSORES POLIMÉRICOS ELETRODEPOSITADOS E REDES NEURAIS ARTIFICIAIS 
SÉRGIO TONZAR RISTORI OZAKI

\title{
DETECÇÃO DE ADULTERAÇÃO DE COMBUSTÍVEIS COM SENSORES POLIMÉRICOS ELETRODEPOSITADOS E REDES NEURAIS ARTIFICIAIS
}

\author{
Dissertação apresentada à Escola \\ Politécnica da Universidade de São Paulo \\ para obtenção do título de Mestre em \\ Engenharia Elétrica
}




\section{DETECÇÃO DE ADULTERAÇÃO DE COMBUSTÍVEIS COM SENSORES POLIMÉRICOS ELETRODEPOSITADOS E REDES NEURAIS ARTIFICIAIS}
Dissertação apresentada à Escola Politécnica da Universidade de São Paulo para obtenção do título de Mestre em Engenharia Elétrica

Área de concentração:

Engenharia Elétrica - Microeletrônica

Orientador: Prof. Livre-Docente Fernando Josepetti Fonseca 


\section{DEDICATÓRIA}

Dedico este trabalho aos meus pais. 


\section{AGRADECIMENTOS}

Ao Grupo de Eletrônica Molecular (GEM) da Escola Politécnica da Universidade de São Paulo.

Ao orientador deste trabalho, Prof. Dr. Fernando Josepetti Fonseca, pelo apoio no desenvolvimento e contribuição com idéias para este trabalho.

À Dra. Alessandra A. Corrêa Forner pela fabricação dos filmes e ao Dr. Leonardo Giordano Paterno também pelo acompanhamento nas atividades de pesquisa.

Ao IPT e à ANP pela colaboração com a análise de combustíveis.

Aos funcionários do Laboratório de Microeletrônica (LME) pelo suporte nas atividades de laboratório.

Ao Conselho Nacional de Desenvolvimento Científico e Tecnológico (CNPq) e à Fundação de Amparo à Pesquisa do Estado de São Paulo (FAPESP).

Aos meus pais, Sérgio e Lúcia, pelo apoio e incentivo constantes ao meu estudo. 


\section{RESUMO}

A adulteração de combustíveis é uma grande preocupação no Brasil. A agência reguladora nacional (ANP) detecta anualmente de 1 a $3 \%$ de adulterações nas amostras coletadas, o que é um índice alto considerando o tamanho do mercado brasileiro. As alternativas de adulteração são vastas e muito dinâmicas, por isso os arranjos de sensores baseados no conceito de "seletividade global" parecem os mais adequados para detectar falsificação de combustíveis. O conceito de seletividade global leva em conta a sensibilidade cruzada de sensores químicos não específicos e o uso de métodos de análise multivariada de dados para encontrar padrões para amostras de diferentes composições químicas. Os sensores químicos podem ser obtidos de uma variedade de materiais sensoativos, cujas respostas elétricas variam de acordo com as propriedades físico-químicas do meio em que se encontra. Os polímeros condutores são excelentes materiais sensoativos, pois sua condutividade elétrica é grandemente influenciada pelas condições ambientais e podem ser processados na forma de filmes finos através várias técnicas. No presente trabalho, filmes de poli(3-metiltiofeno) (PMTh) e poli(3-hexiltiofeno) são depositados por cronopotenciometria e cronoamperometria sobre microeletrodos interdigitados e são caracterizados por espectroscopia de impedância. Os dados são analisados por redes neurais artificiais do tipo multilayer perceptron e bons resultados são obtidos na detecção de adulteração de gasolina. O mesmo estudo também pode ser aplicado na deteç̧ão de adulteração de álcool etílico combustível com um desempenho um pouco pior.

Palavras-chave: Sensores químicos. Combustíveis veiculares. Redes Neurais Artificiais. Falsificação 


\begin{abstract}
Fuel adulteration is a major concern in Brazil. The local governmental agency detects from 1 to $3 \%$ of problematic samples yearly, which is a lot considering Brazil's market size. The myriad of adulteration possibilities is vast and it is very dynamic, thus array of sensors based on "global selectivity" concept seems to be more suitable methodology to detect problems in fuel. The global selectivity concept encompasses the cross-sensitivity of non-specific chemical sensors and the use of multivariated data analysis methods as a way to provide "fingerprints" for samples of different chemical composition. The chemical sensors can employ different types of sensoactive materials, whose electrical responses are dependent on the physicochemical characteristics of the media they get in contact with. Conducting polymers (CP) are per excellence suitable sensoactive materials, since their electrical conductivity is highly influenced by the environmental conditions and they can be easily processed in the thin film form by different techniques. In the present work films of poly(3-methylthiophene) (PMTh) and poly(3-hexylthiophene) (PHTh) are deposited by chronopotenciometry and chronoamperometry onto interdigitated microelectrodes and characterized through Impedance Spectroscopy. This data was analyzed with Multilayer perceptron neural networks and a very good performance is found in gasoline adulteration detection. A less great performance was also achieved in the investigation vehicular ethanol adulteration.
\end{abstract}

Keywords: Chemical sensors. Vehicular fuel. Artificial neural networks. Falsification. 


\section{LISTA DE ILUSTRAÇÕES}

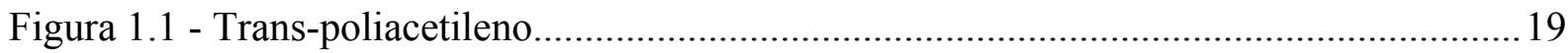

Figura 1.2 - Estrutura química de alguns polímeros conjugados.......................................... 21

Figura 1.3 - Diagrama de um sensor condutométrico constituído de uma estrutura

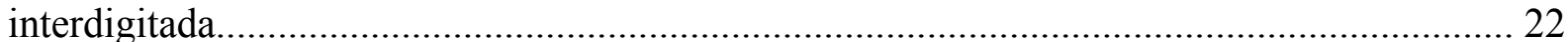

Figura 1.4 - Potenciostato e célula eletroquímica................................................................ 23

Figura 1.5 - (a) Modelo elétrico de um metal recoberto por um material pouco condutivo imerso em um eletrólito (TAYLOR; MACDONALD, 1987). (b) e (c) Gráficos de Bode e Nyquist para um circuito com: $\mathrm{Rb}=10 \mathrm{M} \Omega, \mathrm{Cb}=2 \mathrm{nF}, \mathrm{Cg}=20 \mathrm{pF}, \mathrm{Rt}=100 \mathrm{M} \Omega, \mathrm{Cd}=100 \mathrm{nF}$ e $\mathrm{Rd}=100 \mathrm{k} \Omega$.

Figura 1.6 - (a) Modelo elétrico de um recobrimento orgânico sobre um eletrodo metálico (LOVEDAY et al., 2004). (b) e (c) Gráficos de Bode e Nyquist para um circuito com: $\mathrm{Ru}=10 \Omega, \mathrm{Cc}=10 \mathrm{nF}, \mathrm{Rporo}=1 \mathrm{k} \Omega, \mathrm{Cd}=1 \mu \mathrm{F}, \mathrm{Rp} 10 \mathrm{k} \Omega$.

Figura 1.7 - (a) Microscopia eletrônica de varredura de um filme de poli(tiofeno-3-ácido acético) (GARCIA-BELMONTE; BISQUERT, 2001). (b) Microscopia de força atômica de um filme de Pani/PSS depositado por automontagem (BRAGA et al., 2008)..........................27 Figura 1.8 - Modelo de um único poro (FLETCHER, 1992)................................................. 28 Figura 1.9 - Simulação (BISQUERT et al., 1999 e 2000). (a) Simulação do circuito (d). (b) e (c) simulação do circuito (e). (d) Modelo considerando transporte de carga no PC. (e) Modelo considerando a transferência de carga entre polímero e o eletrólito.

Figura 1.10 - Correção de deriva. (a) PCA de dois dias sem correção. (b) PCA com correção multiplicativa (HAUGEN, 2000)

Figura 1.11 - Cromatografias gasosas típicas de ga solinas de duas refinarias: (a) Manguinho e

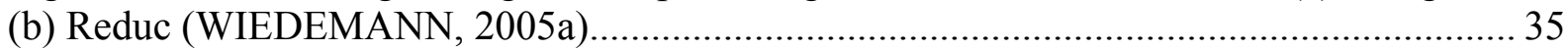

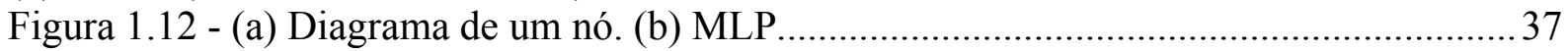

Figura 1.13 - (a) Rede modular. (b) Rede não modular.......................................................... 40

Figura 2.14 - Microeletrodo interdigitado. (a) Principais parâmetros. (b) Ilustração e

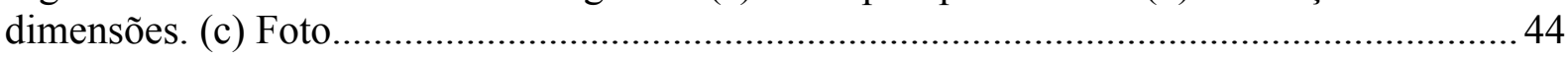

Figura 2.15 - Automontagem (a) e Língua Eletrônica (b)................................................... 45

Figura 2.16 - Estrutura química dos reagentes para automontagem..................................... 46

Figura 2.17 - (a) Poli(3-metiltiofeno) -PMTh (b) Poli(3-hexiltiofeno) - PHTh........................ 47

Figura 2.18 - (a)Micrografia do poli(3-metiltiofeno) preparado por cronoaperometria a 1,5V e

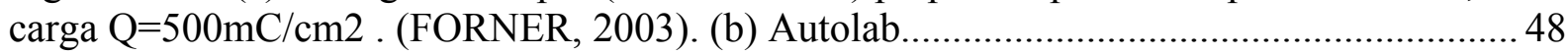

Figura 2.19 - Sistema convencional de medidas - gases e líquidos..................................... 49

Figura 2.20 - Diagrama do sistema de gás com câmara.........................................................50

Figura 2.21 - Sistema de medição de gás em câmara. (a) Diagrama, (b) Detalhes do sistema de entrada de gás, (c) Câmara, (d) Diagrama do fluxo de gás na câmara, (e) Câmara com sensores e (f) Sistema completo de medição........................................................................ 52 Figura 3.22 - Resposta de diferentes sensores expostos ao vapor de etanol medidos em $1 \mathrm{kHz}$ em função do tempo. (a) Condutância e (b) capacitância do circuito RC paralelo equivalente.

Figura 3.23 - Espectroscopia de impedância de um filme de para POEA/PSS. Curvas de cores preta, azul e amarela são do período da manhã e vermelha, verde e cinza da tarde.................56 Figura 3.24 - Espectroscopia de impedância de um filme de para Pani/Ni-TS-PC. Curvas de cores preta, azul e amarela são do período da manhã e vermelha, verde e cinza da tarde........56 Figura 3.25 - Espectroscopia de impedância de um filme de para POMA/PPy. Curvas de cores preta, azul e amarela são do período da manhã e vermelha, verde e cinza da tarde.........57 
Figura 3.26 - Espectroscopia de impedância de um filme de para POMA/PEDOT. Curvas de cores preta, azul e amarela são do período da manhã e vermelha, verde e cinza da tarde........57 Figura 3.27 - Espectroscopia de impedância de um filme de para PAni/LS. Curvas de cores preta, azul e amarela são do período da manhã e vermelha, verde e cinza da tarde. .58 Figura 3.28 - Condutância (gráficos a), c) e e))e Capacitância (gráficos b), d) e f)) dos sensores medidos na câmara de medidas, sendo que a) e b) são sensores de Pani/Fc-Ts-Ni, c) e d) são sensores de POMA/PEDOT e e) e f) são sensores de Pani/LS.

Figura 3.29 - Efeito da umidade sobre a capacitância do sensor de PAni/LS.........................61

Figura 3.30 - PCA de amostras de etanol combustível comercial.........................................62

Figura 3.31 - Respostas de condutância e capacitância da LE em 1kHz............................... 63 Figura 3.32 - Sensibilidade de sensores de liquido às misturas de etanol e gasolina medida em três freqüências.

Figura 3.33 - Aproximação por circuito equivalente filme PMTh 1,0mA imerso em gasolina.

(a) Gráfico da impedância Real x Imaginária. (b) Gráficos de módulo e fase x freqüência.....65

Figura 3.34 - Espectroscopia de impedância do microeletrodo T10.

Figura 3.35 - Parâmetros do circuito equivalente em função da composição do combustível.

Figura 3.36 - (a) Análise PCA de gasolinas comerciais. (b) Região A ampliada. B: amostra com Temperatura de 90\% evaporado inferior ao especificado. C: amostras com teor alcoólico acima de 40\%. D: Amostras conformes. E: Amostras com teor alcoólico alto ou com elevado ponto final de ebulição...

Figura 3.37 - (a) Análise PCA de etanol combustível comercial. (b) Ampliação da região esquerda do gráfico. Aproximadamente, região A: mostra uma amostra com elevada CE. B: amostras conformes e não-conformes. C: amostras conformes. 


\section{LISTA DE TABELAS}

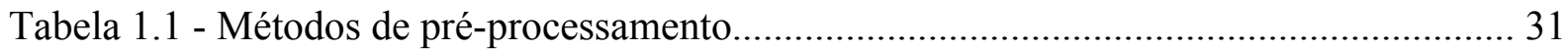

Tabela 2.2 - Parâmetros de dimensão geométrica dos microeletrodos.................................... 44

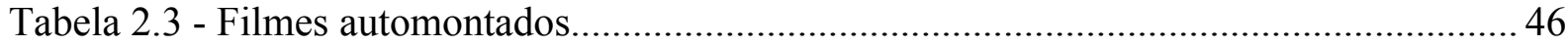

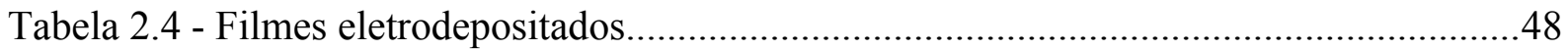

Tabela 3.5 - Valor dos parâmetros do circuito equivalente para sensor PMTh-1,0mA com

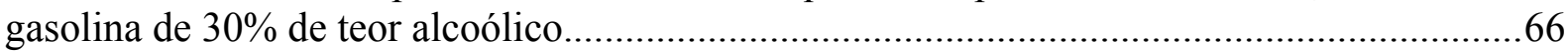

Tabela 3.6 Amostras comerciais de gasolina com respectivos valores de análise físico-química e limites de conformidades vigentes no período de medição....................................................71

Tabela 3.7 Amostras comerciais de álcool etílico hidratado combustível e suas respectivas análises físico-químicas e limites de conformidade vigentes no período................................ 74 Tabela 3.8 Comparação do algoritmo com resultado do proben1 para rede neural sem camada

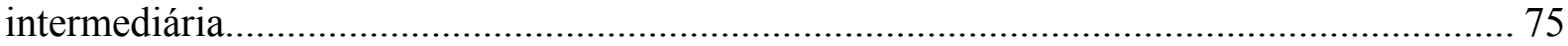

Tabela 3.9 Comparação do algoritmo com resultado do proben1 para rede com camada

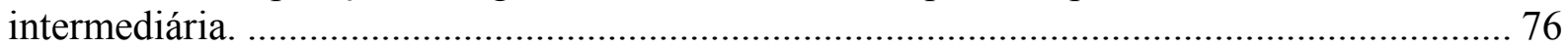

Tabela 3.10 Desempenho da RNA sem camadas intermediárias para combustíveis reais....... 77

Tabela 3.11 Desempenho da RNA com camadas intermediárias para combustíveis reais.......77

Tabela 3.12 Matriz de confusão para conjunto Etanol 1..................................................... 78

Tabela 3.13 Matriz de confusão para conjunto Etanol 2 ........................................................ 78

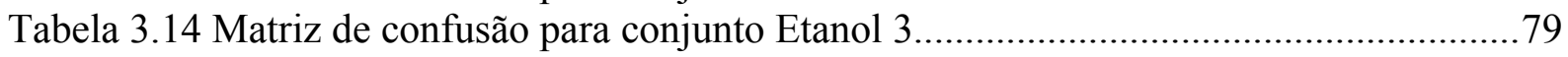

Tabela 3.15 Matriz de confusão para conjunto Gasolina 1......................................................79

Tabela 3.16 Matriz de confusão para conjunto Gasolina 2 .................................................. 79

Tabela 3.17 Matriz de confusão para conjunto Gasolina 3 ................................................... 80 


\section{LISTA DE ABREVIATURAS E SIGLAS}

$\begin{array}{ll}\text { AC } & \text { Corrente (elétrica) alternada } \\ \text { AEAC } & \text { Álcool etílico anidro combustível } \\ \text { AEHC } & \text { Álcool etílico hidratado combustível } \\ \text { Bissetriz } & \text { Algoritmo de treinamento da RNA baseado no EBP } \\ \text { CE } & \text { Condutividade elétrica } \\ \text { CI } & \text { Circuito Integrado } \\ \text { CNLS } & \text { Método de mínimos quadrados não-linear complexo (Complex } \\ & \text { nonlinear least squares) } \\ \text { DC } & \text { Corrente (elétrica) contínua } \\ \text { EBP } & \text { Error backpropagation. } \\ \text { EI } & \text { Espectroscopia de impedância } \\ \text { Embrapa } & \text { Empresa Brasileira de Pesquisa Agropecuária } \\ \text { HOMO } & \text { Orbital molecular mais alto ocupado (Highest occupied molecular } \\ & \text { orbital) } \\ \text { LB } & \text { Técnica de deposição Langmuir-Blodget } \\ \text { LE } & \text { Língua eletrônica } \\ \text { LS } & \text { Lignina sulfonada } \\ \text { LUMO } & \text { Orbital molecular mais baixo desocupado (Lowest unoccupied } \\ & \text { molecular orbital) } \\ \text { MLP } & \text { Multilayer perceptron } \\ \text { NE } & \text { Nariz eletrônico } \\ \text { Ni-TS-Pc } & \text { Ftalocianina tetrasulfonada de níquel } \\ \text { PAni } & \text { Polianilina } \\ \text { PC } & \text { Polímero conjugado } \\ \text { PCA } & \text { Análise de componentes principais } \\ \text { PEDOT } & \text { Poli(3,4 etilenodioxitiofeno) } \\ \text { PFE } & \text { Ponto final de ebulição } \\ \text { POEA } & \text { Poli(o-etoxianilina) } \\ \text { POMA } & \text { Poli(o-metoxianilina) } \\ \text { PPy } & \text { Polipirrol } \\ \text { PSS } & \text { Poliestireno sulfonado } \\ \text { PTh } & \text { Politiofeno } \\ \text { REDOX } & \text { Reações químicas de redução e oxidação } \\ \text { RNA } & \text { Rede neural artificial } \\ \text { SOM } & \text { Mapas auto-organizáveis } \\ \text { T10\% } & \text { Em uma curva de destilação, esta é a temperatura em que 10\% do } \\ \text { T50\% } & \text { volume são evaporados. } \\ \text { T90\% uma curva de destilação, esta é a temperatura em que 50\% do são evaporados. } \\ \end{array}$




\section{LISTA DE SÍMBOLOS}

$\begin{array}{ll}\mathrm{K} & \text { Kelvin } \\ \mu & \text { Mobilidade de portadores de carga } \\ \sigma & \text { Condutividade elétrica } \\ \mathrm{Gp} & \text { Condutância de um circuito RC paralelo } \\ \mathrm{Rp} & \text { Resistência de um circuito RC paralelo } \\ \mathrm{Cp} & \text { Capacitância de um circuito RC paralelo } \\ \mathrm{Rs} & \text { Resistência de um circuito RC série } \\ \mathrm{Cs} & \text { Capacitância de um circuito RC série }\end{array}$




\section{SUMÁRIO}

INTRODUÇ̃̃O)

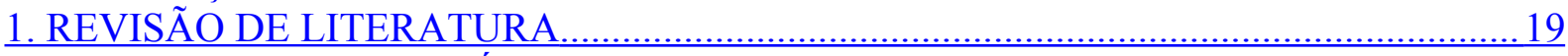

1.1. SENSORES DE POLÍMEROS CONJUGADOS......................................................19

1.1.1. Polímeros conjugados......................................................................................... 19

1.1.2. Sensores Poliméricos..................................................................................... 21

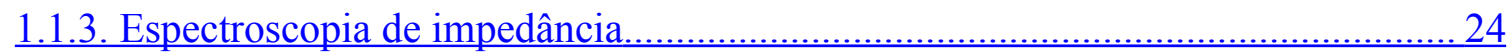

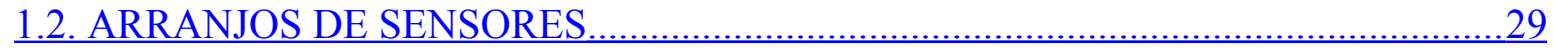

1.2.1. Seletividade global............................................................................................29

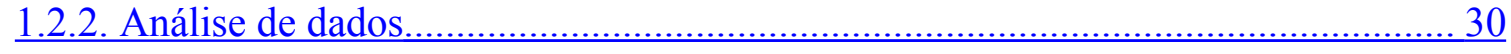

1.2.3. Variacão temporal dos sensores..........................................................................31

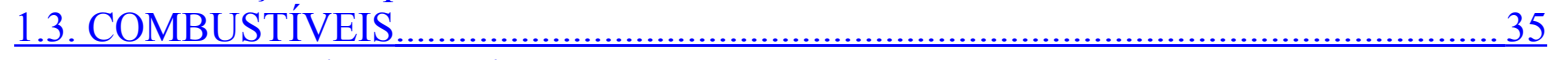

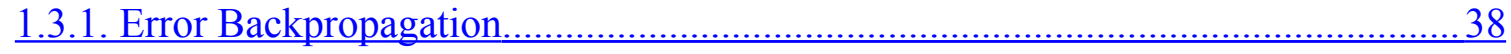

1.3.2. Redes Modulares......................................................................................4 40

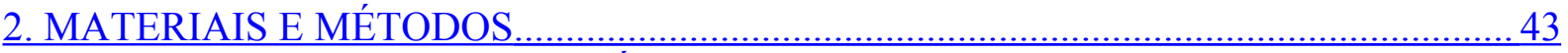

2.1. AMOSTRAS DE COMBUSTÍVEIS..................................................................... 43

2.2. MICROELETRODO INTERDIGITADO................................................................ 43

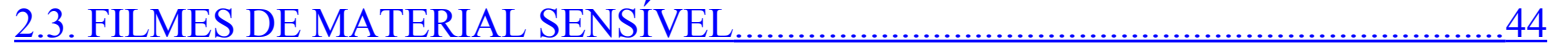

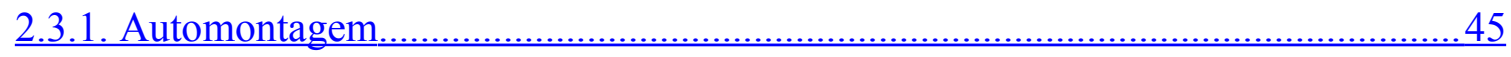

2.3.2. Deposição eletroquímica...................................................................................47

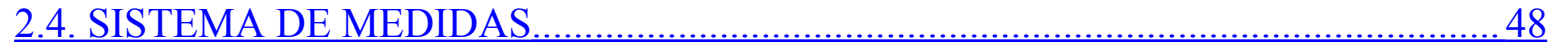

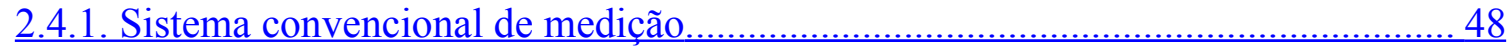

2.4.2. Sistema com câmara para medição de gases..........................................................49

2.5. REDES NEURAIS ARTIFICIAIS................................................................... 52

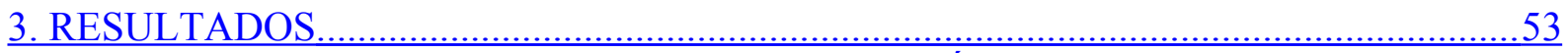

3.1. SENSORES PARA GASOLINA E ETANOL - GÁS.................................................53

3.1.1. Ensaio de ciclagem ar/mistura de etanol e água destilada......................................53

3.1.2. Ensaio de espectroscopia de impedância das misturas de etanol e água destilada. 55

3.1.3. Ensaios de ciclagem gasolina e etanol na câmara ..................................................59

3.1.4. Ensaios de efeito da umidade .................................................................................61

3.1.5. Ensaios com etanol combustível comercial........................................................61

3.2. SENSORES PARA GASOLINA E ETANOL - LÍQUIDO........................................ 62

3.2.1. Ensaio de ciclagem ar/mistura de etanol e gasolina................................................62

3.2.2. Ensaio de sensibilidade à mistura de etanol e gasolina..........................................63

3.2.3. Ensaio espectroscopia de impedância.................................................................64 64

3.2.4. Ensaio de gasolinas comerciais..........................................................................69

3.2.5. Ensaio de álcool combustível comercial..............................................................72

3.3. REDES NEURAIS ARTIFICIAIS ....................................................................... 74

3.3.1. Validação do algoritmo da rede ..................................................................... 74

3.3.2. Desempenho com combustíveis comerciais........................................................ 76

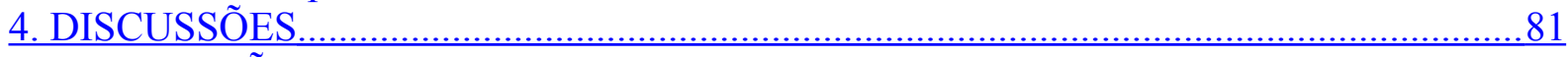

5. CONCLUSÕES …………………………………………………………………….... 83

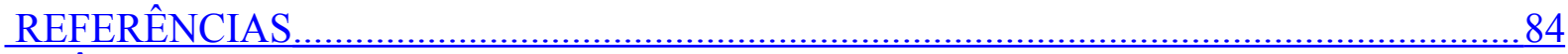

APÊNDICE A - Resumo de ensaios de conformidade ................................................... 90

APÊNDICE B - Software de automação do Solartron1260A e multiplexador........................96

ANEXO A - PORTARIA ANP No 309 (Regulamento técnico)...............................................98

ANEXO B - RESOLUCC̃̃O ANP No 36 (Regulamento técnico) ............................................103 
ANEXO C - Boletim Mensal de Qualidade.............................................................. 108 


\section{INTRODUÇÃO}

No Brasil, há grande preocupação sobre a qualidade dos combustíveis automotivos vendidos pelos postos de abastecimento. No ano de 2009, a agência de regulamentação e fiscalização brasileira, a ANP (Agência Nacional do Petróleo, Gás Natural e Biocombustíveis) detectou que 1,4\% amostras de gasolina comum tipo C e 2,3\% das amostras de álcool etílico hidratado combustível (AEHC) apresentavam algum tipo de não conformidade, em um universo de 74.934 amostras de gasolina e 41.350 de álcool. Apesar de haver tendência de queda nos últimos anos e essas porcentagens parecerem relativamente muito pequenas, quando aplicadas ao mercado brasileiro, onde são vendidos aproximadamente 25 milhões de metros cúbicos de gasolina e 16 milhões de metros cúbicos de álcool hidratado ao ano ${ }^{1}$, as perdas com a falsificação são muito grandes. Os principais prejudicados com as adulterações são os consumidores, o Estado, que deixa de recolher os devidos tributos, o meio ambiente pelo aumento na emissão de poluentes, e as marcas das distribuidoras, que têm suas imagens prejudicadas, sendo que nestes casos, as próprias redes de distribuição promovem ações para coibir a adulteração realizada pelos donos de postos.

O universo das adulterações é bastante amplo. Em relação à gasolina, os maiores índices de detecção de não conformidade são encontrados pelos ensaios de teor alcoólico e de destilação ${ }^{2}$. No primeiro caso, ocorre adição de álcool em níveis maiores que o estabelecido, atualmente em $25 \%(\mathrm{v} / \mathrm{v})$, o que gera perdas na eficiência do motor (CAMPOS, 1990). No segundo caso, a maior suspeita de adulteração está relacionada à adição de solventes orgânicos, principalmente os hidrocarbonetos aromáticos e frações alifáticas leves e pesadas (WIELDMAN, 2005), provindo da indústria petrolífera e petroquímica. As frações alifáticas leves alteram as características da partida do motor, as pesadas propiciam um detonamento precoce da gasolina na câmara de combustão e causam o desgaste do motor, e os hidrocarbonetos aromáticos possuem maior octanagem.

\footnotetext{
${ }^{1}$ ANP - Dados Estatísticos: Venda de combustíveis (www.anp.gov.br, acessado em 16/02/2009)

${ }^{2}$ ANP - Boletim Mensal de Qualidade de janeiro de 2010 (Anexo C)
} 
Em relação ao álcool, as não conformidades são apontadas principalmente pelos ensaios de teor alcoólico, condutividade elétrica e $\mathrm{pH}$ dos combustíveis, relacionados com adição de água ou outros álcoois como o metanol.

Pela gravidade deste problema, a área de pesquisa de sensores tenta trazer soluções para um controle rigoroso nos postos de distribuição. Hoje este controle já é feito através de técnicas de cromatografia gasosa (WIEDEMANN, 2005) e espectroscopia de infravermelho (MENDONÇA, 2005), além de ensaios físicoquímicos (apêndice A). Uma alternativa é a utilização de sensores químicos para esta finalidade, com a promessa de serem de análise rápida e expedita e não destrutivos (em relação aos materiais de análise).

Os sensores químicos são dispositivos capazes de converter informações químicas provindas do meio analisado em um sinal analiticamente mensurável (RIUL, 2002). A utilização de polímeros condutores em sensores químicos é uma das grandes apostas de institutos de pesquisa e vêm sendo bastante estudados nos últimos anos. Recentemente, a Embrapa Instrumentação Agropecuária de São Carlos em parceria com a Escola Politécnica da USP de São Paulo desenvolveu um dispositivo conhecido como "língua eletrônica" (LE), o qual tem se mostrado extremamente eficiente na certificação de bebidas como café, vinho (RIUL et al., 2003b, 2004; SANTOS, 2003) e água (RIUL et al., 2003a), por meio da análise de sabores (FERREIRA, 2003). Além da certificação, este sistema é capaz de detectar contaminantes em água, tais como metais pesados (ANTUNES et al., 2005) e pesticidas (CONSTANTINO et al., 2004).

O sistema LE é constituído por um arranjo de sensores construídos com a deposição de diferentes filmes de polímeros condutores sobre microeletrodos interdigitados. Cada filme tem sua impedância elétrica modificada diferentemente quando em contato com o líquido de análise. Em geral, os polímeros condutores a serem utilizados não necessariamente precisam ser específicos a nenhum componente químico dos combustíveis. O que se busca no caso é a "seletividade global", que é alcançada a partir da combinação da sensibilidade de vários sensores (TOKO, 1998). 
A utilização deste tipo de estratégia está baseada no fato de que os combustíveis podem apresentar características químicas diferentes dependendo do processo de obtenção - no caso da gasolina, sua composição pode variar com o processo utilizado nas refinarias e com a origem do petróleo. Além disso, a variabilidade de adulterações possíveis é muito grande. Por estes dois motivos, a utilização de sensores altamente específicos para encontrar adulteração torna-se difícil e a escolha de um grupo (ou arranjo) de sensores menos específicos torna-se interessante à medida que seja possível encontrar um padrão de respostas que globalmente represente combustíveis conformes e combustíveis não-conformes.

Similarmente aos líquidos, estes sensores também podem ser aplicados aos gases. Este trabalho também tenta abordar um estudo preliminar da utilização destes sensores para fase gasosa baseado no trabalho de WIZIACK (2007), pois existem indícios de complementaridade das informações dos dois sistemas (Di NATALE et al., 2004).

Hoje em dia, uma das principais atividades relacionadas ao desenvolvimento deste tipo de sensor é a análise de dados. Uma variedade de técnicas é empregada, como a análise de componentes principais (PCA) (RIUL et al., 2003b), método dos mínimos quadrados parciais (Partial Least Squares - PLS), redes neurais artificiais (RNA) (RIUL et al, 2004), quantização por vetor de aprendizagem (LVQ) (CIOSEK, 2006), máquinas de suporte vetorial (SVM) (ACEVEDO, 2007) e lógica fuzzy (WIZIACK, 2005). O grande desafio é modelar o comportamento dos sensores através destas ferramentas matemáticas de forma que seja possível determinar de forma rápida e acurada a adulteração dos combustíveis.

Neste âmbito, há grande aposta de um bom desempenho das redes neurais artificiais (RNA) do tipo Multilayer perceptron (MLP), que, de forma geral, têm grande capacidade de associar sinais de entradas a sinais de saída de diferentes naturezas e são muito utilizadas em aproximação de funções, reconhecimento e classificação de padrões. Esta arquitetura de RNA foi testada no desenvolvimento deste trabalho. 
Justificativa

A principal justificativa deste trabalho é a existência de demanda por um sistema sensor de fácil operação que consiga discriminar entre gasolinas conformes e nãoconformes qualitativamente, porém de forma portátil (realizada no próprio posto), rápida e expedita, e com a maior acurácia possível. Além disso, como a as formas de adulteração são diversas e mudam com o tempo, o sistema não necessita acusar especificamente o tipo de adulteração, mas sim apontar as amostras que devem passar por análises mais rigorosas em laboratório por terem grandes probabilidades de adulteração. Isto possibilitará um melhor monitoramento dos postos de abastecimento, pois os laboratórios, que têm capacidade de número de análises limitada, poderão ser mais eficientes na detecção de estabelecimentos irregulares.

Objetivos

O objetivo do trabalho de obter um sistema multisensor utilizando sensores não específicos, baseados em filmes poliméricos eletrodepositados sobre microeletrodos interdigitados e dedicados à detecção de adulteração em gasolina e álcool.

\section{Objetivos Específicos}

1. Estudo e caracterização dos sensores

2. Definição de procedimento de medida e escolha de sensores e sinais a serem utilizados na detecção de adulteração

3. Desenvolver ferramentas de análises de dados e classificação utilizando Redes Neurais Artificiais.

Resultados esperados

1. Criar uma base de dados de medições utilizando o sistema proposto

2. Avaliar desempenho da utilização de Redes Neurais Artificiais na classificação de combustíveis adulterados 


\section{REVISÃO DE LITERATURA}

1.1.

SENSORES DE POLÍMEROS CONJUGADOS

\subsubsection{Polímeros conjugados}

Os polímeros conjugados (PC) são macromoléculas, cujos átomos de carbono da cadeia principal possuem uma alternância entre ligações duplas e simples. As ligações simples são sempre do tipo sigma $(\sigma)$ e as duplas são compostas de uma ligação $\sigma$ e uma $\pi$ (pi), cujo elétron possui maior mobilidade em relação à ligação $\sigma$. Esta arranjo alternado e repetitivo propicia a delocalização dos elétrons dos orbitais ligantes das ligações $\pi$, que ganham a possibilidade se movimentar para os orbitais anti-ligantes $\pi^{*}$, que anteriormente estavam desocupados. Respectivamente, estes orbitais são chamados de HOMO (highest occupied molecular orbital) e de LUMO (lowest unoccupied molecular orbital). A possibilidade de elétrons poderem se movimentar por estes orbitas, que possuem diferenças de energia 1,5 e 4,0 eV (SANTOS, 2007) é o que dá a propriedade condutora aos PC. Os primeiros trabalhos sobre a condutividade elétrica de PCs foram feitos por Shirakawa (CHIANG et al., 1977) Neste estudo, os pesquisadores estudaram o poliacetileno (Figura 1.1), um dos PCs mais simples.

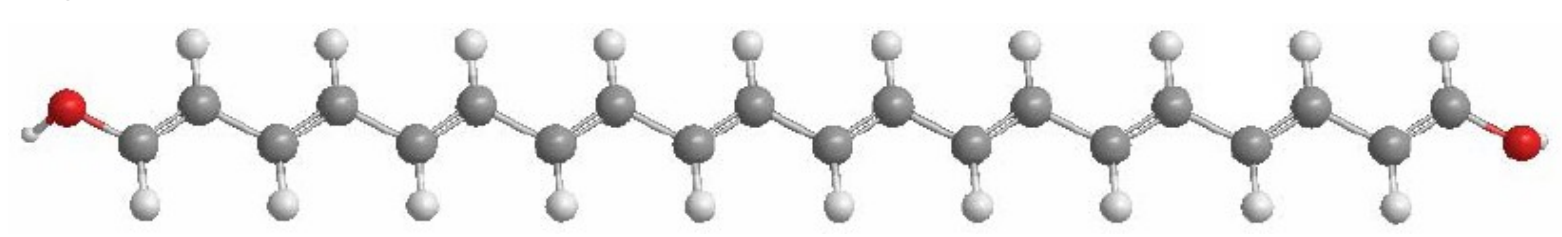

Figura 1.1 - Trans-poliacetileno.

A simples presença da conjugação, contudo, não proporciona a condutividade elétrica nos polímeros. Para que ela ocorra é preciso gerar portadores de carga através da dopagem do polímero. Há três maneiras de se conseguir isto segundo MacDiarmid (2002): por reações do tipo oxirredução REDOX, por reações sem íons dopantes e por protonação. 
No primeiro processo, o polímero é oxidado (perde elétrons) ou reduzido (ganha elétrons) química ou eletroquimicamente, o que caracterizam dopagens do tipo p ou $\mathrm{n}$, respectivamente. Neste tipo de dopagem há sempre a presença de um contra íon, por exemplo, iodo (I-) ou perclorato (ClO4-) na dopagem tipo p e a $\mathrm{Na}+$ ou $\mathrm{Li}+\mathrm{no}$ tipo $n$.

No segundo tipo, a condutividade é obtida por efeito fotoelétrico, em que fótons com energia adequada promovem a transição de elétrons do HOMO para o LUMO. Nesta categoria também se encontra o processo de injeção de carga, em que o polímero é depositado sobre um condutor recoberto por um dielétrico que os separam. Quando uma tensão elétrica apropriada é aplicada, o aparecimento de portadores cargas no polímero é induzido.

O terceiro tipo de dopagem é denominado protonação, que é um processo exclusivo da PAni e seus derivados. Neste processo os íons $\mathrm{H}+$ de ácidos protônicos são incorporados (protonados) aos nitrogênios dos grupos imima.

Uma boa revisão bibliográfica sobre polímeros conjugados pode ser encontrada nos trabalhos de Medeiros; Paterno e Mattoso (2006).

Consideradas as questões de dopagem, a condutividade $(\sigma)$ é proporcional à mobilidade $(\mu)$ dos portadores de carga e, nos PCs em geral, esta é baixa quando comparada a dos materiais inorgânicos. A limitação na condutividade está relacionada ao fato de que o transporte de carga nos PCs é função da difusão de portadores internamente nas cadeias poliméricas e das interações entre cadeias, hopping. Pela morfologia desordenada dos polímeros, usualmente o segundo efeito prevalece.

Weder (2006) faz uma revisão sobre estudos visando reduzir este efeito e diz que bons resultados foram obtidos em polímeros com alto grau de ordenamento supramolecular, contudo, a obtenção deste ordenamento, salvo exceções, é custosa. Outra possibilidade é a introdução de ligações cruzadas (cross-link) com conjugação $\pi$ entre os PCs como forma de proporcionar um acoplamento eletrônico entre cadeias. Neste caso, a ligação cruzada deve possuir níveis LUMO e HOMO compatíveis com os do PC. Estas redes poliméricas podem ser obtidas de duas maneiras, por ligações covalentes e não-covalentes. As redes covalentes são obtidas através da incorporação de monômeros tri-funcionais (ou com um grau mais alto de funcionalização) a monômeros bi-funcionais. A desvantagem principal neste 
caso é a dificuldade de processamento da rede e, por isso, esta deve ser processada antes ou durante a sua formação. As redes não-conjugadas são baseadas em ligações cruzadas físicas, por exemplo, por pontes de hidrogênio e por atração eletrostática. Neste tipo de rede observam-se efeitos interessantes, mas a natureza da ligação cruzada não é bem definida. Há um terceiro tipo de processo, também não-covalente em que ligações de coordenação são formadas entre sítios de moléculas orgânicas e ligações cruzadas metálicas, o que resulta em uma rede organometálica, que também não é facilmente processável, mas podem ser obtidas por reações de troca de ligante (ligand-exchange reaction) ou pela polimerização de um complexo ligante-metal pré-fabricado.

Par concluir esta seção, na Figura 1.2 estão as estruturas químicas de alguns polímeros conjugados.

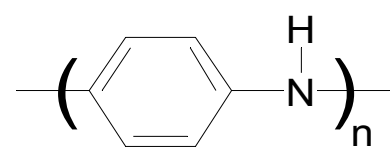

PAni

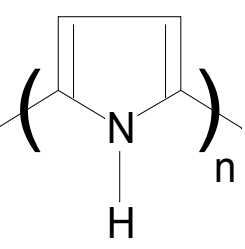

PPy

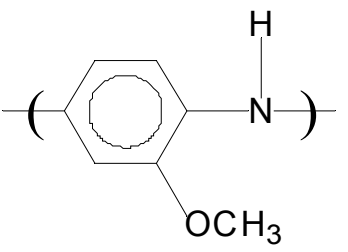

POMA

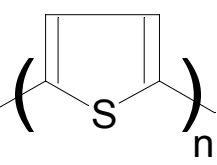

PTh

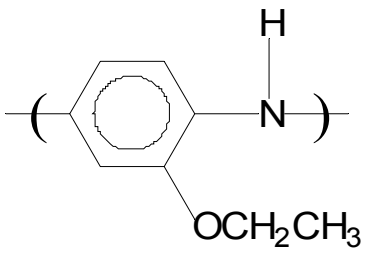

POEA

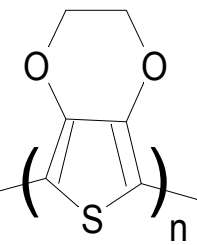

PEDOT

Figura 1.2 - Estrutura química de alguns polímeros conjugados.

\subsubsection{Sensores Poliméricos}

Pequenas mudanças no ambiente, como polaridade, acidez, a umidade, etc, podem afetar a conformação das cadeias poliméricas, a distribuição eletrônica e o nível de dopagem e estes fenômenos podem ser utilizados em sensores (MEDEIROS; et al., 2006). 
Além desta característica dada pela conjugação, os PC podem ter também suas propriedades de superfície projetadas com a introdução de grupos funcionais para promover adsorção de biomateriais, para recobrimento e proteção contra degradação e para adsorção não-específica (CHIARI et al., 2008).

No trabalho de Medeiros ET al(2006), encontramos uma revisão sobre o emprego de PCs em sensores. Neste trabalho, há a descrição de dois métodos de fabricação de filmes de polímeros conjugados, a automontagem, criada por Decher (1997), e a técnica LB (Langmuir-Blodgett), além da citação de dois outros métodos, a polimerização eletroquímica e a centrifugação (spin-coating).

De acordo com os princípios químicos, físicos ou biológicos de sensoriamento e transdução, os polímeros conjugados podem ser empregados em diversas tecnologias de medição.

Os sensores do tipo condutométricos baseiam-se em medidas de impedância elétrica $A C$ ou DC através dos métodos de duas ou quatro pontas. Neste caso, é usual depositar os filmes poliméricos conjugados sobre substratos e realizar a medição de impedância através de pontas de prova. Um exemplo são os filmes poliméricos depositados sobre estruturas interditigadas (Figura 1.3).

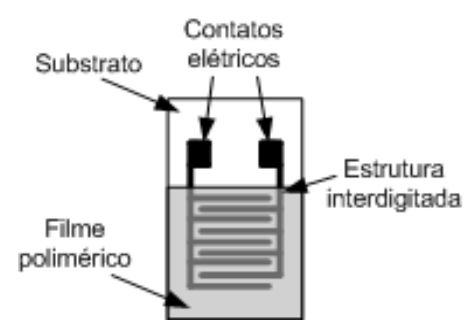

Figura 1.3 - Diagrama de um sensor condutométrico constituído de uma estrutura interdigitada.

Há também os sensores eletroquímicos. Neste sistema (Figura 1.4), o eletrólito, ou o líquido sob análise, é disposto dentro de uma célula eletroquímica. Em contato com o eletrólito estão os eletrodos de trabalho, cuja superfície em geral é modificada pelo material polimérico, o eletrodo de referência e o contra eletrodo. O potencial elétrico é medido entre os eletrodos de trabalho e de referência e a corrente que flui entre o eletrodo de trabalho e o contra eletrodo também é medida. Com este sistema é possível realizar ensaios potenciométricos, amperométricos e galvanométricos capazes de descrever as dinâmicas das reações de redox que ocorrem entre o eletrodo de trabalho e o contra-eletrodo. 


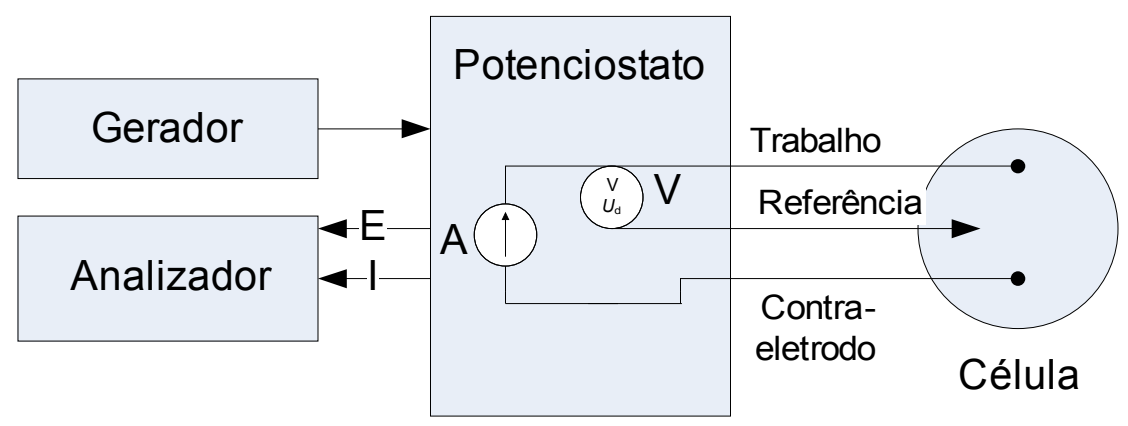

Figura 1.4 - Potenciostato e célula eletroquímica.

Além destas duas categorias, há os sensores baseados em princípios gravimétricos. Dentre eles se destacam as microbalanças de quartzo constituídas em geral de um pequeno disco de cristal de quartzo disposto entre dois eletrodos de ouro. Este sistema apresenta uma freqüência de ressonância que varia proporcionalmente à massa do sistema, obedecendo a equação de Sauerbrey. Este sistema é então recoberto com material sensoativo que promove interações específicas com as amostras; de acordo com a adsorção e dessorção de substâncias, é possível estipular suas concentrações pelas variações na freqüência.

Outro tipo importante de sensor gravimétrico são os sensores SAW (onda acústica superficial - surface acoustic wave), que são constituídos de um cristal piezoelétrico sobre o qual são dispostas duas estruturas interdigitadas em cada extremidade. Um sinal em rádio freqüência é aplicado a umas das estruturas; isto provoca contração e expansão do cristal e, conseqüentemente, uma onda acústica; esta por sua vez se propaga através do cristal até a outra estrutura interdigitada, onde há a medição de um sinal elétrico com freqüência proporcional à massa do sistema. A partir deste sistema, uma camada sensoativa é depositada no percurso da onda acústica, entre as duas estruturas interdigitadas, e a variação da freqüência da onda estará relacionada à concentração de substâncias.

Um último tipo de sensor baseado em polímeros conjugados são os baseados em propriedades ópticas. Uma técnica que pode ser utilizada é a SPR (ressonância plasmônica de superfície - surface plasmon resonance), baseada no princípio de oscilação eletrônica causada na interface entre dielétrico e metal pela incidência de fótons com um ângulo determinado. Este sistema é constituído por um dielétrico recoberto com um filme metálico, ouro ou prata em geral. O filme metálico é recoberto também por um filme sensoativo, e este ficará em contato com a amostra. 
$\mathrm{Na}$ outra face do dielétrico é montado um sistema óptico capaz de emitir luz com um determinado ângulo de incidência e um receptor que capta a luz refletida. A freqüência de ressonância e a intensidade da onda refletida são muito sensíveis às propriedades da interface dielétrico/metal. Há também outros tipos de sensores ópticos os baseados na fluorescência dos PCs e os baseados em fibras ópticas, em que o filme de PC é depositado nas terminações ou como recobrimento da fibra óptica e mudanças na absorbância e fluorescência são detectadas.

\subsubsection{Espectroscopia de impedância}

Os sensores baseados em princípios condutométricos e eletroquímicos, descritos anteriormente, podem ser caracterizados através da espectroscopia de impedância $(E I)$, que é uma técnica poderosa para caracterizar muitas propriedades de materiais e suas interfaces. Barsoukov e MacDonald (2005) escreveram um amplo trabalho sobre aplicações e a teoria envolvida neste tipo de análise, que, em suma, torna possível caracterizar a dinâmica de reações, a mobilidade de cargas na parte massiva ou na interface dos materiais e até dados sobre morfologia, sendo que diversos fenômenos podem ser associados a elementos de circuitos equivalentes.

A principal desvantagem em relação a esta técnica é a possível ambigüidade de interpretação dos fenômenos e, no presente momento, a maior parte dos sensores baseados em impedância utilizam dados brutos, sem que se tente fazer um ajuste a modelos de circuito equivalente.

Contudo, uma análise prévia baseada em El pode dar uma maior compreensão dos fenômenos que ocorrem no sensor e dar indicativos das melhores condições de medida.

Neste item, discutiremos três modelos propostos para estes eletrodos recobertos por filmes e imersos em um eletrólito. O primeiro é o resultado de experimentos de Taylor e MacDonald (1987) com eletrodos de cobre recobertos por filmes de PVC depositados por centrifugação (spin coating) e por LB, imersos em eletrólito iônico com diversas concentrações de $\mathrm{KCl}$. No modelo proposto (figura 1.6), GT representa a transferência de carga na interface eletrólito/filme e CG a capacitância entre 
eletrodos. A dupla camada elétrica que se forma na interface filme eletrólito é modelada por Cd e Gd e o filme orgânico é modelado por GB e CB.

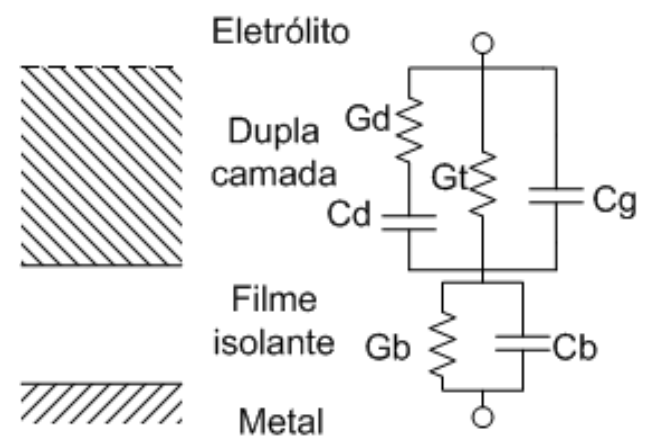

(a)

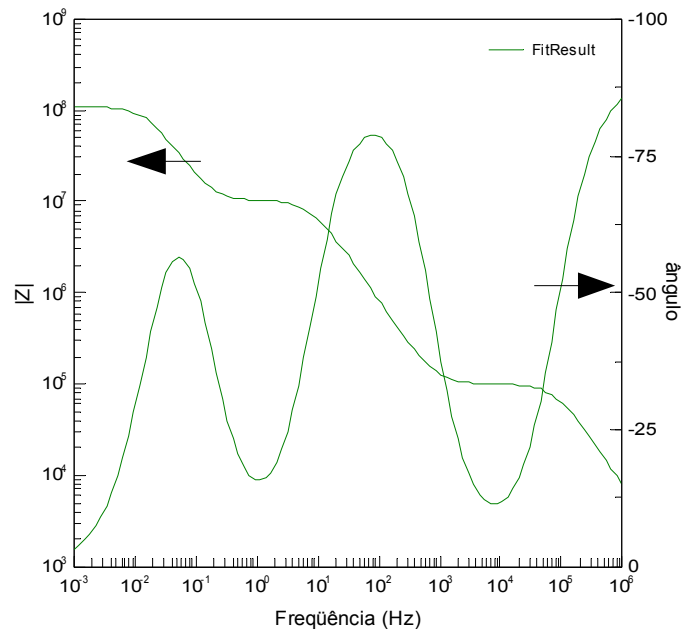

(b)

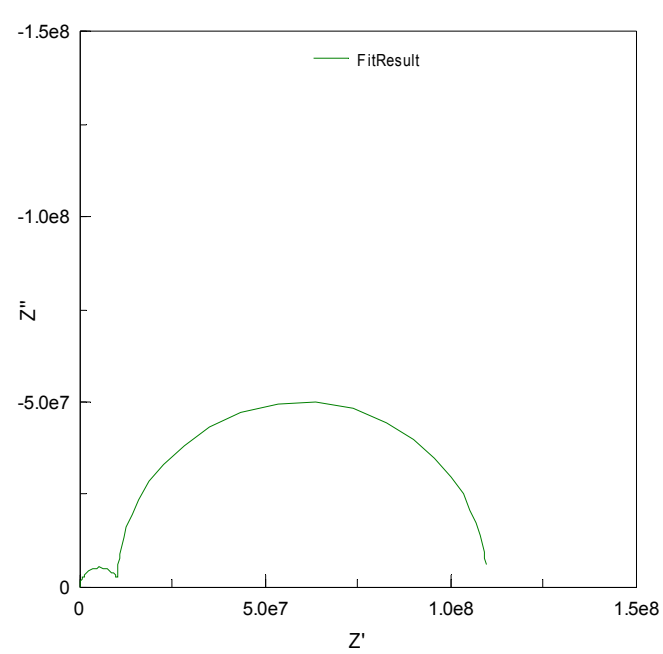

(c)

Figura 1.5 - (a) Modelo elétrico de um metal recoberto por um material pouco condutivo imerso em um eletrólito (TAYLOR; MACDONALD, 1987). (b) e (c) Gráficos de Bode e Nyquist para um circuito com: $\mathrm{Rb}=10 \mathrm{M} \Omega, \mathrm{Cb}=2 \mathrm{nF}, \mathrm{Cg}=20 \mathrm{pF}, \mathrm{Rt}=100 \mathrm{M} \Omega, \mathrm{Cd}=100 \mathrm{nF}$ e $\mathrm{Rd}=100 \mathrm{k} \Omega$.

Um outro modelo interessante (Figura 1.6) é o descrito por Loveday (2004). Neste caso há a modelagem de um eletrodo metálico com um recobrimento orgânico. Ru é a resistência do eletrólito, Cc é a capacitância do recobrimento ou filme orgânico, Rporo representa a condutividade iônica dentro dos poros. Rp é a resistência de polarização e é proporcional à velocidade de reação (ou corrosão, no caso citado). Por fim, Cd é a capacitância de dupla camada iônica. 


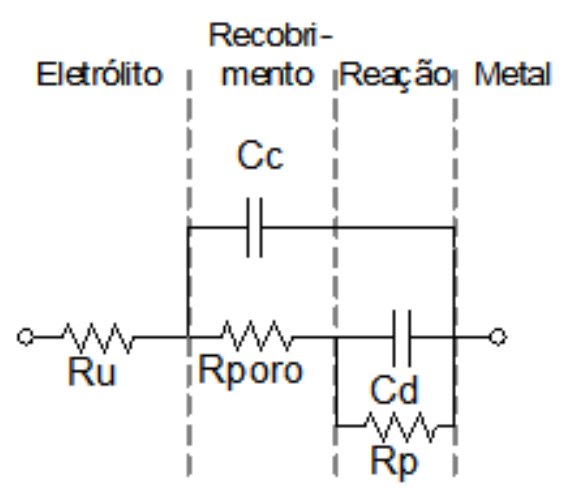

(a)

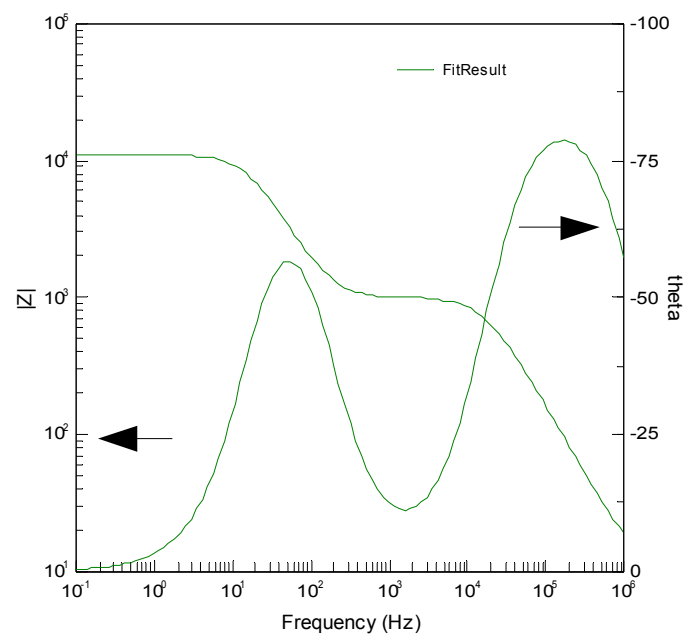

(b)

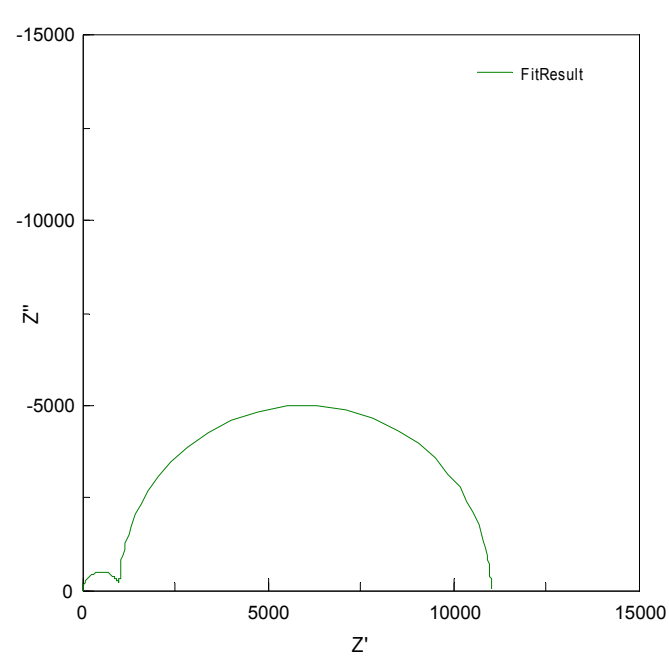

(c)

Figura 1.6 - (a) Modelo elétrico de um recobrimento orgânico sobre um eletrodo metálico (LOVEDAY et al., 2004). (b) e (c) Gráficos de Bode e Nyquist para um circuito com: $R u=10 \Omega, C c=10 n F$, Rporo $=1 \mathrm{k} \Omega, \mathrm{Cd}=1 \mu \mathrm{F}, \mathrm{Rp} 10 \mathrm{k} \Omega$.

Neste modelo, em uma situação de um filme orgânico intacto, temos o circuito formado por Ru, Cc e Rporo. Quando ocorre adsorção de água, Cc aumenta. Conforme o eletrólito penetra nos poros, Rporo diminui até que se inicia a corrosão do metal. Ao longo do processo de corrosão Rporo tende a parar de diminuir e até a aumentar devido aos produtos das reações, que tendem a bloquear os poros. A reação de corrosão é modelada pelos elementos $\mathrm{Cd}$ e $\mathrm{Rp}$ e, conforme o recobrimento é destruído, $\mathrm{Rp}$ diminui e Cd aumenta.

Um terceiro tipo de abordagem tenta levar em conta duas características do PCs. A primeira é o transporte de carga no interior polímero, que pode ser estudado por modelos de saltos (hopping), que resultam em uma condutividade no polímero 
proporcional à potência da freqüência $\left(\sigma(\omega) \propto \omega^{\wedge} S\right.$, para $\left.\omega>>\omega_{c}\right)$. A outra característica diz respeito à desordem dos polímeros, que, além de poderem mascarar o transporte de carga nos polímeros, podem dar origem a outros tipos de modelamento que levam em conta a porosidade do material, que pode ser atestada pelas imagens da figura 1.8 .

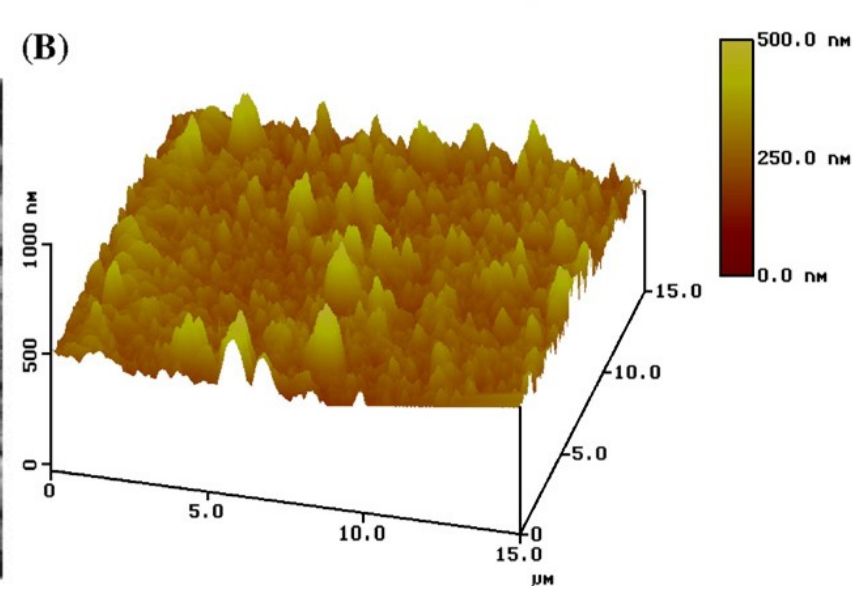

(a)

(b)

Figura 1.7 - (a) Microscopia eletrônica de varredura de um filme de poli(tiofeno-3-ácido acético) (GARCIA-BELMONTE; BISQUERT, 2001). (b) Microscopia de força atômica de um filme de Pani/PSS depositado por automontagem (BRAGA et al., 2008).

Com ênfase na modelagem da estrutura porosa, Fletcher $(1992,1993)$ propõe um novo modelo baseado em linhas de transmissão de duplo canal (Figura 1.8 a), em que $\mathrm{o}$ subcircuito $\mathrm{x}$ corresponde à resistência do eletrólito dentro do poro, $z$ representa a impedância do PC e y representa a interface polímero/eletrólito com um comportamento basicamente capacitivo. É bom notar que no modelo proposto pela Figura 1.8 (b) considera-se que não há transferência de carga entre o PC e o eletrólito, a presença de C1 e C2 (dupla camada) não permitem a passagem de carga. z é uma aproximação do circuito de Randles, descrevem materiais que microscopicamente possuem duas regiões, uma ordenada (R $\Omega$ ) e com alta condutividade e outra desordenada ( $\mathrm{Rz}$ e $\mathrm{Cz}$ ). 


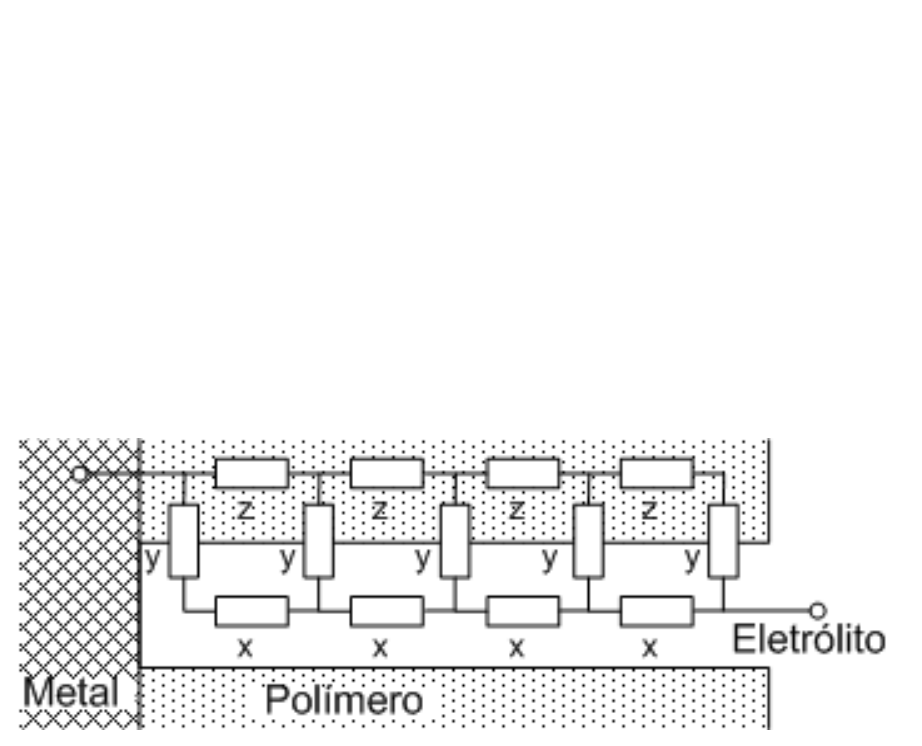

(a)
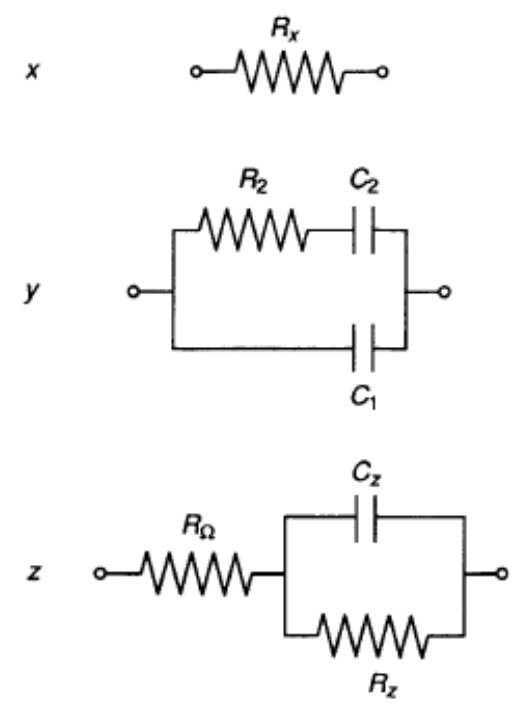

b)

Figura 1.8 - Modelo de um único poro (FLETCHER, 1992).

Bisquert e Garcia-Belmonte adotaram o sistema de Fletcher e fizeram algumas modificações. Na Figura 1.9, há dois circuitos propostos por Bisquert, sendo que um contempla a condutividade no PC (Figura $1.9 \mathrm{~d}$ ) devido ao transporte de portadores de cargas (elétrons, lacunas ou pólarons) por saltos discretos; e outro (Figura 1.9 e) a transferência de carga e dispersão da freqüência devido à polarização na interface. Em ambos os modelos, o componente q segue a lei de potência: $q \propto$ $1 /(j \omega)^{\wedge} p$. 
(a)

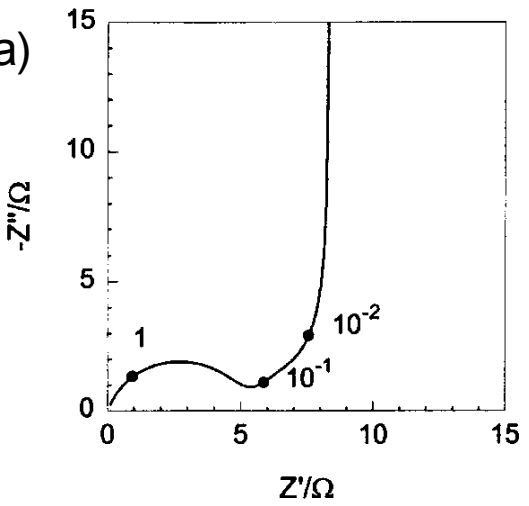

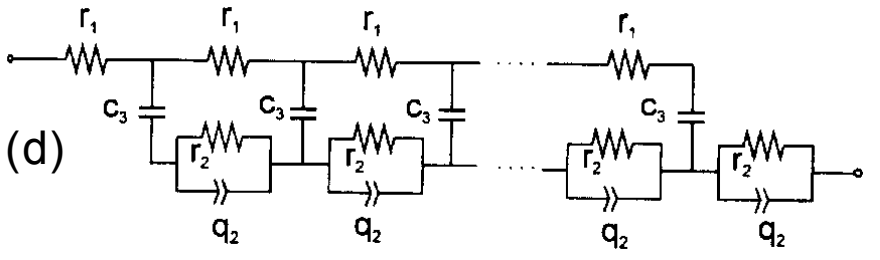
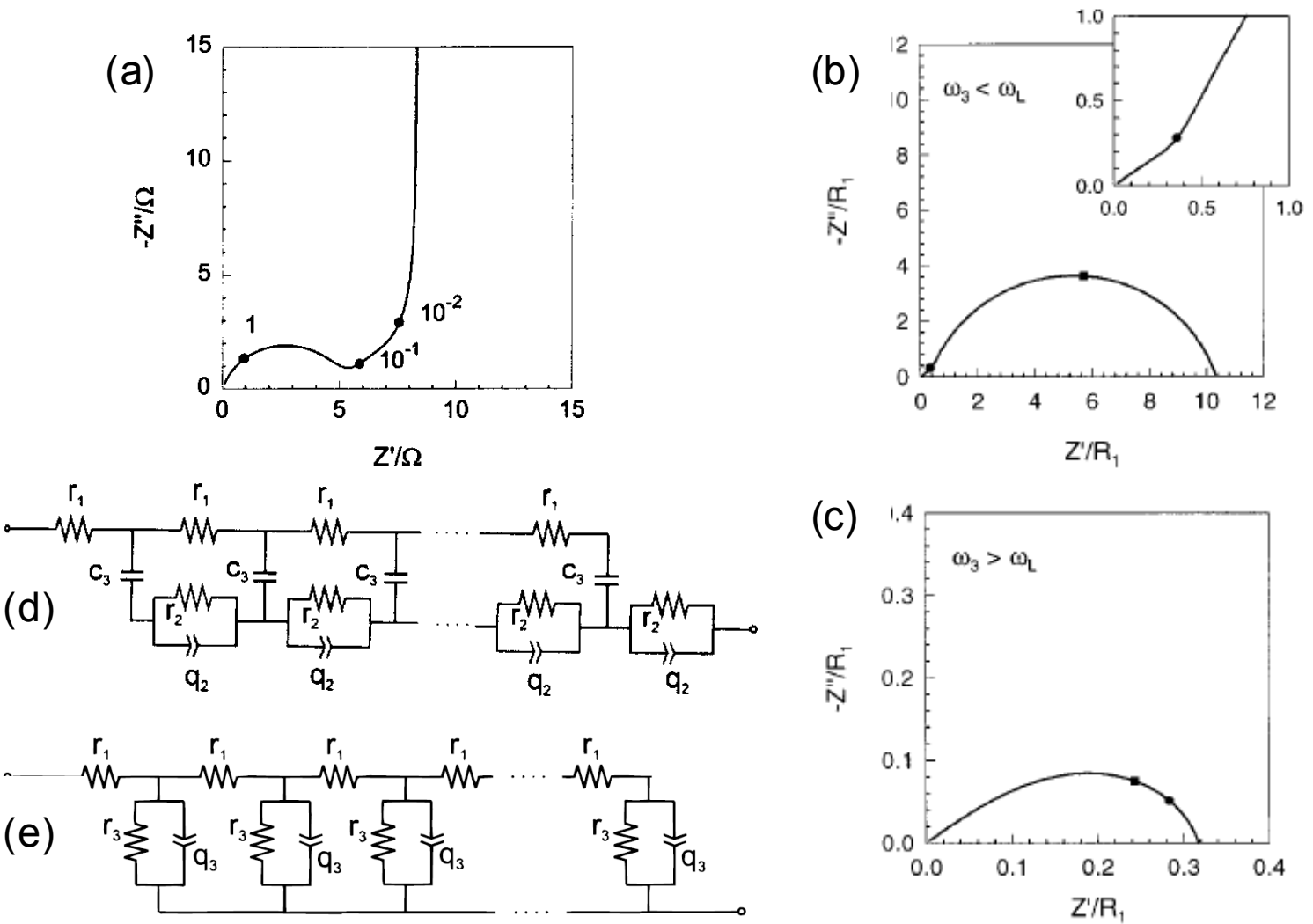

Figura 1.9 - Simulação (BISQUERT et al., 1999 e 2000). (a) Simulação do circuito (d). (b) e (c) simulação do circuito (e). (d) Modelo considerando transporte de carga no PC. (e) Modelo considerando a transferência de carga entre polímero e o eletrólito.

\subsubsection{Seletividade global}

Vlasov em sua revisão (VLASOV; LEGIN e RUDNITSKAYA, 2001) dá uma perspectiva histórica dos sensores do tipo LE e NE, cuja origem foi decorrência de trabalhos na área de sensores químicos. Os sensores químicos baseados em princípios potenciométricos já são estudados desde 1909. Nesta ocasião, um sensor baseado em eletrodos íon-seletivos foi desenvolvido e desde então, muitas pesquisas em busca dos materiais mais seletivos foram realizadas, contudo o número de sensores altamente seletivos ainda permaneceu baixo. Entretanto, a necessidade de melhorar o desempenho de sistemas analíticos fez com que sensores menos seletivos, porém com seletividade cruzada, fossem combinados 
com os sensores altamente seletivos em arranjos. Da combinação das respostas destes sensores, que isolados poderiam ser sensíveis ou não a uma dada substância, mas que certamente não eram seletivos, se espera que pudesse ser possível alcançar uma "seletividade global", um termo proposto por Toko (1998).

O que deu impulso a este conceito de "seletividade global" foi a observação dos sistemas sensoriais dos mamíferos. Primeiramente, observou-se que o sistema olfativo dos animais é constituído por um grande número de receptores nãoespecíficos e pouco sensíveis que interagem (reagem quimicamente) com compostos voláteis e enviam um estímulo ao cérebro. Apesar da precariedade dos receptores isolados, os animais conseguem detectar quantidades ínfimas de milhares de odores com alta seletividade. Posteriormente, esta observação logo se estendeu para o sistema gustativo dos mamíferos, que em comparação ao olfativo é menos sofisticado. Os seres humanos, por exemplo, são capazes de identificar apenas cinco grupos de substâncias: as salgadas (típico de sais como $\mathrm{NaCl}$ e $\mathrm{KCl}$ ), as amargas (representadas pelo quinino, a cafeína e o $\mathrm{MgCl}_{2}$ ), as doces (típico de sacarose, frutose, glicose e outros açúcares), as azedas (devido íons $\mathrm{H}+$, oriundos de $\mathrm{HCl}$, ácido acético, ácido cítrico e outros) e as umamis (dada pelo glutamato de sódio, substância comumente encontrada em algas).

O trabalho de Persaud e Dodd (1982) foi o que deu início e vigor a esta área de pesquisa arranjos de sensores para detecção de odores e desde então diversos trabalhos utilizando óxidos (Gardner and Bartlett, 1992) e polímeros condutores foram realizados (BAI e SHI, 2007). No caso das línguas eletrônicas, elas foram extensamente estudadas em aplicações do âmbito da indústria alimentícia, podendo citar alguns grupos de destaque: Toko e colaboradores (Japão), Winquist e colaboradores (Suécia), Vlasov e colaboradores (Rússia) e Mattoso e colaboradores (Brasil).

\subsubsection{Análise de dados}

A análise de dados no âmbito de arranjo de sensores baseados no conceito de "seletividade global" é indispensável e existe uma extensa variedade de técnicas matemáticas de aproximação de funções e discriminação de classes. Jurs no seu 
artigo de 2000 faz uma revisão de vários métodos utilizados no âmbito de sensores do tipo LE e NE, com descrições, usos e críticas.

Antes de abordar alguns métodos computacionais em si, é interessante listar uma série de técnicas de pré-processamento dos dados. A utilização tende a melhorar o desempenho do tratamento dos dados e em muitos casos sua aplicação é feita de maneira empírica. Na Tabela 1.1 há um resumo de várias técnicas de préprocessamento.

Tabela 1.1 - Métodos de pré-processamento.

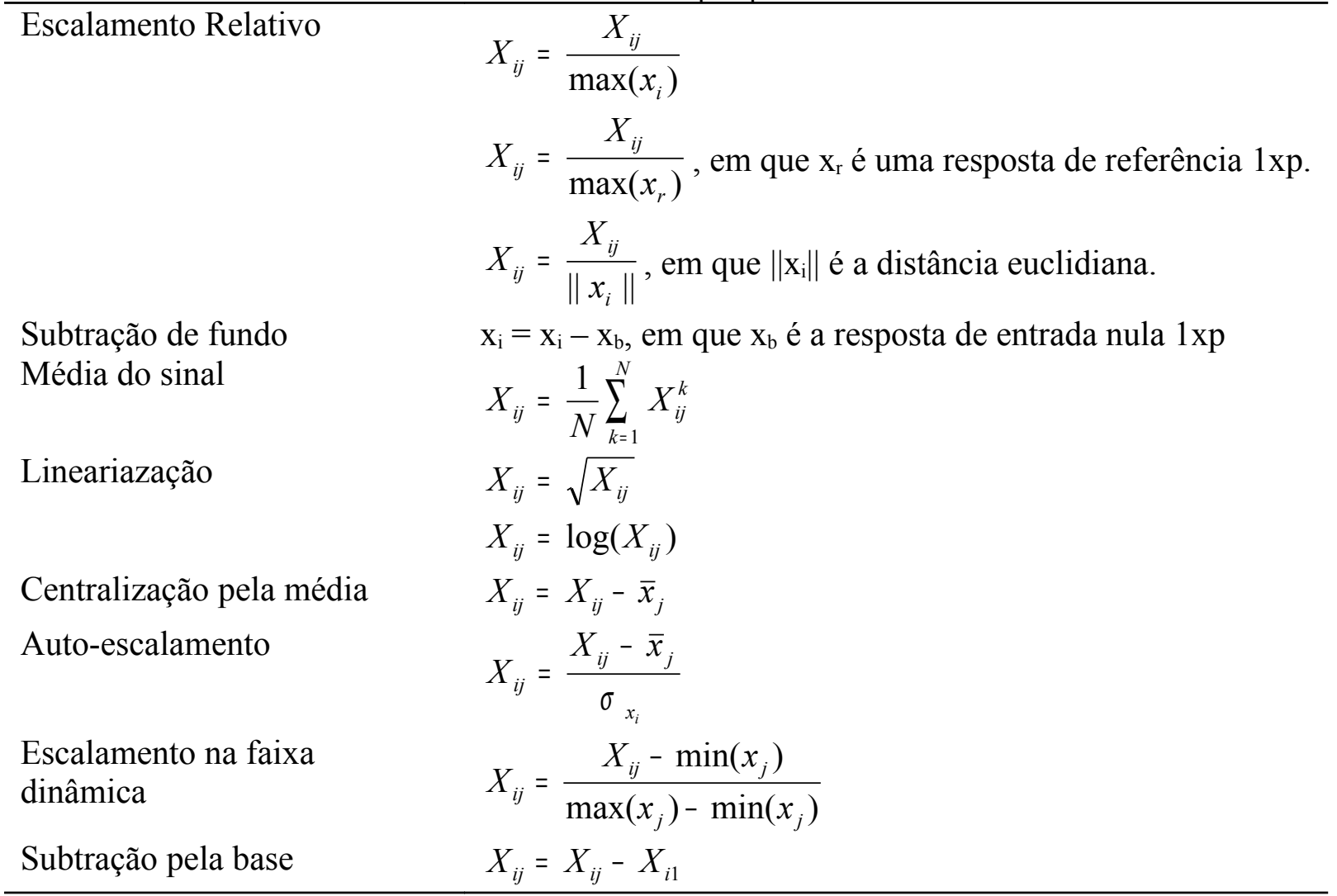

X é uma matriz de calibração $n \times p$ ( $n$ amostras e $p$ sensores). Xij denota a resposta após a i-ésima amostra e o j-ésimo sensor, xi é um vetor $1 \mathrm{x} p$ de resposta para a i-ésima amostra e xj são todas as amostras do j-ésimo sensor.

\subsubsection{Variação temporal dos sensores}

Uma característica importante dos sensores químicos, tanto nos destinados à análise de líquidos quanto aos destinados à análise de gases é que suas respostas variam com o tempo e depois de um certo período os sensores necessitam de uma nova calibração para que possam continuar a serem utilizados. Este problema 
denominado deriva (drift) está presente nos sensores químicos em geral, inorgânicos e orgânicos, e pode ser atribuído a vários fenômenos, como o envenenamento, o envelhecimento e as mudanças no ambiente, e dificilmente é possível de se encontrar um modelo que compense esta variação. Além disso, a deriva não é exclusividade dos sensores orgânicos, mas dos inorgânicos também, como pode ser visto nos trabalhos de Fu et al. (2007), Holmberg et al. (1996).

Na Figura 1.10, há dois PCAs representando dados de sensores de gás inorgânicos utilizados para medir a qualidade de leite em dois dias. Os pontos brancos representam amostras de leite pasteurizado e os pontos pretos representam amostras de leite pasteurizado oxidado. Nota-se a deriva na Figura 1.10 (a) e o resultado de um método de correção de deriva na Figura 1.10 (b).

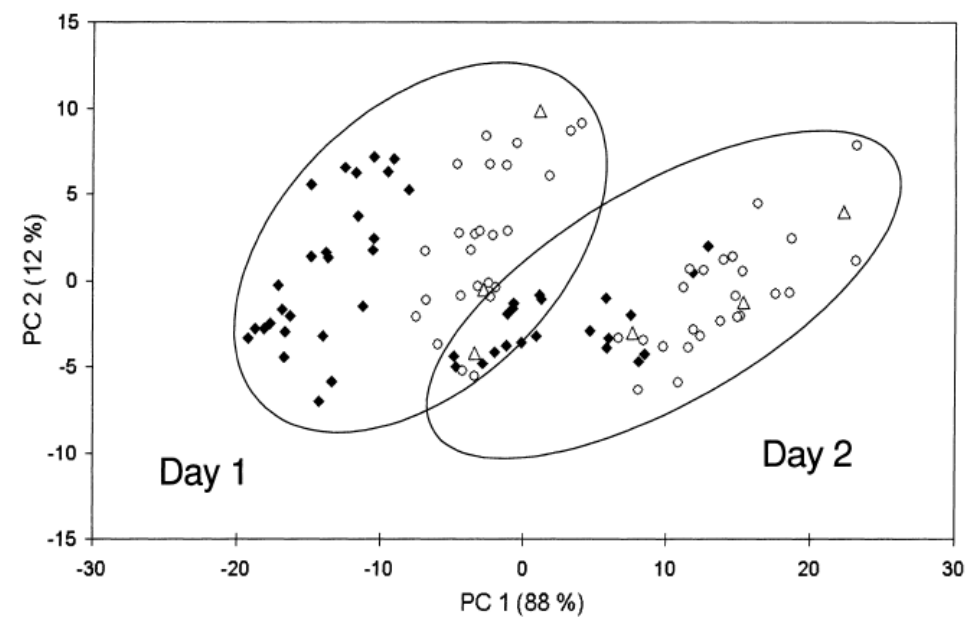

(a)

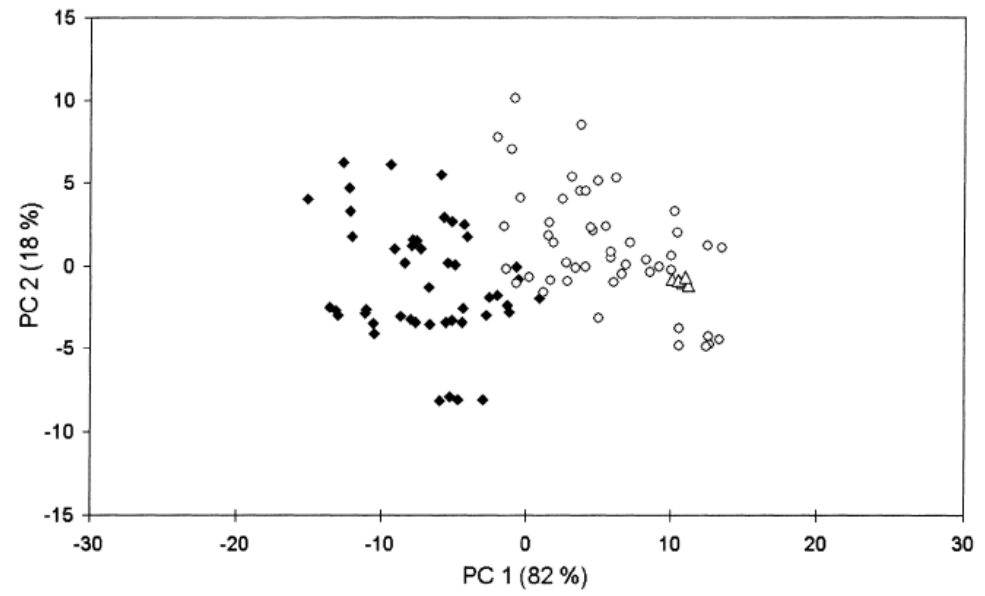

(b)

Figura 1.10 - Correção de deriva. (a) PCA de dois dias sem correção. (b) PCA com correção multiplicativa (HAUGEN, 2000).

Tomic et al. (2004) descreve dois métodos de correção de deriva, um considerando a mudança individual do sensor no tempo e outro considerando a resposta as várias 
variáveis concomitantemente. O primeiro método é denominado correção multiplicativa de deriva e a segunda, correção de componente, utilizada em análise PCA. Ambas as técnicas tentam detectar e corrigir variações sistemáticas em medidas de amostras de referência ocorridas durante ou entre seqüências de medições.

\subsubsection{Correção multiplicativa de deriva}

Na correção multiplicativa de deriva (Tomic et al., 2004) , a variação temporal das medidas de referências é analisada através de regressões lineares do tipo $f_{n k}=a_{k} x_{n}+b_{k}$, em que é um fator de correção $f_{n k}$ do sensor $k$ deve ser multiplicado à $n$ ésima amostra ( $x_{n}$ é a variação temporal entre a primeira medida e a $n$-ésima) de uma seqüência de medidas. O coeficiente $b_{k}$ é geralmente 1 e o $a_{k}$ deve ser determinado. Pode-se também utilizar regressões com polinômios de ordens maiores.

\subsubsection{Correção de componente}

A correção de componente (Tomic et al., 2004) esta baseada nas análises PCA e se dá da seguinte maneira. Primeiramente, uma análise PCA é a aplicada em uma nas amostras de referência para detectar a existência e o sentido da deriva. Do PCA são obtidas as matrizes de transformação Pref (loadings) e matriz de coordenadas das amostras em relação ao novo sistema de coordenadas Tref (scores). Assume-se então que a primeira componente principal (representada por p1, ref e t1, ref) já consiga conter o comportamento da deriva e uma transformação às amostras originais $X$ possa ser feita. Desta maneira temos que:

$$
\mathrm{X}_{\text {corrigido }}=\mathrm{X}-\left(\mathrm{tp}^{\top}\right)_{1, \text { ref }}
$$

Caso seja necessário, em casos onde há não-linearidades, por exemplo, outras componentes principais podem ser utilizadas no processo de correção. 
Nos trabalhos de Artursson (2000) e de Tomic (2004) são feitas comparações de desempenho entre as duas técnicas de correção, a correção multiplicativa e a correção de componente, porém houve divergências entre os resultados de forma que Artursson aponta a segunda técnica como sendo mais eficaz e Tomic aponta que a primeira técnica é um pouco mais eficaz. Deste modo, a escolha entre ambas as técnicas deve ser feita de forma empírica.

\subsubsection{SOM na correção de deriva}

As RNAs também são utilizadas para tentar corrigir ou tornar o sistema mais robusto em relação à deriva. A arquitetura mais utilizada neste caso é de Mapas Autoorganizáveis (SOM). Dois exemplos de sua utilização estão nos trabalhos de Holmberg et al. (1996) e de Marco et al. (1998).

No trabalho de Holmberg, de tempos em tempos é feita adaptação do SOM com amostras de referência. Ele conclui que este tipo de técnica é simples e bastante poderosa, mas que também possui algumas restrições, por requer que as medidas contenham pouco ruído e que amostras de referência sejam medidas regularmente. No outro trabalho, a estratégia utilizada por Marco para correção de deriva é manter o treinamento durante o funcionamento do sensor. Neste caso, durante a operação, a taxa de aprendizagem é mantida em um valor bastante baixo e somente o neurônio ativado tem seus pesos adaptados. Ele aponta que o nível de acertos se mantém estável, enquanto que o desempenho de um sistema idêntico, porém sem adaptação dinâmica dos pesos, decai já com pequenas variações. Marco no entanto aponta que quando há variações nos sensores superiores à $20 \%$, o desempenho deste sistema de correção de deriva degrada rapidamente.

\subsubsection{RNA do tipo KIII}

O sistema das RNAs do tipo KIII são baseados em sistemas olfativos biológicos e sua descrição e exemplo de aplicação em arranjos de sensores pode ser lida no 
trabalho de Fu et al. (2007). Por ser um modelo constituído de várias camadas, com transmissões e realimentações de sinais fundamentadas em sistemas neurofisiológicos, espera-se que este sistema seja mais robusto e menos suscetível à deriva e ao ruído.

Fu relata em seu trabalho que este tipo de rede possui desempenho semelhante ou melhor do que um sistema RNA do tipo MLP treinado com o tradicional algoritmo de back-propagation. Fu também relata que esta arquitetura também tem um poder de generalização maior do que um método baseado apenas em distâncias euclidianas entre amostras. Por fim, o sistema foi considerado menos sensível à deriva e torna capaz a utilização dos sensores até dois meses depois do treinamento.

A adulteração de combustíveis pode trazer uma série de malefícios, entre eles, reduzir da vida útil dos motores, causar danos ao meio ambiente, provocar a evasão de divisas (impostos) e promover a concorrência desleal entre postos de combustível. Entretanto, as adulterações podem ser dos mais variados tipos e mesmo a gasolina conforme pode possuir composição diferente dependendo do petróleo de origem e dos métodos de obtenção utilizados pelas refinarias (Apêndice 1). Na Figura 1.11 são apresentadas análises de cromatografia gasosa das gasolinas típicas de duas refinarias e é possível notar diferenças.

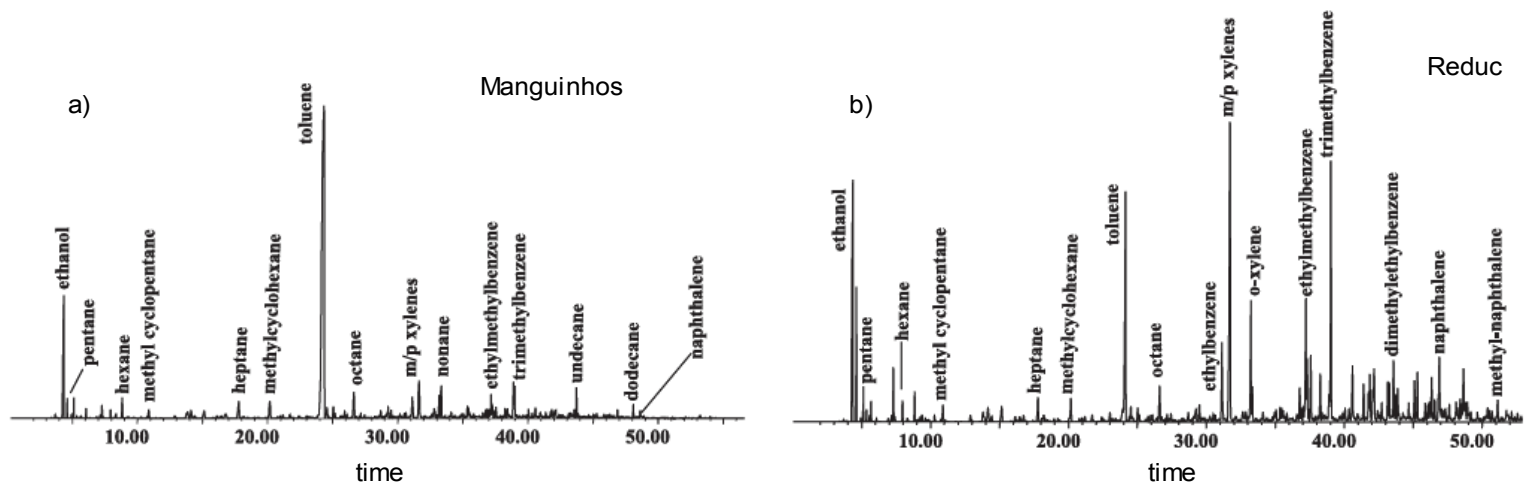

Figura 1.11 - Cromatografias gasosas típicas de ga solinas de duas refinarias: (a) Manguinho e (b) Reduc (WIEDEMANN, 2005a). 
Para tentar detectar adulterações diversas abordagens podem ser feitas. A primeira é a já citada cromatografia gasosa (SKROBOT et al., 2005) que é relativamente custosa e apresenta dificuldade de usabilidade. Existem também os ensaios físicoquímicos (Apêndice 1), como os parâmetros da curva de destilação (OLIVEIRA et al, 2004), a massa específica e o teor alcoólico, que são inclusive oficialmente adotados pela agência reguladora brasileira. No trabalho de Wiedemann et al. (2005b) concluiu-se que estas técnicas físico-químicas possuem bom desempenho na detecção de adulterações, principalmente quando a adulteração é por hidrocarbonetos alifáticos pesados, mas que, no entanto, adulterações por hidrocarbonetos aromáticos ou alifáticos mais leves são mais difíceis de serem detectadas.

Outra técnica utilizada é análise de qualidade de combustível por espectroscopia de infravermelho. Há um trabalho bastante específico em relação à detecção de adulteração realizado por Mendonça (2005) em que é mostrada a viabilidade da utilização do infravermelho próximo (NIR) pelas das técnicas FT-NIR (Fourrier transform NIR) e NIRS (NIR Reflectance spectroscopy) em conjunto com análises estatísticas PCA, LDA, QDA e PLS para determinar adulteração. Ferreira em (2006) e Klingbeil (2008) também desenvolveram trabalhos baseado em FT-IR, sendo que o primeiro tenta detectar por PCA possíveis adulterações com diversos produtos, como querosene, nafta, etc, e o segundo descreve modelos para determinar frações de alcanos, olefínicos, aromáticos e oxigenados.

Ainda na área de espectroscopia, outra técnica, baseada em espectroscopia $\mathrm{H}^{+1}$ NMR (proton nuclear magnetic resonance), foi desenvolvida visando atender grandes demandas de análises laboratoriais e os resultados também indicam capacidade de determinar frações de hidrocarbonetos aromáticos, olefínicos e alifáticos de gasolinas comerciais (BURRI, 2004).

$\mathrm{Na}$ área de sensores para gás, abordagens preliminares utilizando NEs baseados em óxido de estanho também existem. Um exemplo é o trabalho de Soba'nski de 2006 em que é tentado discriminar uma série de substâncias, metanol, etanol, tolueno, xileno, etc, através de um arranjo de sensores e análises PCA e de redes neurais.

$\mathrm{Na}$ área de polímeros condutores, o trabalho de Benvenho (2008) mostra resultado na determinação do teor alcoólico da gasolina por meio de análise de vapores e 
medidas de impedância de um novo co-polímero baseado em PPV depositado sobre estruturas interdigitadas.

Por fim, um último trabalho levando em conta apenas a condutividade e a constante dielétrica dos combustíveis foi realizado por Rocha e Simões (2005) e também mostrou resultados na determinação da porcentagem de etanol na gasolina.

\section{REDES NEURAIS ARTIFICIAIS}

As redes neurais artificiais de forma geral têm grande capacidade de associar sinais de entradas a sinais de saída de diferentes naturezas e, por isso, são muito utilizadas em aproximação de funções, reconhecimento e classificação de padrões e vêm sendo extensivamente empregadas na análise de dados de LEs (RIUL et al, 2004). De acordo com o teorema de Kolmogorov e Cybenko (CYBENKO, 1989), qualquer função pode ser aproximada por uma soma de funções sigmóides. Como a soma de sigmóides é justamente a um dos constituintes das RNAs do tipo Multilayer perceptron (MLP), com ela com ela é possível realizar a aproximação universal e classificação universal. Logo, se os dados dos sensores apresentarem padrões distintos para combustíveis conforme e não-conformes, é possível fazer a classificação.

(a)

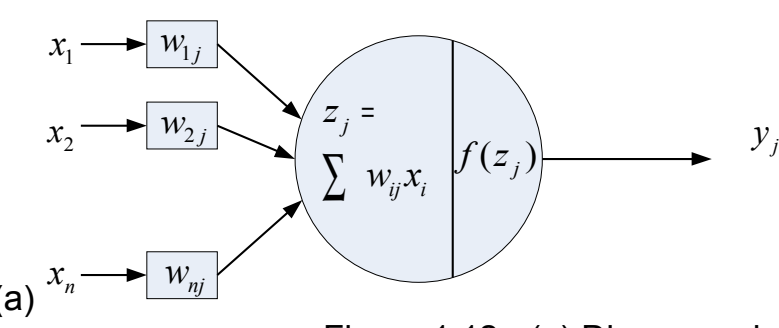

Figura 1.12 - (a) Diagrama de um nó. (b) MLP

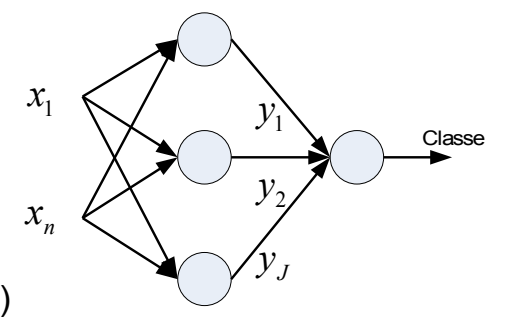

món (b) MLP

Brevemente, uma rede MLP é composta por uma série de nós (unidade de processamento ou neurônios da rede neural artificial -Figura 1.12.a). A função $f(x)$ de transferência é uma sigmóide ou tangente hiperbólica.

Apesar de ser possível a classificação universal com a MLP, o grande problema é determinar o número de nós e o valor dos pesos w de cada nó. A determinação desses parâmetros é realizada de forma computacional através de um processo de 
treinamento em que são apresentados exemplos de dados com valor de entrada e saída esperada. Grande parte do sucesso depende deste conjunto de dados de treinamento, que deve abranger uma parcela significativa do universo de situações possíveis. Varias técnicas de treinamento se propõem a realizar a configuração da rede, sendo que a mais tradicional é a Error Backpropagation (EBP).

\subsubsection{Error Backpropagation}

O Error Backpropagation (EBP) é um algoritmo de aprendizagem supervisionada, ou seja, utiliza um conjunto de exemplos com entradas e suas respectivas saídas esperadas. Em cada iteração é apresentado um determinado exemplar para a rede e a saída obtida é comparada com a desejada. Então os pesos sinápticos são ajustados de modo a minimizar o erro geral. O processo é finalizado quando a MLP apresentar um mapeamento satisfatório para o conjunto de exemplo, ou quando o número de iterações atinge um limite.

Em uma iteração, o ajuste dos pesos inicia na última camada (camada de saída) e propaga para as camadas anteriores, por isso recebe este nome.

O principio do algoritmo é a minimização do erro quadrático, ajustando os pesos seguindo o gradiente descendente da função erro. Ou seja:

$$
w_{i, j}(k+1)=w_{i, j}(k)-\eta \frac{\partial E}{\partial w_{i, j}}
$$

Onde $k$ é a interação, $w_{\mathrm{i}, \mathrm{j}}$ é o peso da sinapse entre o nó i de uma camada com o nó

j da camada seguinte, $\eta>0$ é o coeficiente de aprendizagem, e $\frac{\frac{\partial E}{\partial w_{i, j}}}{e ́ ~ a ~}$ variação do erro em função do peso. O erro $E$ para um exemplar $n$ é definido da seguinte forma:

$$
E_{n}=\frac{1}{2} \sum_{m=1}^{M}\left(t_{m}^{n}-y_{m}^{n}\right)^{2}
$$

Onde $m=1,2,3, \ldots M$ representa uma saída da rede, $\mathrm{t}_{\mathrm{m}}{ }^{\mathrm{n}}$ é o valor desejado para a $\mathrm{m}$ ésima saída do n-ésimo exemplar, e $y_{m}{ }^{n}$ é a o valor calculado. 
No treinamento em série, os pesos são ajustados para cada exemplo. No treinamento em lote, as atualizações só ocorrem após apresentação de todos os exemplares. Neste caso, utiliza-se o erro médio, definido como:

$$
E=\frac{1}{N} \sum_{n=1}^{N} E_{n}
$$

$\mathrm{n}=1,2,3 \ldots \mathrm{N}$ representa um exemplar do conjunto de treinamento.

O termo $\frac{\partial E}{\partial w_{i, j}}$ é normalmente calculado através da regra da cadeia, decompondo em derivadas mais simples. Para treinamento em lote:

$$
\frac{\partial E}{\partial w_{i, j}}=\sum_{n=1}^{N} \frac{\partial E_{n}}{\partial w_{i, j}}
$$

Então o erro do exemplar $n$ fica:

$$
\frac{\partial E_{n}}{\partial w_{i, j}}=\frac{\partial E_{n}}{\partial y_{j}} \frac{\partial y_{j}}{\partial s_{j}} \frac{\partial s_{j}}{\partial w_{i, j}} \text {, onde s j é produto escalar entre as entradas e }
$$

os pesos do nó j, para o exemplar $n$.

A primeira derivada é determinada como:

$$
\frac{\partial E}{\partial y_{j}}=-\left(t_{j}-y_{j}\right)
$$

Utilizando a sigmóide como função de transferência, a segunda parcela fica:

$$
\frac{\partial y_{j}}{\partial s_{j}}=y_{j}\left(1-y_{j}\right)
$$

Por fim, a última derivada é determina da seguinte forma:

$$
\frac{\partial s_{j}}{\partial w_{i, j}}=\frac{\partial}{\partial w_{i, j}} \sum_{l=1}^{L} y_{l} w_{l, j}=y_{i}
$$

$$
\text { , onde I = 1,2, 3... L são as entradas do nó j. }
$$

Para um peso de um neurônio $h$ na camada anterior, a regra da cadeia resulta:

$$
\begin{gathered}
\frac{\partial E_{n}}{\partial w_{h, i}}=\sum_{j=1}^{M}\left(\frac{\partial E_{n}}{\partial y_{j}} \frac{\partial y_{j}}{\partial s_{j}} \frac{\partial s_{j}}{\partial y_{i}}\right) \frac{\partial y_{i}}{\partial s_{h}} \frac{\partial s_{h}}{\partial w_{h, i}} \\
\text { onde, } \frac{\partial s_{j}}{\partial y_{i}}=\frac{\partial}{\partial y_{i}} \sum_{l=1}^{L} y_{i} w_{i, j}=w_{i, j}
\end{gathered}
$$


Este princípio é aplicado para as demais camadas da rede.

\subsubsection{Redes Modulares}

O conceito de rede modular é empregado no âmbito de problemas de classificação com mais de duas classes. Isto ocorre por que uma rede MLP teoricamente pode possuir vários nós de saída, um para cada classe. Esta abordagem não modular é comumente utilizada. Já as MLPs modulares diferem desta abordagem por apresentarem uma rede independente para cada classe (veja comparação na Figura 1.13). A justificativa da utilização de redes modulares neste caso se deve ao trabalho de Anand et al (1995) em que é mostrado matematicamente que há conflitos de sinais de erro retropropagados pela rede durante a atualização dos pesos, o que retarda o treinamento da rede. Além disso, os módulos MLP designados a cada classe tendem a ter menos nós e no conjunto menos parâmetros (pesos) a serem determinados.

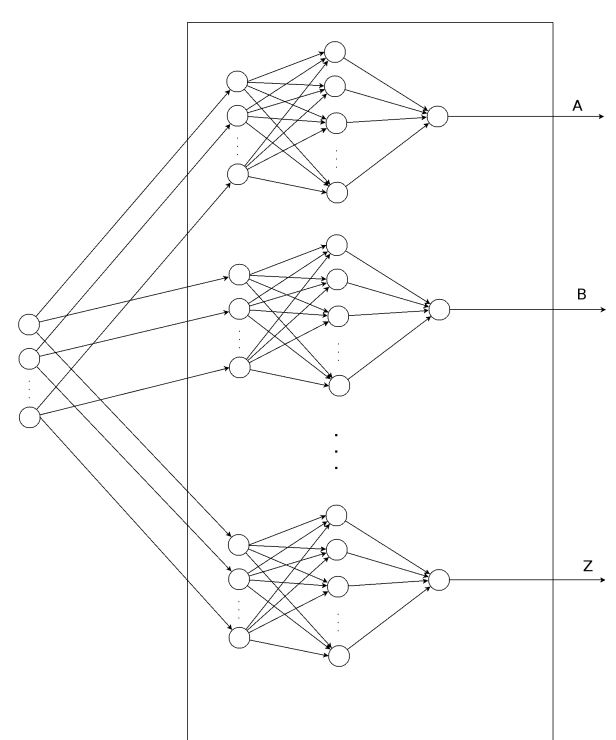

(a)

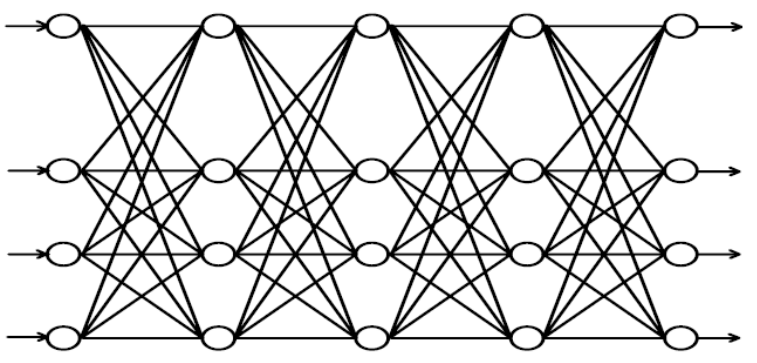

(b)

Figura 1.13 - (a) Rede modular. (b) Rede não modular.

Outra medida para tornar o processo de treinamento da rede MLP é considerar as atualização de pesos independentemente para amostras da classe respectiva ao módulo em treinamento e as classes complementares. Este estudo também realizado por Anand (1995) mostra que a convergência se torna mais rápida e é 
mais imune a conjuntos de treinamentos desbalanceados. Um conjunto desbalanceado é aquele que possui mais amostras de uma classe em relação à outra. Isto faz com que as amostras com maior número predominem na atualização dos pesos e o erro para a classe complementar aumente e divirja no início do treinamento e que o processo com um todo dure mais para corrigir esta divergência inicial.

Estas afirmações são explicadas segundo o seguinte raciocínio:

No caso de uma MLP com um único nó de saída, a prática mostra que nas primeiras iterações do EBP em lote, o erro quadrático dos exemplares da classe dominante decresce rapidamente, enquanto para a outra classe, esse valor cresce consideravelmente. Nos passos seguintes, a taxa de diminuição do erro da classe subordinada é muito baixa, resultando na convergência lenta do erro geral da rede. Em uma MLP com uma camada escondida e um nó de saída, a variação dos pesos da última camada para um exemplar é definida da seguinte forma no EBP tradicional:

$$
\Delta w_{i}=\eta\left((t-y) y(1-y) y_{i}\right)
$$

Onde $y_{\mathrm{i}}$ é a saída do i-ésimo nó da camada escondida e y é a saída da rede.

Para entradas positivas, o sinal de $\Delta w_{i}$ é determinado apenas pela parcela $(t-y)$. Na primeira iteração, os exemplares da classe C1 (saída desejada 0), tendem a fazer um ajuste negativo, enquanto que os da classe $\mathrm{C} 2$ tende a ser positivo. $\mathrm{O}$ sinal do ajuste é propagado para a camada anterior.

Desta forma, o gradiente do erro dos exemplares de uma classe possui sinal oposto do da classe complementar. Desta forma o produto vetorial entre eles é negativo.

$$
\nabla E_{1}(W) \cdot \nabla E_{2}(W)<0
$$

Ou seja, no espaço dos pesos, os vetores gradiente formam um ângulo maior que 90 graus.

Supondo a inicialização dos pesos seja aleatória, a relação das esperanças do quadrado dos módulos dos vetores gradientes é aproximadamente igual a relação das quantidades de exemplares de cada classe, ou seja: 


$$
\frac{\varepsilon\left(\left\|\nabla E_{1}(W)\right\|^{2}\right)}{\varepsilon\left(\left\|\nabla E_{2}(W)\right\|^{2}\right)} \approx \frac{n_{1}^{2}}{n_{2}^{2}}
$$

Este teorema implica que, quanto maior a quantidade de exemplares de uma classe em relação a outra, a maior é a probabilidade do vetor gradiente desta classe ser muito maior que o outro nas primeiras iterações. Como $\nabla E=\nabla E_{1}+\nabla E_{2}$, se a classe C2 for a dominante, então $\nabla E \approx \nabla E_{2}$. Quando se atualiza os pesos em direção do vetor gradiente geral, o erro geral diminui. Como este vetor é muito próximo de $\nabla E_{2}$ (para o caso da classe C2 ser a dominante), então o erro para esta classe diminui. Porém, o da classe C1 aumenta consideravelmente, já que o ângulo entre $\nabla E_{\mathrm{e}} \nabla E_{1}$ é maior que 90 graus (estão em direções opostas).

Quando o erro na saída é grande $(|t-y| \approx 1)$, a variação dos pesos tende a ser pequena, uma vez que a saída y normalmente é próxima de 1 ou de 0 , resultando,em ambos os casos, em $\Delta$ wi $\approx 0$.

Desta forma, nas iterações iniciais, a tendência é diminuir rapidamente o erro para os exemplos da classe dominante e aumentar consideravelmente $\mathrm{o}$ da classe subordinada. Desta forma, para os exemplares da primeira classe (erro elevado), a variação do peso será pequena, enquanto os da segunda classe (erro pequeno) também apresentarão uma baixa taxa de convergência. O resultado é o aumento de iterações necessárias para convergir. 


\section{MATERIAIS E MÉTODOS}

\section{1.}

\section{AMOSTRAS DE COMBUSTÍVEIS}

As gasolinas utilizadas neste trabalho foram compradas na rede de abastecimento de combustíveis de São Paulo em estabelecimentos idôneos, segundo uma análise subjetiva feita pelos pesquisadores envolvidos. O álcool PA utilizado foi adquirido em fornecedores de produtos químicos quando não é explicitada a sua origem no texto. Para os testes com combustíveis (gasolina e álcool) com adulterações reais encontradas na região da cidade de São Paulo tivemos a colaboração da Agência Nacional do Petróleo (ANP) e do Instituto de Pesquisas Tecnológicas do estado de São Paulo (IPT). Ao longo do trabalho a ANP permitiu que o IPT nos fornecesse amostras de gasolina e etanol analisados nos laboratórios deste último e com informações quanto à conformidade ou não conformidade em relação às leis nacionais vigentes na época. Os combustíveis nos foram entregues sem a identificação da origem, mas, com o resultado das análises de laboratório.

Os combustíveis fornecidos pelo IPT foram analisados e mantidos sobre refrigeração em nosso laboratório.

\section{2.}

\section{MICROELETRODO INTERDIGITADO}

As estruturas interdigitadas são comumente utilizadas como suporte para camadas sensíveis utilizadas em sensores. O seu princípio de transdução baseia-se na impedância elétrica (capacitância ou resistência) medida entre dois terminais, eletrodos, da estrutura. A Figura 2.14 ilustra os microeletrodos.

No presente trabalho, os microeletrodos utilizados foram fabricados através da deposição via sputtering de ouro ( $\mathrm{Au}$ ) sobre substrato de vidro (borosilicato). Antes da deposição do ouro, uma fina camada de níquel-cromo ( $\mathrm{NiCr}$ ) foi depositada, também por sputtering, sobre o vidro para melhorar a adesão do ouro. A espessura 
da camada total ( $\mathrm{NiCr} / \mathrm{Au}$ ) é de cerca de $200 \mathrm{~nm}$. As estruturas interdigitadas foram fotogravadas à posteriori, sendo que suas geometrias descritas na Tabela 2.2.

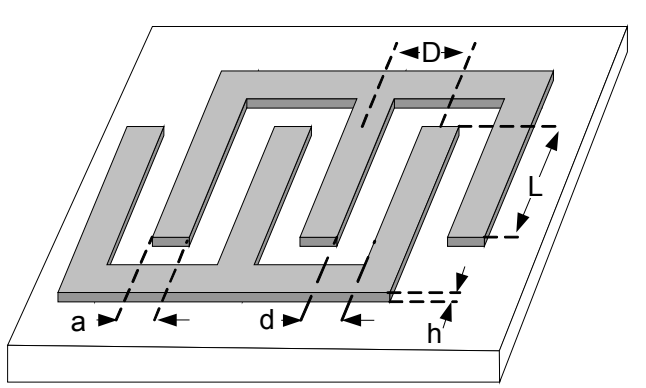

(a)

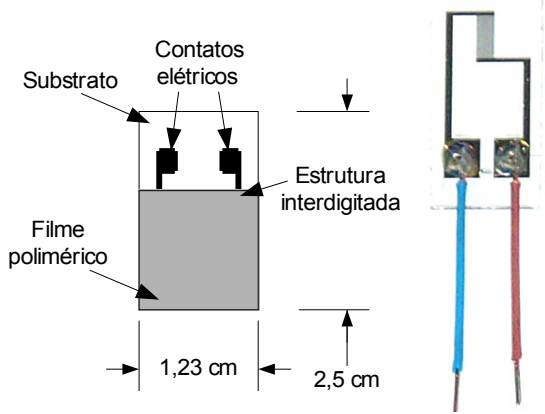

(b) (c)

Figura 2.14 - Microeletrodo interdigitado. (a) Principais parâmetros. (b) llustração e dimensões. (c) Foto.

Tabela 2.2 - Parâmetros de dimensão geométrica dos microeletrodos.

\begin{tabular}{|c|c|c|c|c|}
\hline Código & $\begin{array}{c}\text { Pares de } \\
\text { dígitos (N/2) }\end{array}$ & $\begin{array}{c}\text { Distância entre } \\
\text { dígitos }(\mathbf{d})[\boldsymbol{\mu m}]\end{array}$ & $\begin{array}{c}\text { Comprimento do } \\
\text { dígito }(\mathbf{L})[\boldsymbol{\mu m}]\end{array}$ & $\begin{array}{c}\text { Largura do } \\
\text { dígito }(\mathbf{a})[\boldsymbol{\mu m}]\end{array}$ \\
\hline $\mathrm{T} 10$ & 50 & 10 & 4975 & 10 \\
\hline $\mathrm{T} 50$ & 50 & 50 & 5000 & 10 \\
\hline $\mathrm{N} 10$ & 1 & 10 & 16000 & 1000 \\
\hline
\end{tabular}

2.3.

FILMES DE MATERIAL SENSÍVEL

Os materiais sensíveis estudados neste trabalho foram os polímeros condutores. Polímeros condutores de eletricidade foram descobertos pelo grupo do professor Shirakawa (CHIANG et al., 1977) na década de 80 no Japão e há diversos estudos da utilização deste tipo de material em sensores (MEDEIROS; et al., 2006).

Dentre outras características, os polímeros conjugados influem na adsorção de moléculas em sua superfície e pequenas mudanças no ambiente, como na polaridade, na acidez, na umidade, etc, podem afetar a conformação das cadeias poliméricas, sua distribuição eletrônica e o seu nível de dopagem, causando alteração em sua condutividade.

As duas técnicas utilizadas neste trabalho para a formação de filme ultrafino polimérico na superfície dos microeletrodos são a automontagem e a deposição eletroquímica, descritas adiante e utilizadas em colaboração com o trabalho de Wiziack (2007). 


\subsubsection{Automontagem}

A automontagem, baseada no princípio da adsorção espontânea de materiais com cargas eletrostáticas opostas, foi proposta por Decher (1997) e esquematizada brevemente na Figura 2.15.a. Na Figura 2.15.b apresentamos a Língua Eletrônica utilizando os microeletrodos interdigitados com os filmes poliméricos depositados por automontagem.

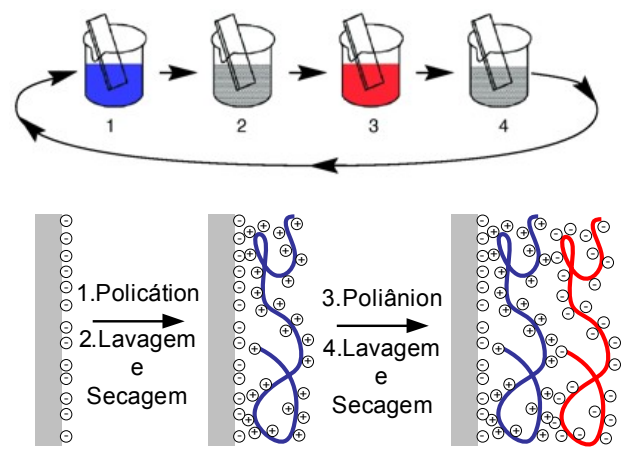

(a)

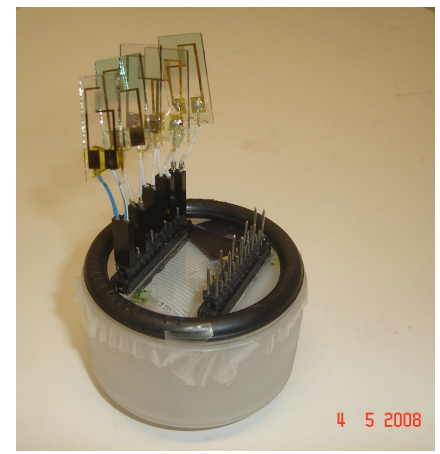

$=(\mathrm{b})$

Figura 2.15 - Automontagem (a) e Língua Eletrônica (b).

Os polímeros e reagentes utilizados nos filmes foram: A polianilina (PAni), 0 poli(metoxianilina) (POMA) e o poli(etoxianilina) (POEA), obtidos através de seus monômeros pela síntese química proposta por Mattoso et al. (1995). Os compostos ftalocianina tetrasulfonada de níquel (Ni-TS-Pc) e poli(estireno sulfonado de sódio) (Mw $70.000 \mathrm{~g} / \mathrm{mol}$ ) (PSS) e a formulação hidrosolúvel polipirrol (PPy) foram adquiridos da Aldrich Co (EUA). A dispersão aquosa de poli(3,4etilinodioxitiofeno) e PSS (PEDOT:PSS 1:6 em peso ou simplesmente PEDOT) foram adquiridas da Bayer. A lignina sulfonada (Mw $3.000 \mathrm{~g} / \mathrm{mol}$ ) (LS) foi adquirida da Melbar Produtos de Lignina SA (Brasil). 


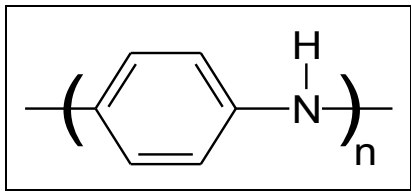

Polianilina-PANI

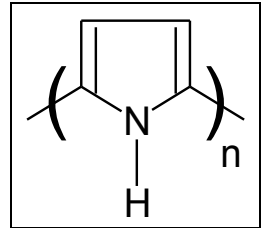

Polipirrol-PPy

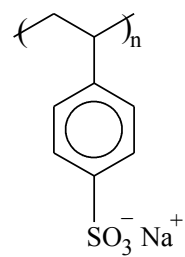

Poli(estireno sulfonato de sódio)-PSS

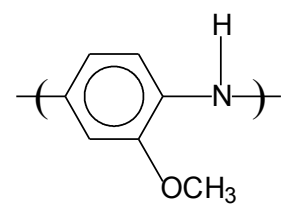

Poli(o-metoxianilina)-POMA

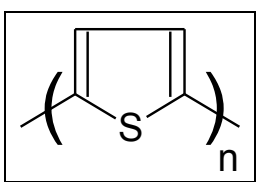

Politiofeno-PTh

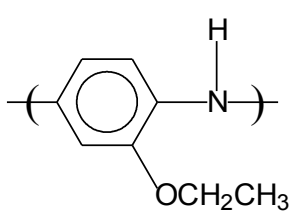

Poli(o-etoxianilina)-POEA<smiles>Cc1sc(C(C)(C)C)c2c1C(C(C)C)OCCO2</smiles>

Poli(3,4-etilenodioxitiofeno)-PEDOT

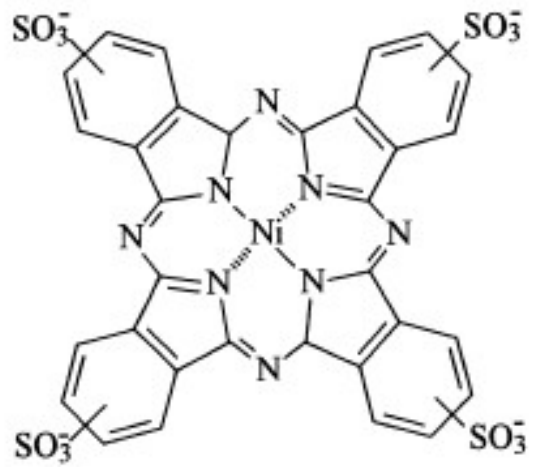

Ftalocianina tetrasulfonada de níquel-NiTS-Pc

Figura 2.16 - Estrutura química dos reagentes para automontagem.

As soluções aniônicas e catiônicas destes materiais foram preparadas das maneiras descritas a seguir. As soluções de PAni, o POMA e POEA dopadas foram obtidas diluindo-se o polímero em uma mistura de dimetil-acetamida (DMAC) e água ultrapura e deixadas sob agitação por 18h. Em seguida, o polímero foi dopado gotejando-se $\mathrm{HCl} 1 \mathrm{M}$ até a dopagem, quando ocorre a mudança de cor de azul para verde. Em seguida, uma solução de $\mathrm{HCl}$ em $\mathrm{pH}$ 2,7 é adicionada para completar 100 $\mathrm{mL}$ de solução. As soluções de LS, Ni-TS-Pc, PSS foram obtidas dissolvendo os componentes em soluçÃo de $\mathrm{HCl}$ pH2,7 e agitadas por $2 \mathrm{~h}$. O PEDOT e o PPy foram também diluídos em solução de $\mathrm{HCl}$ pH 2,7.

Os filmes obtidos destas soluções foram os da Tabela 2.3:

Tabela 2.3 - Filmes automontados.

\begin{tabular}{|c|c|}
\hline Filme & Bicamadas \\
\hline POEA/PSS & 10 \\
\hline POMA/PPy & 10 \\
\hline POMA/PEDOT & 10 \\
\hline PAni/LS & 10 \\
\hline PAni/Ni-TS-PC & 10 \\
\hline
\end{tabular}




\subsubsection{Deposição eletroquímica}

No processo de deposição eletroquímica foi utilizado o equipamento Autolab PGSTAT 302 e o procedimento descrito por Alessandra Forner (2003). A célula eletroquímica utilizada tem o microeletrodo interdigitado como eletrodo de trabalho e o contra-eletrodo de platina. Foi utilizado um fio de prata como referência. Não se utilizou como referência os tradicionais eletrodos $\mathrm{Ag} / \mathrm{AgCl}$ e calomelano, pois o sistema deve ser livre de água. Este processo foi utilizado para se obter os dois polímeros Poli(3-metiltiofeno) (PMTh) e Poli(3-hexiltiofeno) - PHTh (Figura 2.17).

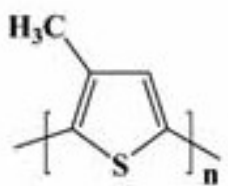

(a)

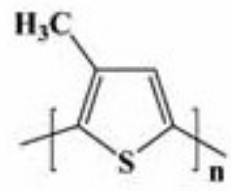

(b)

Figura 2.17 - (a) Poli(3-metiltiofeno) -PMTh (b) Poli(3-hexiltiofeno) - PHTh.

O conteúdo da célula é constituído de uma solução $0,1 \mathrm{M}$ de LiClO4 em acetonitrila e os monômeros. O solvente acetonitrila foi adquirido da Lichrsolv-Merck e o eletrólito de suporte $\mathrm{LiClO}_{4}$ da Alfa-Aesar. Os monômeros 3-metiltiofeno e 3-hexiltiofeno 98\% foram adquiridos da Aldrich.

Preparada esta configuração, a deposição eletroquímica do filmes derivados de tiofeno foi realizado por duas técnicas, a cronoamperometria galvanostática e cronopotenciomentria. Na primeira, um potencial constate de $1,5 \mathrm{~V}$, em relação ao eletrodo de referência, é aplicado ao eletrodo de trabalho, no caso, o microeletrodo interdigitado de ouro, e a corrente elétrica produzia (que flui entre o eletrodo de trabalho e o contra-eletrodo) é monitorada até que se tenha conduzido uma carga elétrica de valor $500 \mathrm{mC} / \mathrm{cm}^{2}$ e, neste momento, o procedimento é interrompido. $\mathrm{Na}$ técnica de cronopotenciomentria, uma corrente constante de $1 \mathrm{~mA}$ é injetada no eletrodo de trabalho por um tempo pré-estabelecido de forma que a mesma carga de $500 \mathrm{mC} / \mathrm{cm}^{2}$ atravesse o sistema. Na Figura 2.18 é possível ver a micrografia de um filme de Poli(3-metiltiofeno) (PMTh) depositado nas condições descritas e o equipamento utilizado para realizar a eletrodeposição 


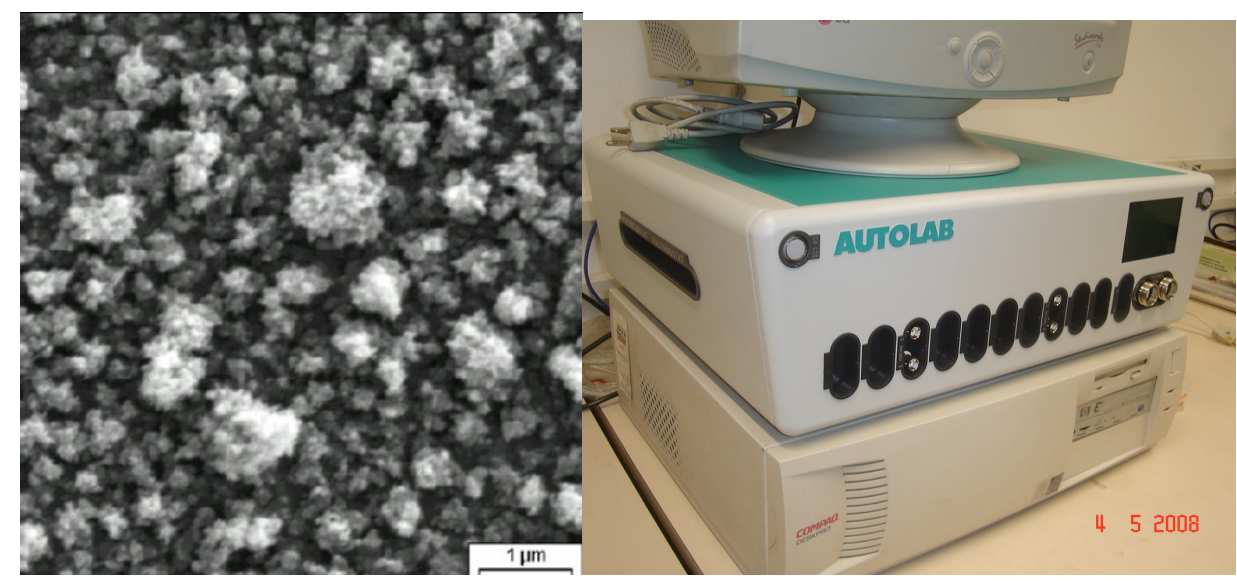

(a)

(b)

Figura 2.18 - (a)Micrografia do poli(3-metiltiofeno) preparado por cronoaperometria a 1,5V e carga $\mathrm{Q}=500 \mathrm{mC} / \mathrm{cm} 2$. (FORNER, 2003). (b) Autolab

Os filmes fabricados foram os da Tabela 2.4 .

Tabela 2.4 - Filmes eletrodepositados

\begin{tabular}{|c|c|c|}
\hline Filme & Técnica & Parâmetro \\
\hline $\begin{array}{c}\text { Poli(3-metiltiofeno) } \\
\text { (PMTh) }\end{array}$ & Cronoamperometria & $1,5 \mathrm{~V}$ \\
\hline $\begin{array}{c}\text { Poli(3-metiltiofeno) } \\
\text { (PMTh) }\end{array}$ & Cronopotenciomentria & $1,0 \mathrm{~mA}$ \\
\hline Poli(3-hexiltiofeno) (PHTh) & Cronoamperometria & $1,5 \mathrm{~V}$ \\
\hline Poli(3-hexiltiofeno) (PHTh) & Cronopotenciomentria & $1,0 \mathrm{~mA}$ \\
\hline
\end{tabular}

2.4 . SISTEMA DE MEDIDAS

A impedância elétrica dos microeletrodos com a superfície modificada pelos polímeros conjugados foi medida através de um analisador de impedância com as duas montagens - sistema convencional e sistema com câmara para gases descritas a seguir.

\subsubsection{Sistema convencional de medição}

O sistema convencional de medidas (Figura 2.19) é capaz de medir tanto amostras líquidas quanto gasosas. No segundo caso a medição é denominada headspace. 
Esta montagem é constituída de três elementos principais, um analisador de impedância Solartron 1260A, um multiplexador para a alternância automática entre os diversos sensores do arranjo, e um software de aquisição automática de dados, executado por um computador. O software de aquisição utilizado é de desenvolvimento próprio (apêndice $B$ ), porém baseado em um similar desenvolvido pela Embrapa. O multiplexador foi desenvolvido pela Embrapa. Além destes equipamentos, também há um banho termostático para manter as amostras em temperatura constante durante as medições.

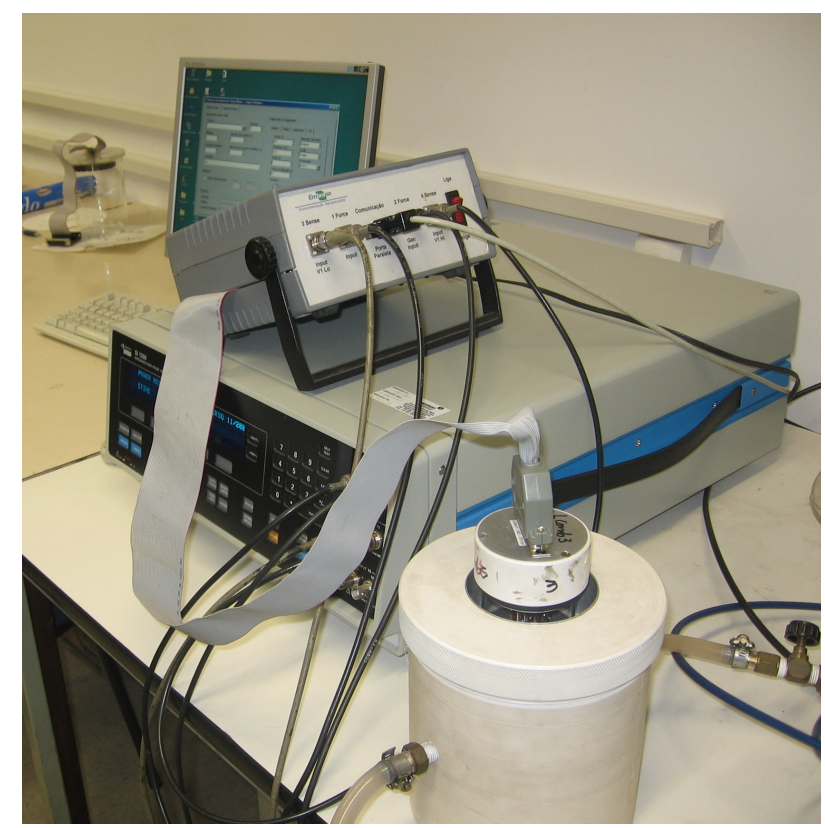

Figura 2.19 - Sistema convencional de medidas - gases e líquidos.

\subsubsection{Sistema com câmara para medição de gases}

Além desta montagem básica, foi estudada também uma montagem mais sofisticada para os sensores de gás, construída com a intenção de proporcionar menor interferência do ambiente externo.

A estrutura principal do sistema é a câmara, cujo diagrama e foto se encontram na Figura 2.21 (a) e na Figura 2.21 (c), respectivamente. Ela possui cinco pontos de admissão de gás e uma saída (Figura 2.21.b) e foi projetada para que haja um fluxo bem distribuído em seu interior (Figura 2.21.d). Os sensores são posicionados dentro da câmara por meio de uma estrutura de acrílico, que também serve como tampa (Figura 2.21.e). 
Além da câmara de medidas, o sistema Figura 2.21.f e Figura 2.20) também é composto de um rotâmetro para controle da vazão do gás de arraste, que é borbulhado na amostra mantida a temperatura constante pelo banho termostático. $O$ gás de arraste pode ser N2 provindo de um cilindro ou ar comprimido fornecido por uma bomba, que também pode ser utilizada com bomba de vácuo. O sistema de medição dos sinais elétricos (Solartron e Multiplexador) é conectado aos sensores e os dados são automaticamente coletados pelo Software de Aquisição no computador. Na saída de gases da também pode ser acoplado um medidor de umidade relativa de mão, modelo HTR170 da Instrutherm.

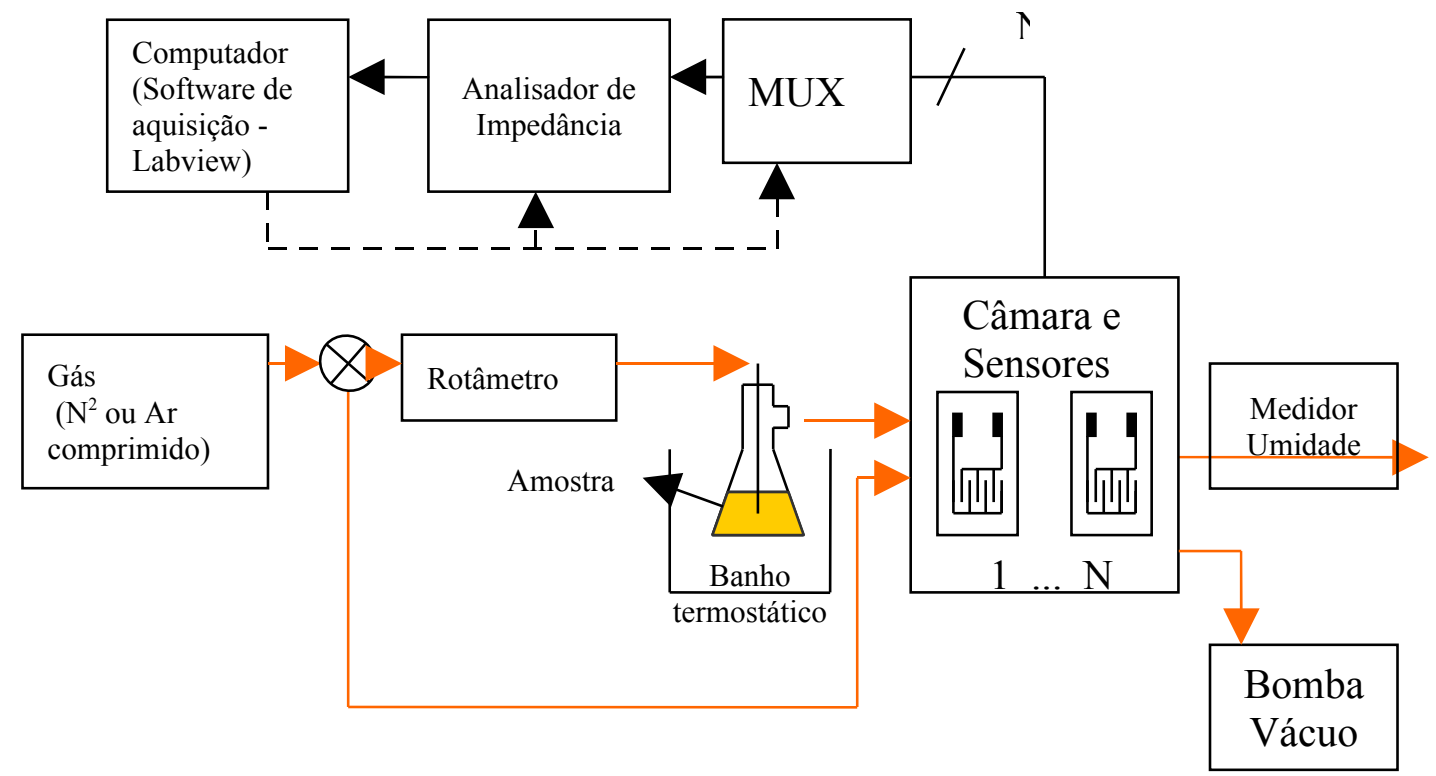

Figura 2.20 - Diagrama do sistema de gás com câmara. 


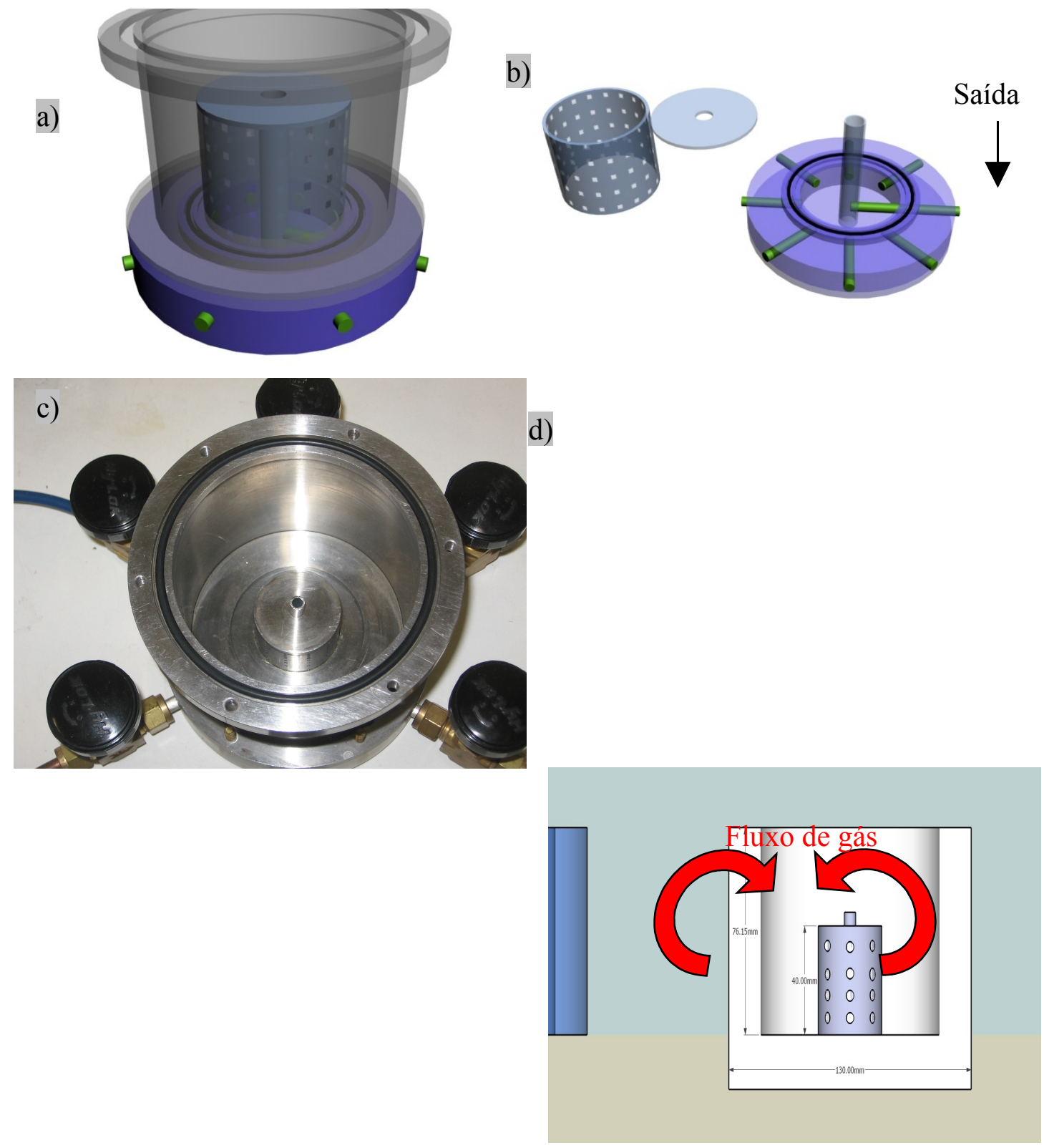



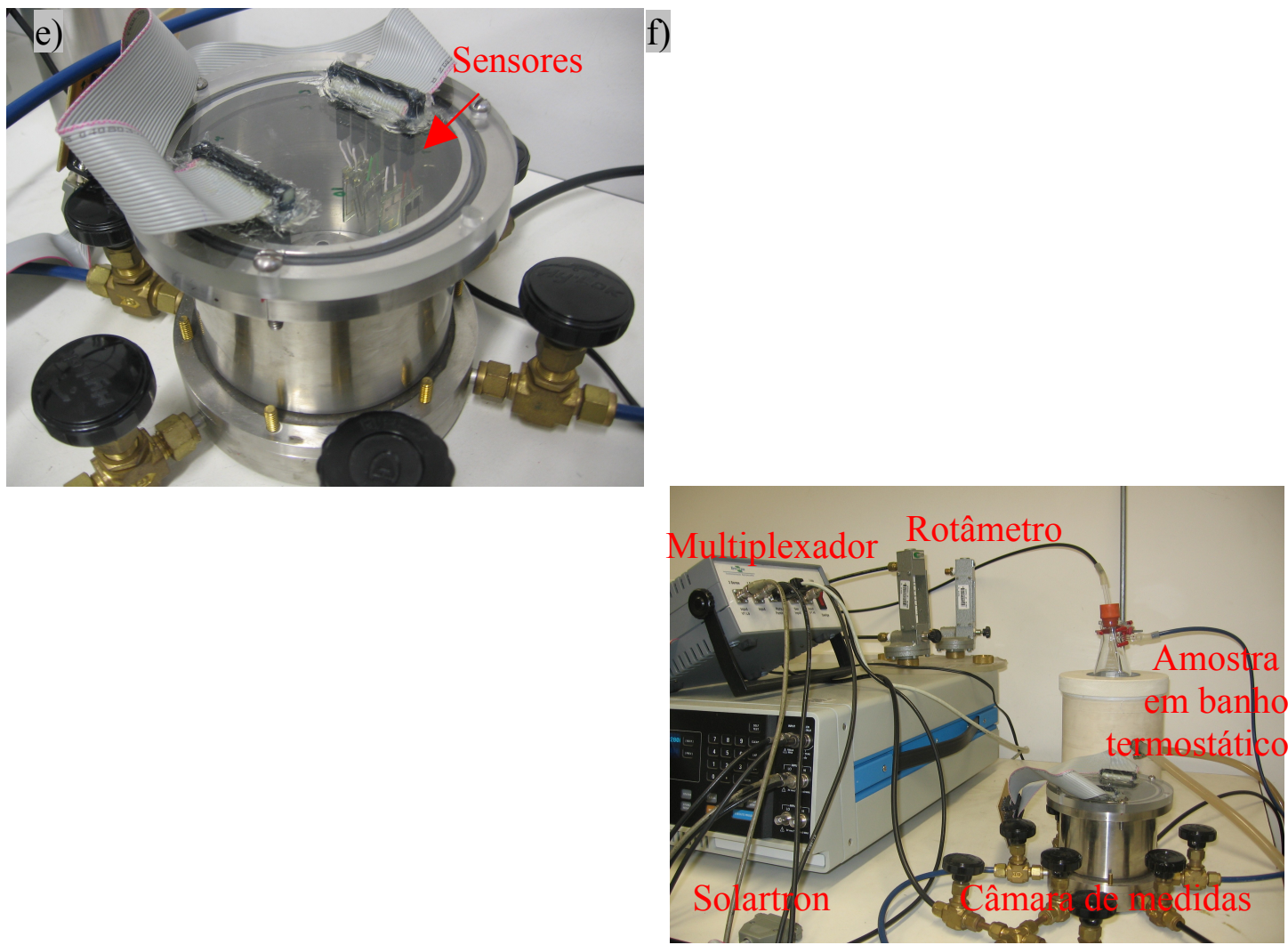

Figura 2.21 - Sistema de medição de gás em câmara. (a) Diagrama, (b) Detalhes do sistema de entrada de gás, (c) Câmara, (d) Diagrama do fluxo de gás na câmara, (e) Câmara com sensores e (f) Sistema completo de medição.

\section{5.}

\section{REDES NEURAIS ARTIFICIAIS}

No presente trabalho, esta rede neural modular foi desenvolvida utilizando a linguagem Java de programação.

O algoritmo desenvolvido segue o proposto por Anand et al (1995) e será denominado Bissetriz.

Para validar o desenvolvimento, os resultados foram comparados aos da base de dados Proben1 (PRECHELT, 1994). 


\section{RESULTADOS}

3.1.

SENSORES PARA GASOLINA E ETANOL - GÁS

Os ensaios com o sistema de gases foram inicialmente realizados no modo headspace, medindo-se $10 \mathrm{~mL}$ de amostra contida em um recipiente, mantido à $20^{\circ} \mathrm{C}$, com o arranjo de sensores de filmes automontados (POEA/PSS, Pani/Ni-TSPC, POMA/PPy, POMA/PEDOT e PAni/LS - geometria T10). A impedância dos sensores foi adquirida pelo equipamento Solartron1260A aplicando-se sinais senoidais de amplitude de $50 \mathrm{mV}$.

\subsubsection{Ensaio de ciclagem ar/mistura de etanol e água destilada}

Durante o processo, duas réplicas de cada sensor foram expostas ciclicamente ao ambiente da sala e às amostras contendo $100 \%, 75 \%$ e $50 \% \mathrm{v} / \mathrm{v}$ de etanol PA em água destilada.

Para efeitos de visualização, as respostas foram escaladas dividindo a grandeza medida pelo seu valor máximo. Também para efeitos de visualização, as respostas de cada tipo de sensor foram deslocadas no eixo y. Para cada tipo de sensor, há duas curvas que representam dois sensores distintos, porém do mesmo tipo, ou seja, são réplicas.

Deste gráfico pode-se concluir que:

Os filmes claramente mostram resposta diferente entre ar, etanol puro e etanol misturado com água. Não é possível distinguir facilmente as misturas de etanol (50 e $75 \%)$.

Em quinze minutos, não chegam a ter suas respostas totalmente estáveis

Quando expostos ao etanol puro, a capacitância de todos os sensores diminui; quando expostos ao etanol com água, aumenta. 
Quando expostos ao etanol puro, a condutância de todos os sensores diminuiu; quando expostos ao etanol com água, a condutância dos sensores com PAni diminuiu e a dos sensores com seus derivados aumentou.

Apesar de conseguirmos obter uma diferenciação dos combustíveis analisados com relação ao ar, fica difícil a distinção entre as várias combinações de combustíveis analisadas.

(a)

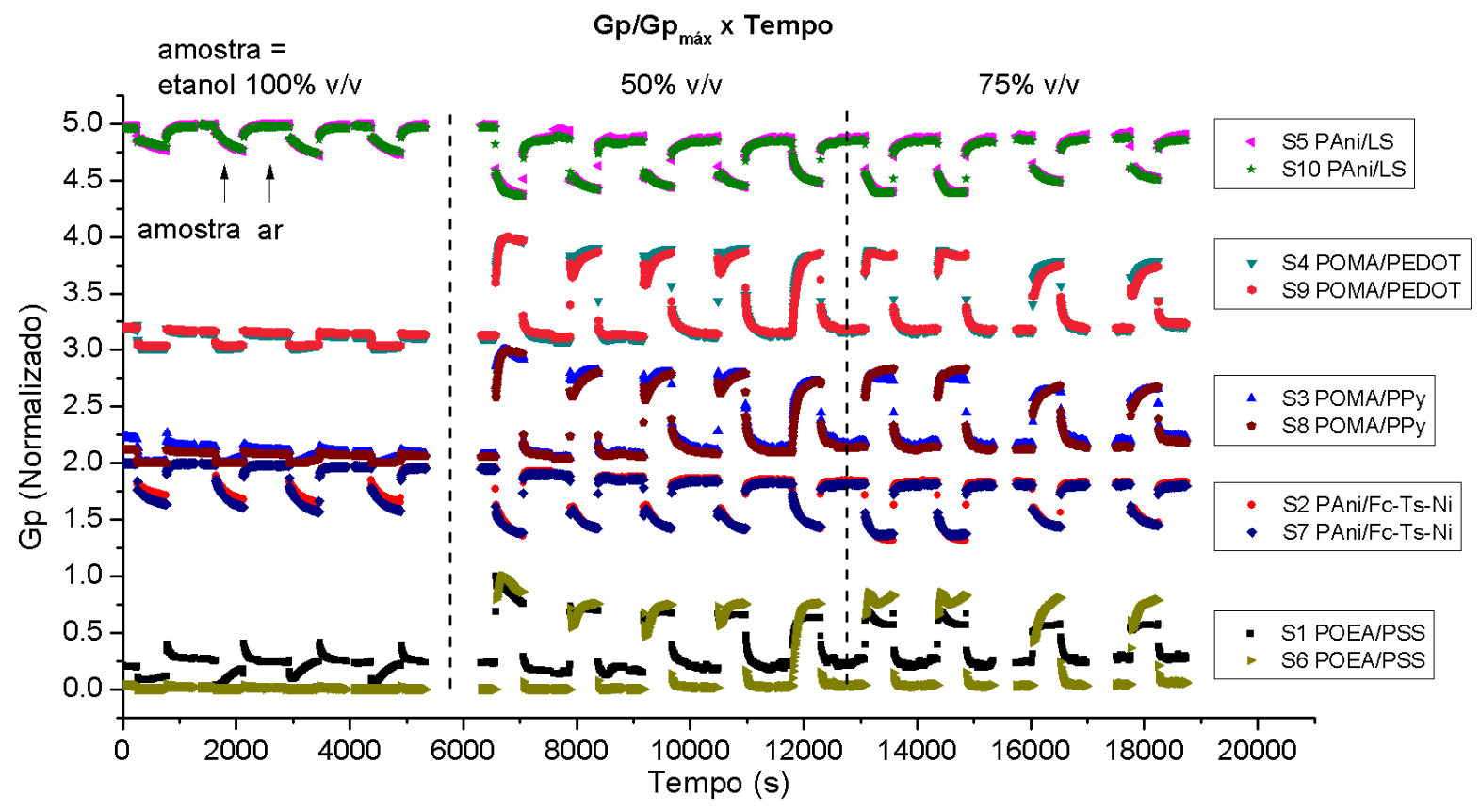


(b)

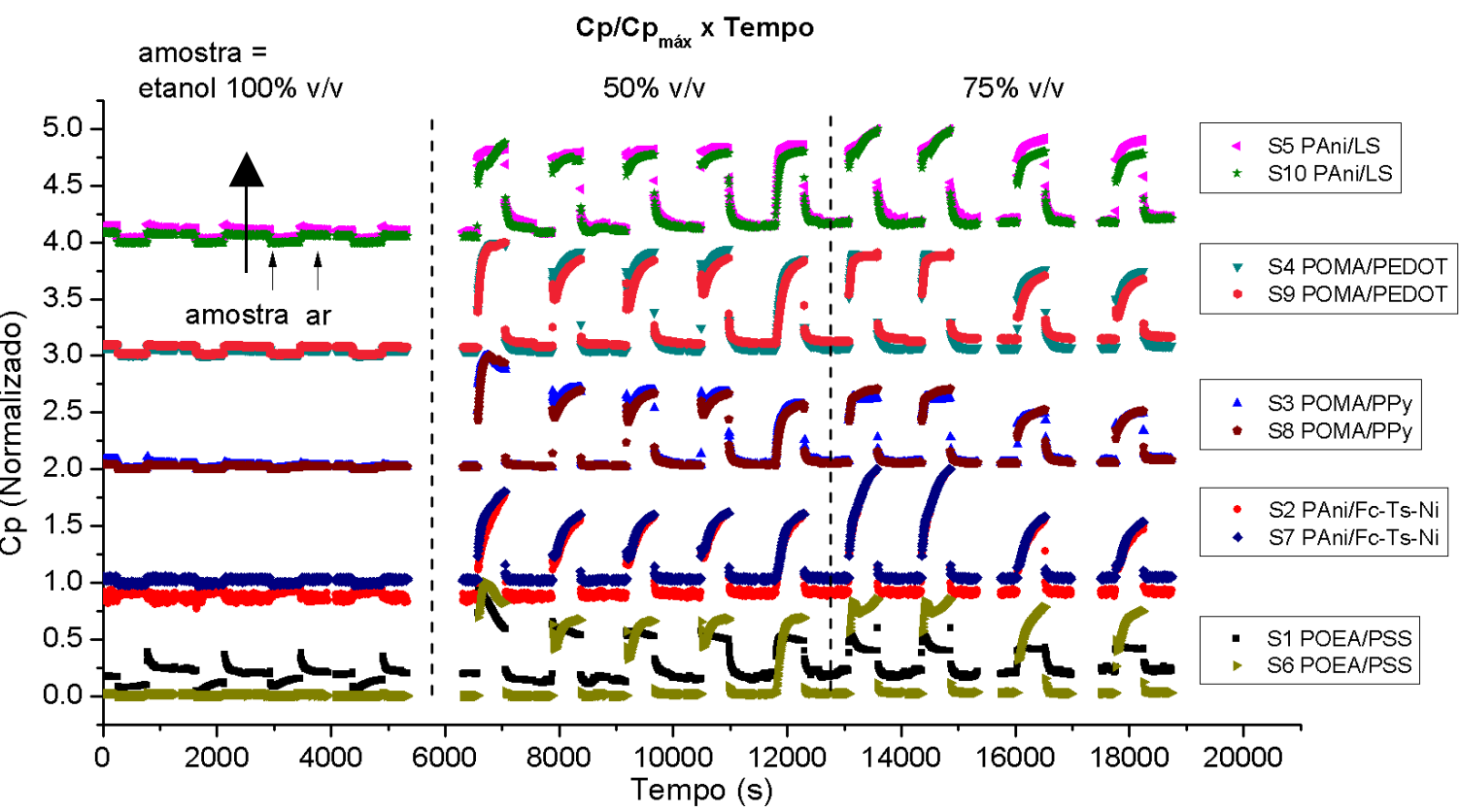

Figura 3.22 - Resposta de diferentes sensores expostos ao vapor de etanol medidos em $1 \mathrm{kHz}$ em função do tempo. (a) Condutância e (b) capacitância do circuito RC paralelo equivalente.

\subsubsection{Ensaio de espectroscopia de impedância das misturas de etanol e água destilada}

$\mathrm{Na}$ mesma configuração (análise dos gases em configuração headspace) e concentrações anteriores, foram realizadas as medições de espectroscopia de impedância que gerou os gráficos da Figura 3.23 até a Figura 3.27, sendo Z' e Z"' as impedâncias em unidade de $\Omega$ real e imaginária, respectivamente

Este ensaio foi uma tentativa de identificar as diversas proporções de misturas de etanol e água através da medida dos voláteis oriundos dos combustíveis analisados utilizando os sensores fabricados até este momento do trabalho. Apesar de obter alguma identificação, ainda não foi atingida a seletividade esperada. 


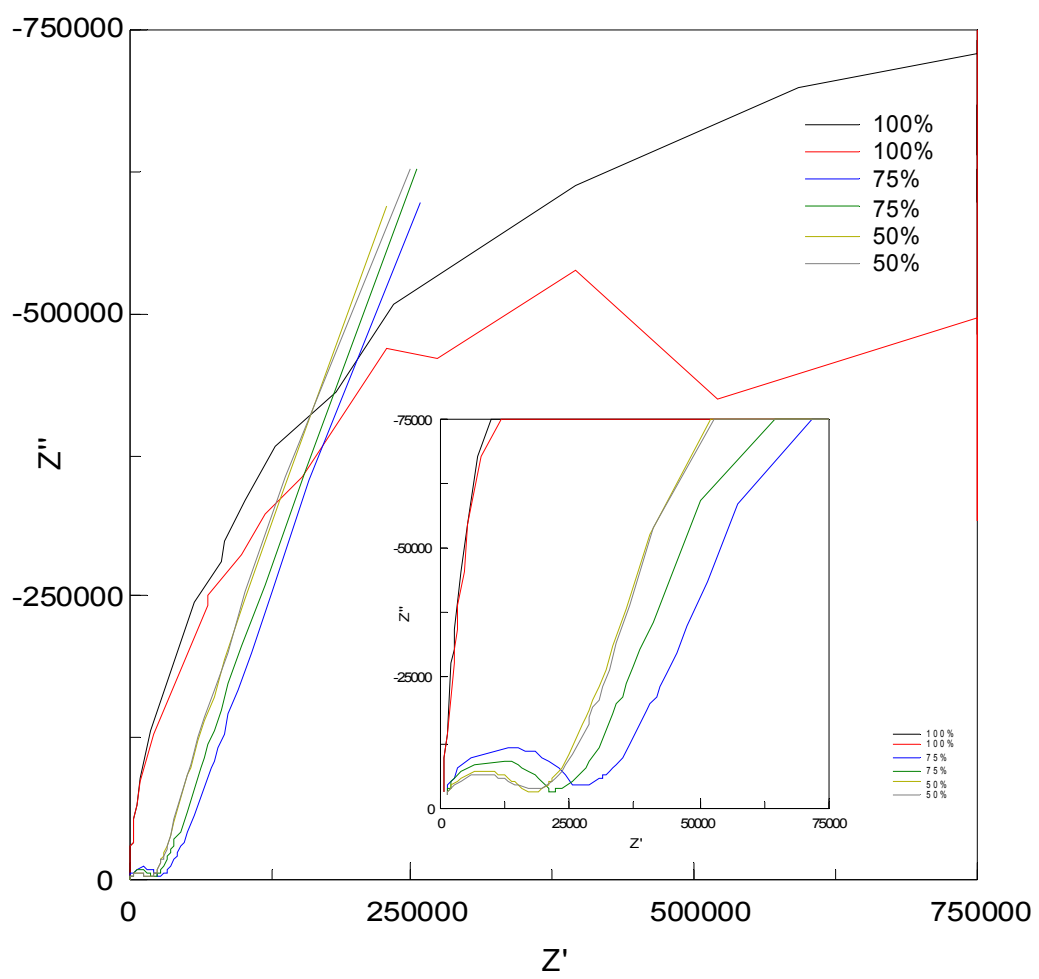

Figura 3.23 - Espectroscopia de impedância de um filme de para POEA/PSS. Curvas de cores preta, azul e amarela são do período da manhã e vermelha, verde e cinza da tarde.

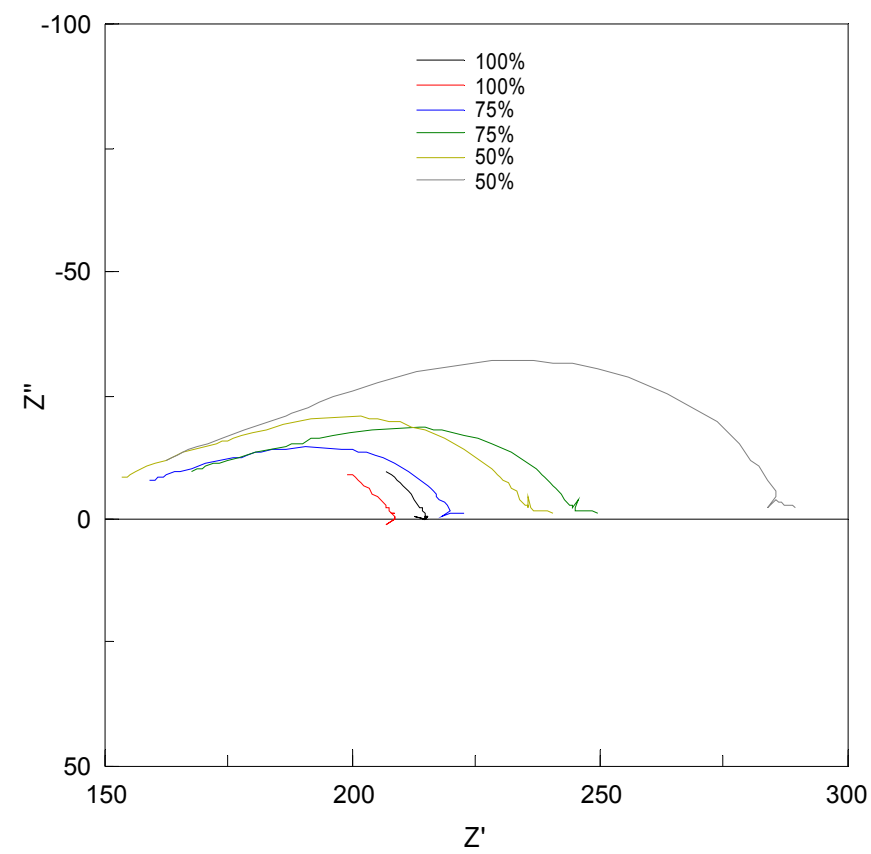

Figura 3.24 - Espectroscopia de impedância de um filme de para Pani/Ni-TS-PC. Curvas de cores preta, azul e amarela são do período da manhã e vermelha, verde e cinza da tarde 


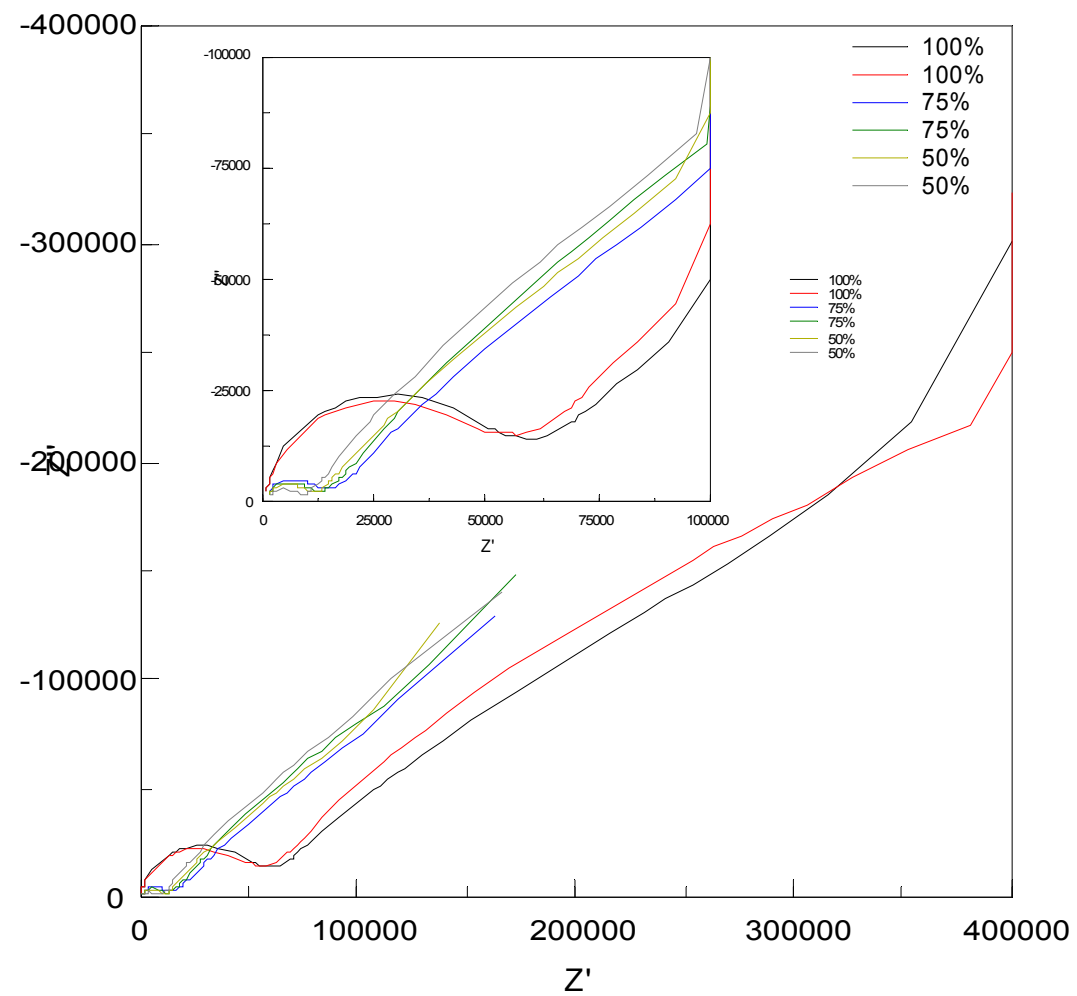

Figura 3.25 - Espectroscopia de impedância de um filme de para POMA/PPy. Curvas de cores preta, azul e amarela são do período da manhã e vermelha, verde e cinza da tarde

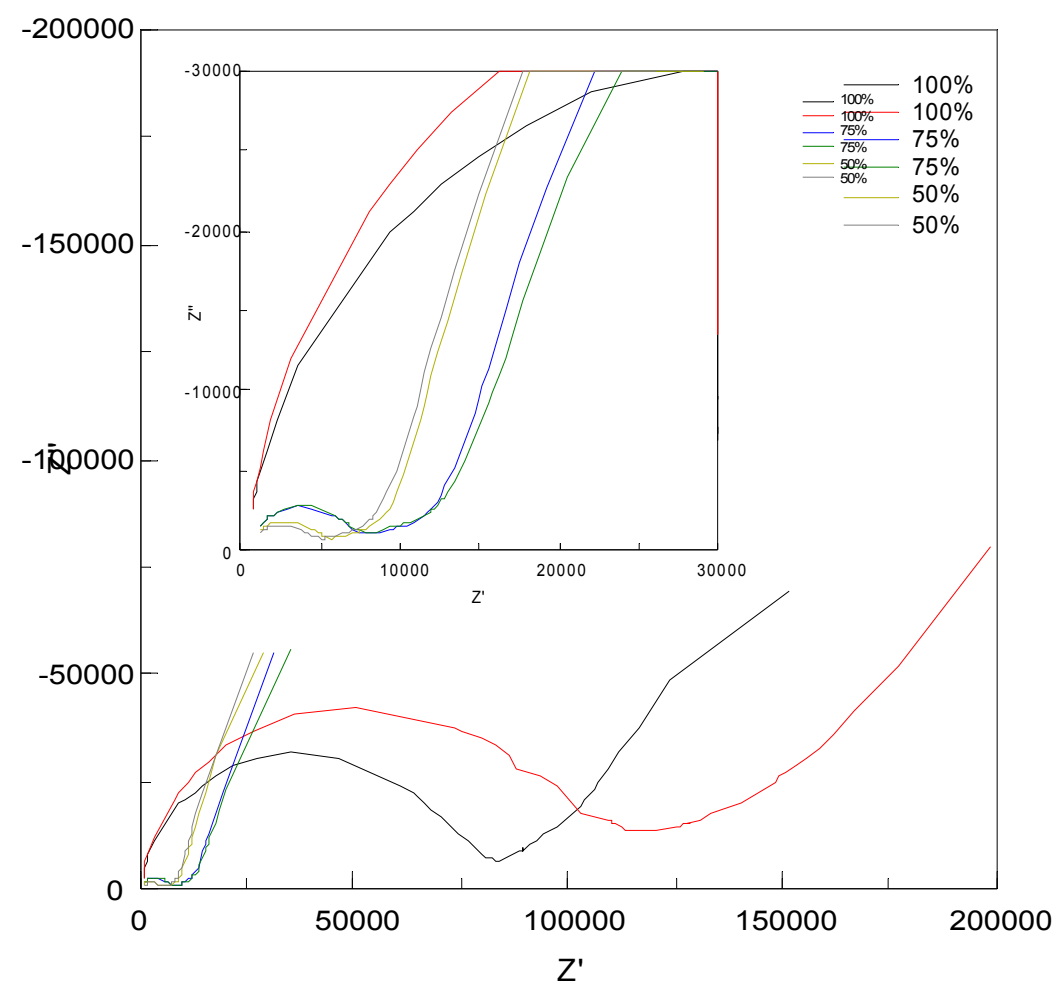

Figura 3.26 - Espectroscopia de impedância de um filme de para POMA/PEDOT. Curvas de cores preta, azul e amarela são do período da manhã e vermelha, verde e cinza da tarde 


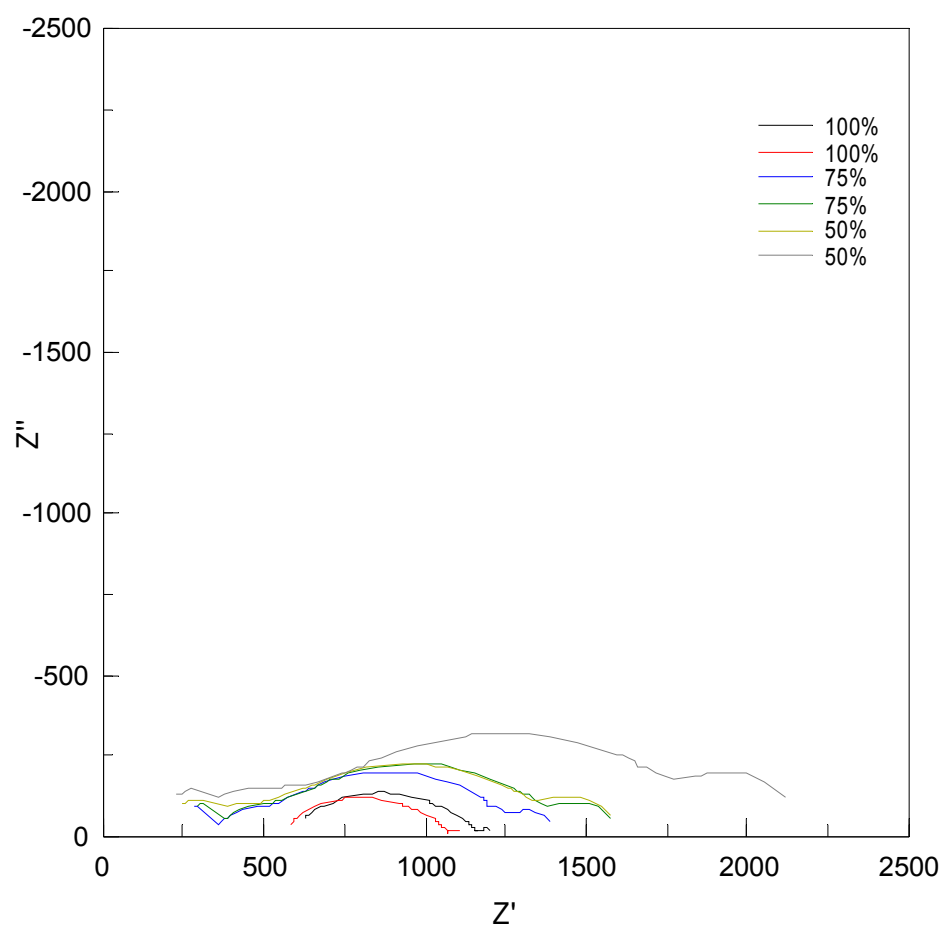

Figura 3.27 - Espectroscopia de impedância de um filme de para PAni/LS. Curvas de cores preta, azul e amarela são do período da manhã e vermelha, verde e cinza da tarde

Da Figura 3.23 até a Figura 3.27 é possível notar que:

Os filmes diferentes se comportam diferentemente. As ordens de grandeza são bastante diferentes.

Os filmes com derivados de PAni (POEA e POMA) têm forma similar. Em baixas freqüências (região direita dos gráficos) apresentam alta impedância, que de forma geral dificultam a precisão das medidas.

O filme com POEA apresenta a mais alta impedância.

Os filmes com PAni, possuem menor impedância, tanto real como imaginária, e em baixas freqüências, a Z"' é pequena em relação a Z'. Estes comportamentos são distintos quando comparados aos de seus derivados. Além disso, o comportamento das curvas dos filmes variara significativamente de acordo com o poliânion (LS ou Ni-TS-PC). Entretanto, para ambos os tipos de filmes, a impedância imaginária é menor do que a real.

Todos os filmes apresentam certa sensibilidade à proporção de etanol, no entanto há uma deriva do sinal em função do período do dia, principalmente nos filmes com PAni. 


\subsubsection{Ensaios de ciclagem gasolina e etanol na câmara}

Com o intuito de testar a montagem com a câmara, os sensores foram expostos ao $\mathrm{N}_{2}$ e aos vapores de gasolina comercial (adquirida em posto de gasolina na cidade de São Paulo) e de etanol PA também arrastados por $\mathrm{N}_{2}$ ciclicamente. Nos dois primeiros ciclos foram medidas amostras de gasolina e nos dois últimos foram medidas amostras de etanol. Ou seja, os resultados apresentados na Figura 3.28 são a resposta ao ciclo:

Gasolina $-\mathrm{N}_{2}-$ Gasolina $-\mathrm{N}_{2}-$ Etanol $-\mathrm{N}_{2}-$ Etanol $-\mathrm{N}_{2}$.

Os sensores de POEA/PSS e POMA/PPy não apresentaram boas respostas. A resposta dos sensores PAni/Ni-Ts-Pc, POMA/PEDOT e PAni/LS podem ser vistas nos gráficos da figura 11. A análise dos resultados foi a seguinte:

Os sinais apresentaram grande variação entre medidas.

As réplicas também têm grande variação.

Isto não torna possível analisar os valores absolutos de capacitância. Uma análise relativa ao momento antes da injeção do combustível torna possível alguma análise. A discriminação entre gasolina e etanol talvez seja possível, pois os formatos das curvas (tempos de subida) são diferentes. Provavelmente, nestas condições de medida não seja possível detectar a composição de misturas.

Melhorias na montagem, regulagem de vazão, quantidade de amostra, e outros fatores devem ser mais bem controlados neste experimento.

A distinção entre o álcool e a gasolina foi obtida para uma parte dos sensores utilizados. A distinção combustível - ar foi razoável. O tempo de resposta dos sensores é relativamente grande se precisarmos realizar muitas medidas num pequeno período de tempo. É preciso continuar procurando um sistema sensorial que melhore os resultados obtidos até esta etapa do trabalho. 
a)

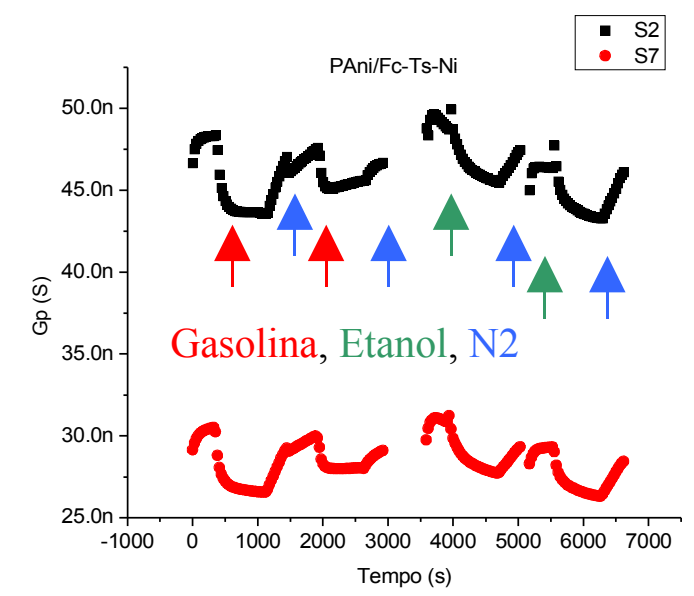

c)

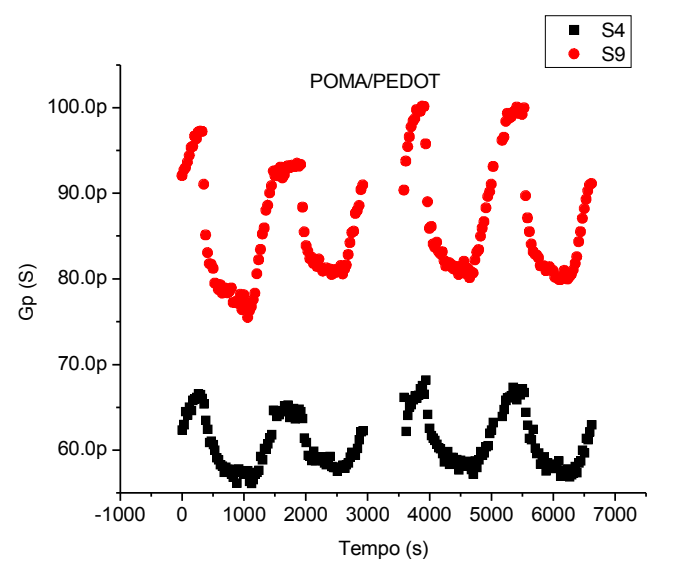

e)

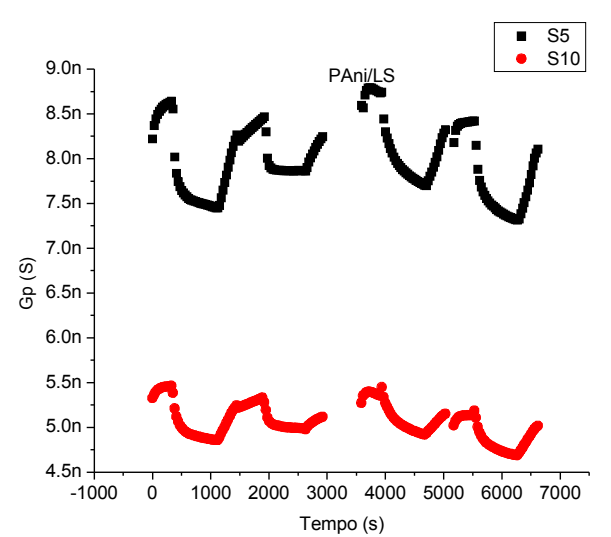

b)

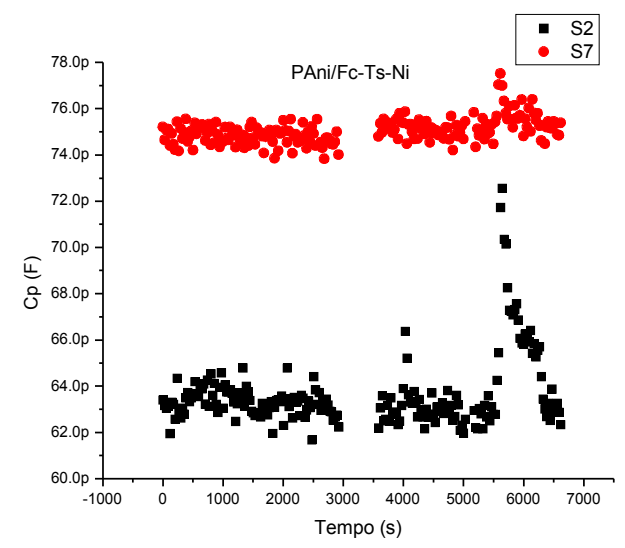

d)

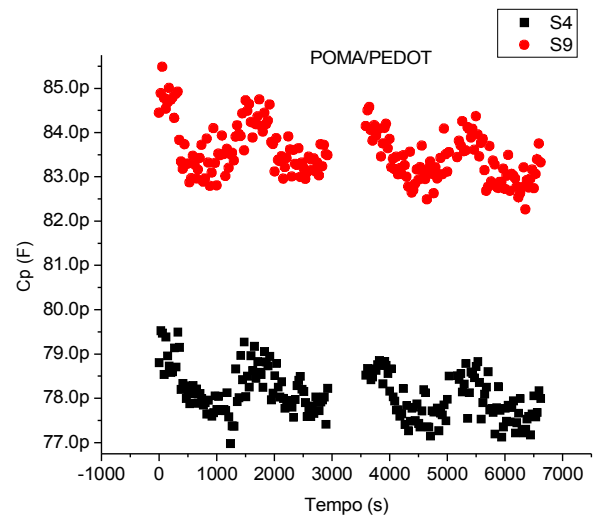

f)

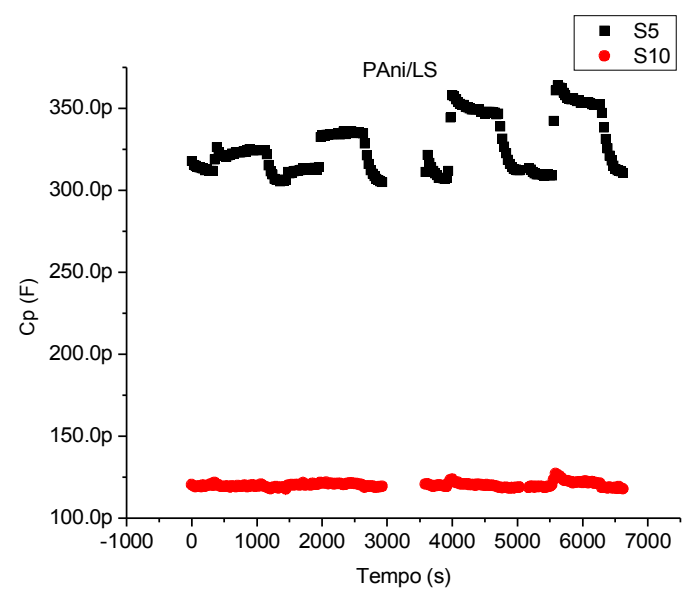

Figura 3.28 - Condutância (gráficos a), c) e e))e Capacitância (gráficos b), d) e f)) dos sensores medidos na câmara de medidas, sendo que a) e b) são sensores de Pani/Fc-Ts-Ni, c) e d) são sensores de POMA/PEDOT e e) e f) são sensores de Pani/LS. 


\subsubsection{Ensaios de efeito da umidade}

O estudo preliminar sobre o efeito da umidade nos sensores foi realizado. Para isto, o gás de arraste $\left(\mathrm{N}_{2}\right)$ foi passado pela câmara e medidas de impedâncias no sensor e umidade na saída do compartimento foram realizadas. Em um âmbito geral, não foi possível estabelecer uma correlação entre umidade relativa e resposta no sensor, com exceção do sensor de PAni/LS.

Este teste foi realizado em 3 dias diferentes e a capacitância do sensor de PAni/LS a $1 \mathrm{kHz}$ apresentou um comportamento bastante linear, porém com uma deriva do sinal do segundo e terceiro dias em relação ao primeiro.

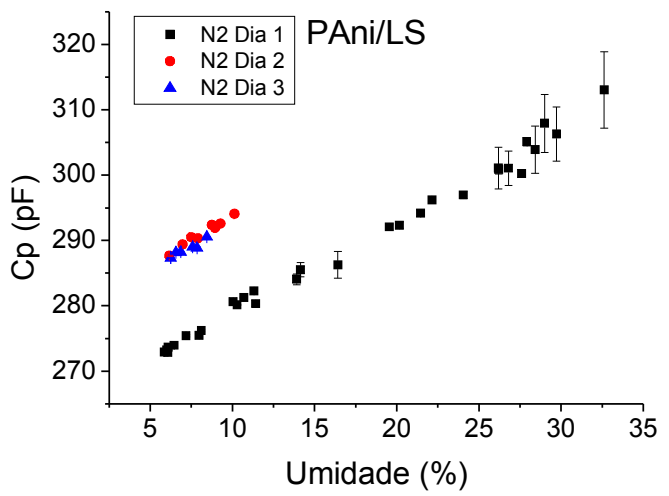

Figura 3.29 - Efeito da umidade sobre a capacitância do sensor de PAni/LS.

\subsubsection{Ensaios com etanol combustível comercial}

Amostras de etanol combustíveis comerciais conformes e não conformes (fornecidos pelo IPT como descrito no item 2.1) foram avaliadas com a montagem convencional e os sensores com filmes automontados. A análise de componentes principais foi realizada resultando no seguinte gráfico: 


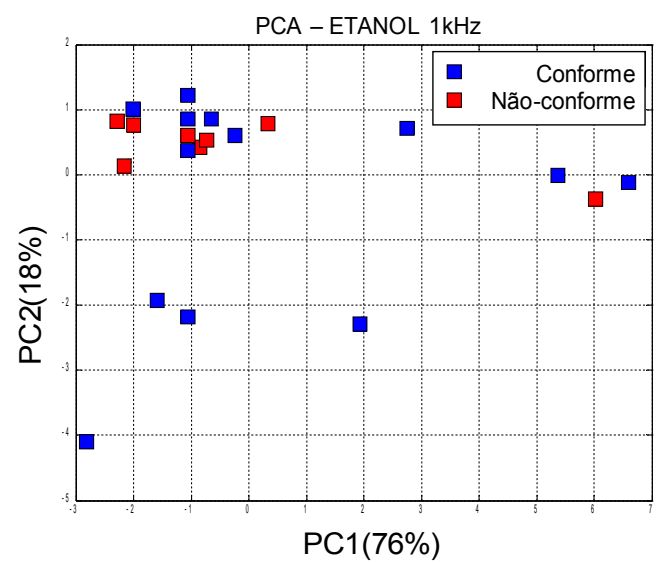

Figura 3.30 - PCA de amostras de etanol combustível comercial

Baseado na Figura 3.30 podemos dizer que:

Não há uma boa separação em grupos entre amostras conformes e não conformes. A presença de amostras tão esparsas no gráfico provavelmente ocorre por dificuldades na medida, pois a impedância de alguns sensores é muito elevada e a precisão fica comprometida. Melhorias no arranjo do equipamento provavelmente gerariam melhores resultados.

Mesmo assim, desconsiderando os pontos mais esparsos, ainda é difícil discriminar as amostras que se encontram mais agrupadas no canto superior esquerdo do gráfico. Isto já era esperado devido à falta de reprodutibilidade das respostas vistas anteriormente. Mesmo assim, preferimos submeter os nossos sensores a estes combustíveis para avaliar os seus desempenhos quando submetidos a um grupo real de combustíveis.

\subsubsection{Ensaio de ciclagem ar/mistura de etanol e gasolina}

Análises de misturas de etanol e gasolina foram realizadas ciclicamente. Utilizou-se a montagem convencional, com as amostras foram mantidas a $25^{\circ} \mathrm{C}$. Utilizou-se os sensores de PMTh-1,5V e PMTh-1,0mA eletrodepositados (tabela 4) sobre microeletrodos T10. Também foram utilizados sensores com microeletrodos sem filme de três geometrias: T10, T50 e N10. 
Os ensaios com líquidos foram realizados no equipamento Solartron1260A, com sinais de amplitude de $50 \mathrm{mV}$ e amostras mantidas a $25^{\circ} \mathrm{C}$. As diferentes concentrações nas amostras foram obtidas adicionando etanol PA a uma gasolina comercial com teor alcoólico de 25\%. Na Figura 3.31 são mostradas as respostas de condutância e capacitância de um circuito RC paralelo medido a $1 \mathrm{kHz}$ em função do tempo. Observa-se que para os sensores sem filmes poliméricos, a resposta é muito rápida, bem inferior a 1 minuto. Este comportamento instantâneo também é visto nos sensores com filmes poliméricos, mas a interação do líquido com o filme é mais lenta e uma resposta estável pode levar de 500 a 1000 s.
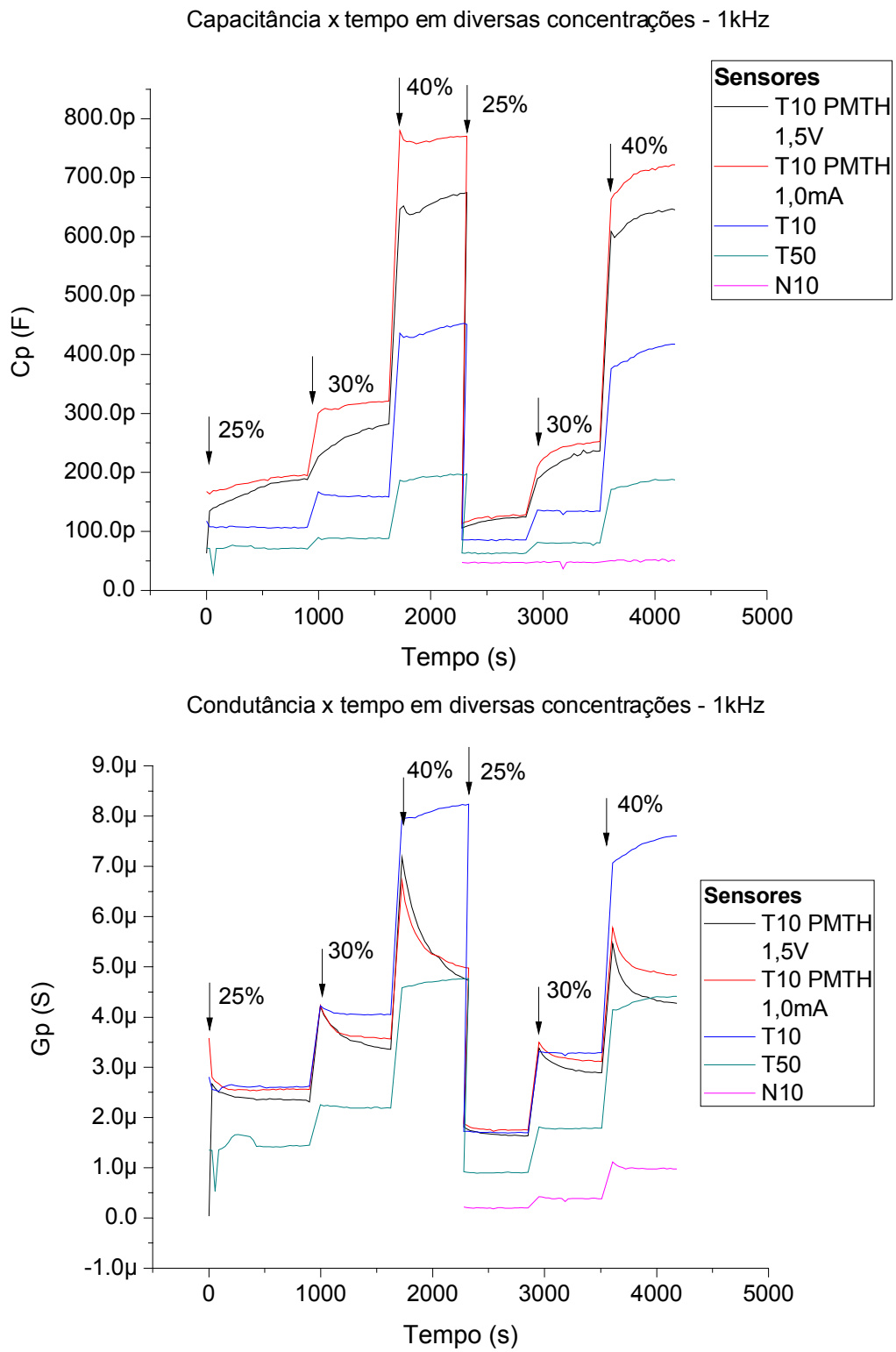

Figura 3.31 Respostas de condutância e capacitância da LE em $1 \mathrm{kHz} .^{3}$

3.2.2.Ensai o de

sensibilidade à mistura de etanol e gasolina

\footnotetext{
${ }^{3}$ No primeiro ciclo o sensor N10 apresentou problemas de mau contato.
} 
Diversas misturas de etanol PA e gasolina foram analisadas nas freqüências arbitrariamente escolhidas de $100 \mathrm{~Hz}, 1 \mathrm{kHz}$ e $100 \mathrm{kHz}$ em função da proporção etanol/gasolina e com os sensores submersos na mistura.
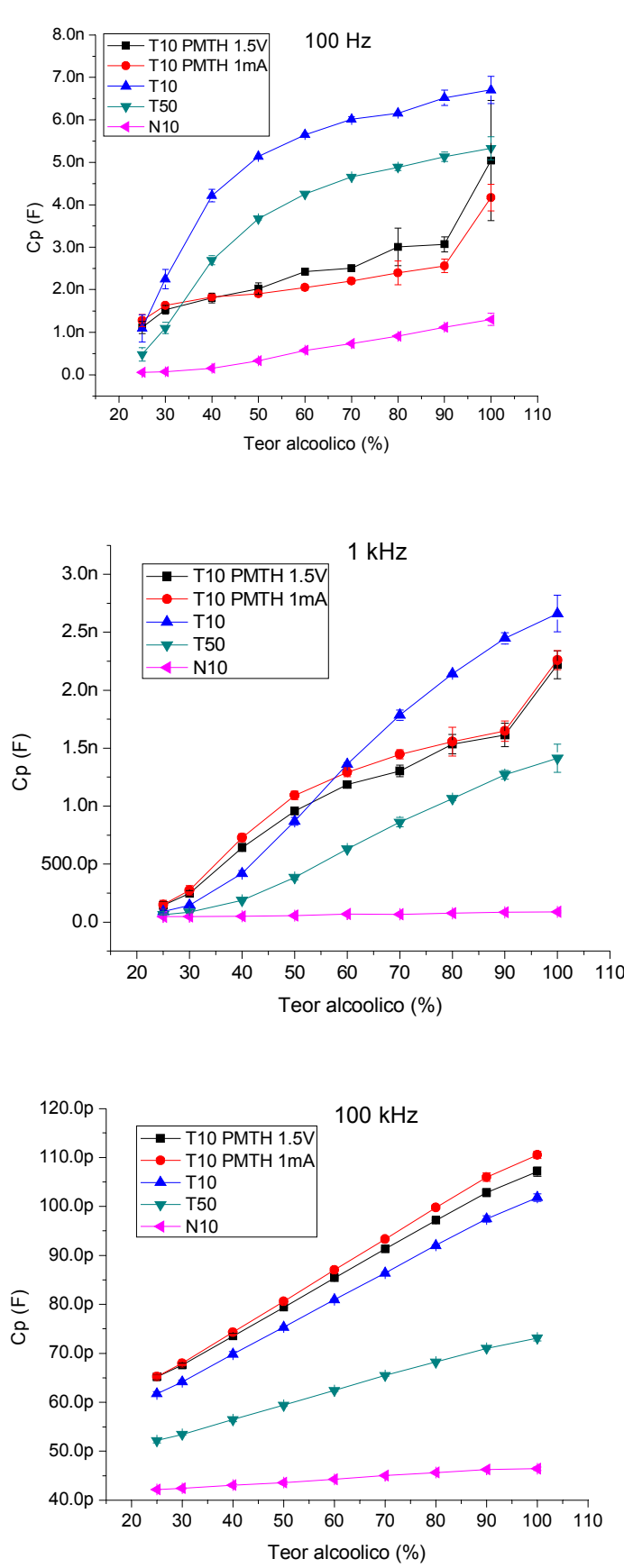
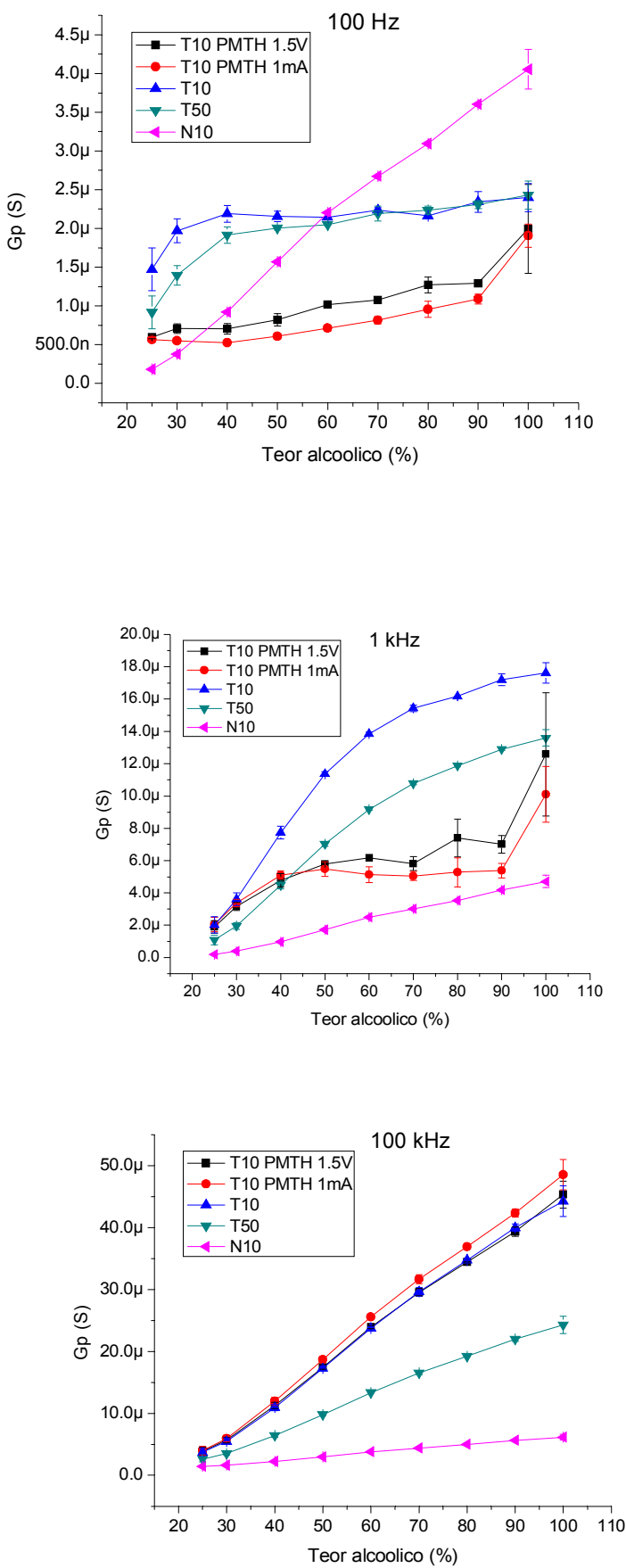

Figura 3.32 - Sensibilidade de sensores de liquido às misturas de etanol e gasolina medida em três freqüências.

\subsubsection{Ensaio espectroscopia de impedância}


As respostas aparentemente melhor comportadas dos sensores para líquido permitiram fazer uma análise mais detalhada por espectroscopia de impedância. $A$ Figura 3.33 mostra a resposta de um sensor ajustadas ao modelo de circuito equivalente proposto por Taylor e MacDonald(1987).

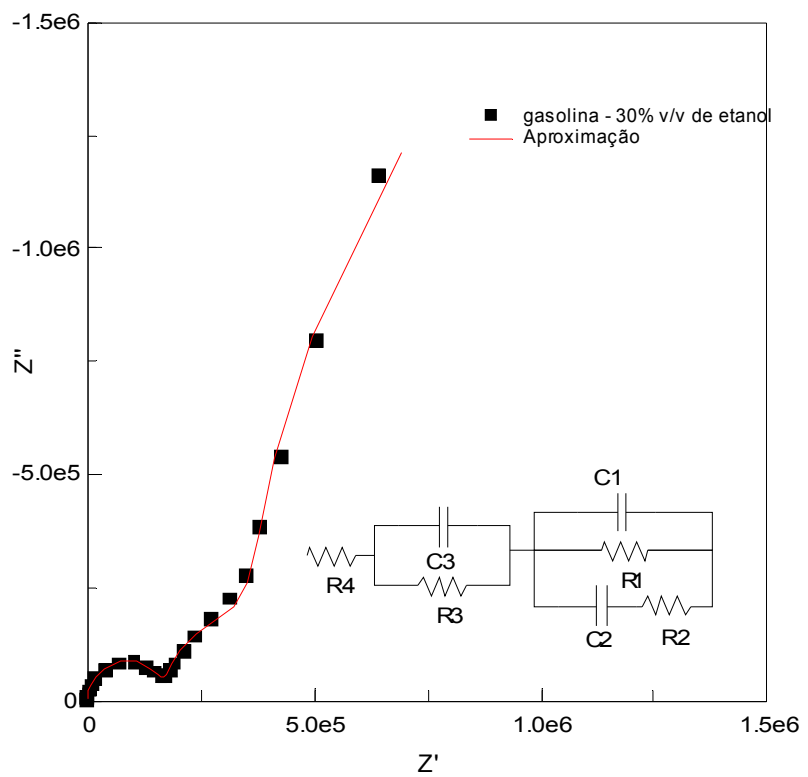

a)
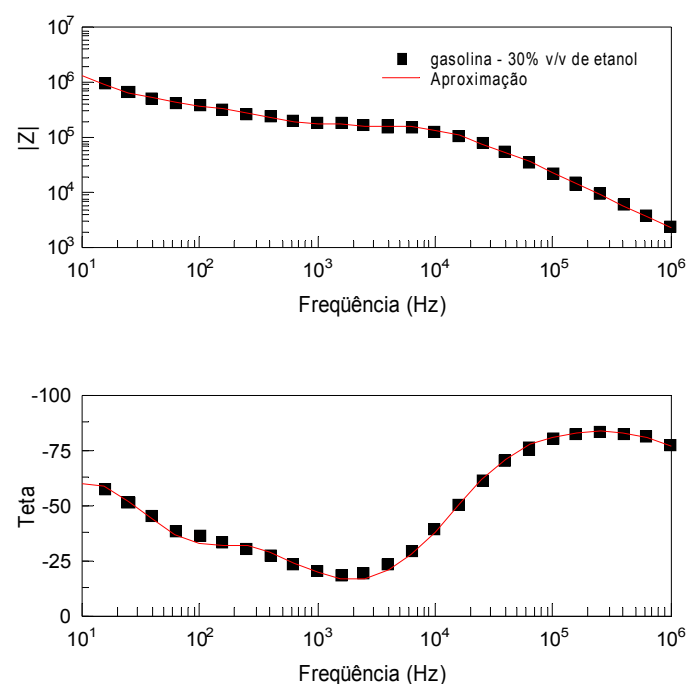

b)

Figura 3.33 - Aproximação por circuito equivalente filme PMTh 1,0mA imerso em gasolina. (a) Gráfico da impedância Real $x$ Imaginária. (b) Gráficos de módulo e fase $x$ freqüência.

O valor dos parâmetros calculados para uma amostra de gasolina com teor alcoólico de cerca de $30 \%$ são os mostrados na tabela a seguir. A partir destes valores, os 
parâmetros foram variados e foi observado qualitativamente como os gráficos são afetados das grandezas, resistência e capacitância do modelo série ou paralelo, Rs e Cs ou $R p$ e $C p$, respectivamente, e em que faixa de freqüências há maior influência.

Tabela 3.5 - Valor dos parâmetros do circuito equivalente para sensor PMTh-1,0mA com gasolina de $30 \%$ de teor alcoólico.

\begin{tabular}{|c||c||c|c|}
\hline Parâmetro & Valor & $\begin{array}{c}\text { Grandeza que } \\
\text { mais influencia } \\
\text { na faixa de } \\
\text { freq. }\end{array}$ & $\begin{array}{c}\text { Faixa de } \\
\text { freqüência }\end{array}$ \\
\hline $\mathrm{R} 1$ & $4.89 \mathrm{M} \Omega$ & $\mathrm{Rp}$ & $10 \mathrm{~Hz}$ \\
\hline $\mathrm{C} 1$ & $70,38 \mathrm{pF}$ & $\mathrm{Cp}$ & $>10 \mathrm{kHz}$ \\
\hline $\mathrm{R} 2$ & $175,7 \mathrm{k} \Omega$ & $\mathrm{Rp}$ & $100 \mathrm{a} 100 \mathrm{kHz}$ \\
\hline $\mathrm{C} 2$ & $11,41 \mathrm{nF}$ & $\mathrm{Cs}$ & $10 \mathrm{e} 100 \mathrm{~Hz}$ \\
\hline $\mathrm{R} 3$ & $195,0 \mathrm{k} \Omega$ & $\mathrm{Rpe} \mathrm{Rs}$ & $10 \mathrm{a} 1 \mathrm{kHz}$ \\
\hline
\end{tabular}

Em freqüências mais altas, a tendência é de que a condutividade do eletrólito e a constante dielétrica do líquido influam mais, isso pode ser visto por meio dos parâmetros R4 e C1.

Nas freqüências mais baixas, efeitos como a transferência de carga e a dificuldade de condução eletrônica devido à desordem do polímero podem ser mais facilmente vistas pelos parâmetros R1 e R3.

Também em freqüências mais baixas é possível ver o acumulo de cargas na dupla camada, C2.

Em freqüências intermediárias, é possível ver também os efeitos sobre a condutividade e dupla camada, mostrada pelos parâmetros R3, C3, R2.

Este ensaio e determinação de parâmetros foram realizados para outros sensores e outras amostras e podem ser vistas na Figura 3.34. É visto que de forma geral, os parâmetros variam de forma condizente de acordo com as amostras, pois é esperado que a condutividade e constantes dielétricas aumentem quanto maior 0 teor e etanol na gasolina e quanto maior o teor de água no etanol. 


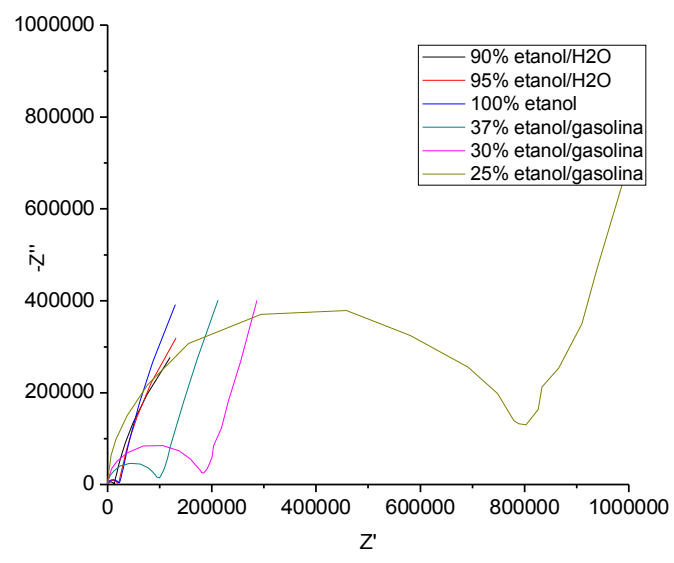

(a)

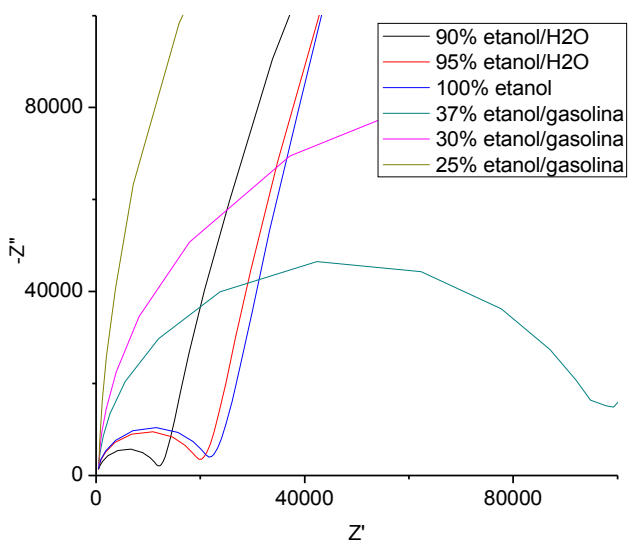

(b)

Figura 3.34 - Espectroscopia de impedância do microeletrodo T10. 

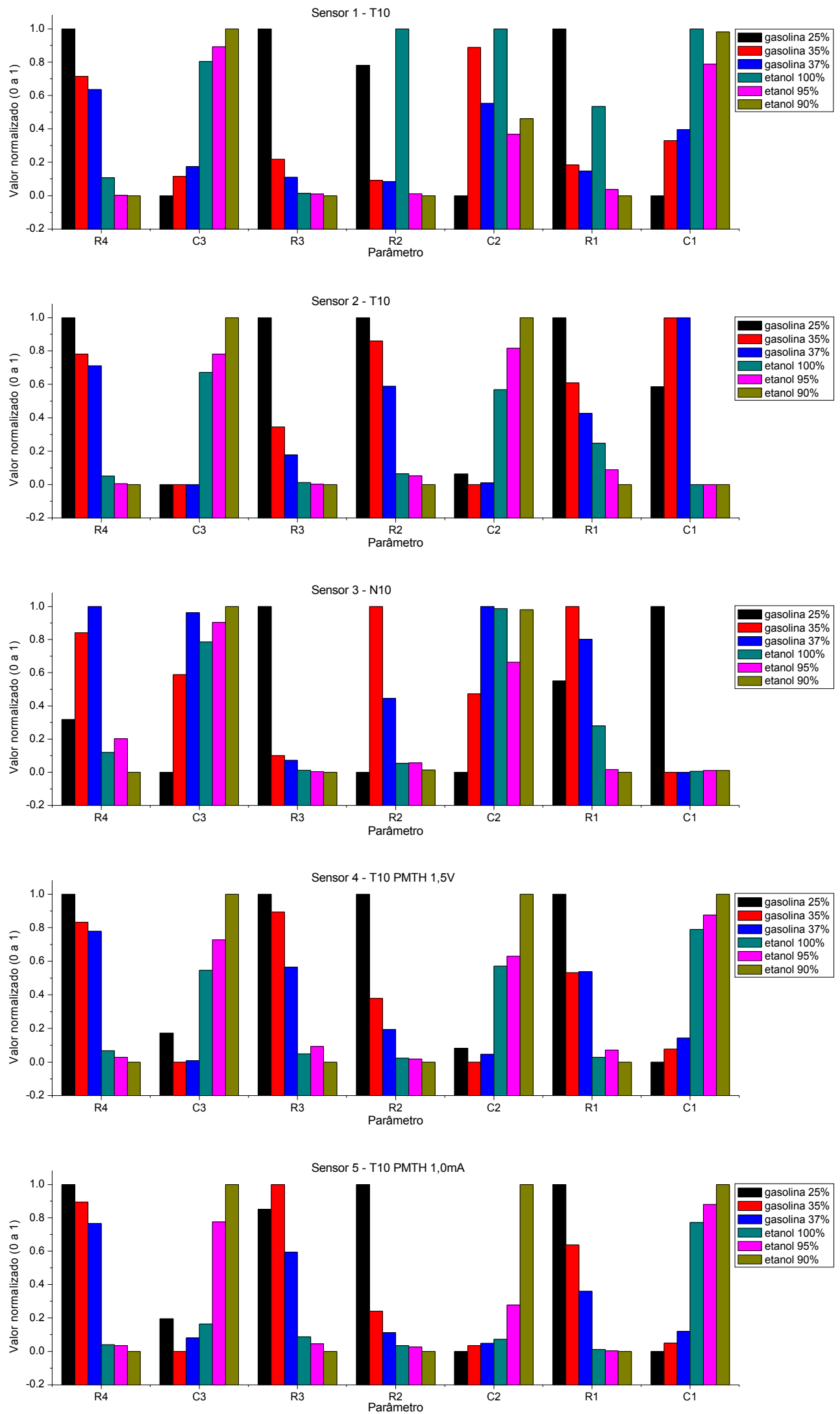

Figura 3.35 - Parâmetros do circuito equivalente em função da composição do combustível. 
Desta etapa, observa-se que todos os parâmetros do circuito são afetados pela mudança na concentração. Pelo fato de cada um destes parâmetros terem efeito em faixas de freqüência distintas, é justificado utilizar em analises futuras mais de uma freqüência.

\subsubsection{Ensaio de gasolinas comerciais}

Quarenta amostras de gasolina fornecidas pelo IPT foram analisadas com o sistema sensorial contendo sensores de PMTh-1,5V, PMTh-1,0mA, PHTh-1,5V, PHTh$1,0 \mathrm{~mA}$, todos com geometria T10, além de sensores com geometria T50 e N10 sem filme. Tomando-se amostras nas freqüências $10 \mathrm{~Hz}, 100 \mathrm{~Hz}, 1 \mathrm{kHz}, 10 \mathrm{kHz}, 100 \mathrm{kHz}$ e $1 \mathrm{MHz}$ obteve-se o gráfico de componentes principais apresentado naFigura 3.36. Neste gráfico, foram visualmente agrupados 4 regiões principais: B, C, D e E.

As análises laboratoriais e suas as condições para sua conformidade seguiram as especificações da ANP resumidas no Anexo A.

Esses grupos foram relacionados às análises físico-químicas dos combustíveis: destilação e teor alcoólico (AEAC - álcool etílico anidro combustível), sendo que da destilação extrai-se os valores de temperatura de 10\%, 50\% e 90\% evaporado (T10\%, T50\% e T90\%, respectivamente), temperatura do ponto final de ebulição (PFE) e porcentagem em volume de residual.

Uma análise da Tabela 1.1 leva a concluir que as amostras do grupo B têm temperatura de $90 \%$ evaporada inferior ao especificado. O grupo C contém amostras com teor alcoólico muito acima do especificado. O grupo D contém amostras conformes e o grupo E, amostras ou com etanol acima do especificado ou com elevado ponto final de ebulição. A proximidade destes últimos grupos, D e E, não descarta certo nível de sobreposição de regiões.

Dentro deste universo de 40 amostras, 3 amostras fora das especificações seriam classificadas com conforme, ou seja, um índice falso-negativo de 7,5\%. 
a) Análise de Componentes Principais

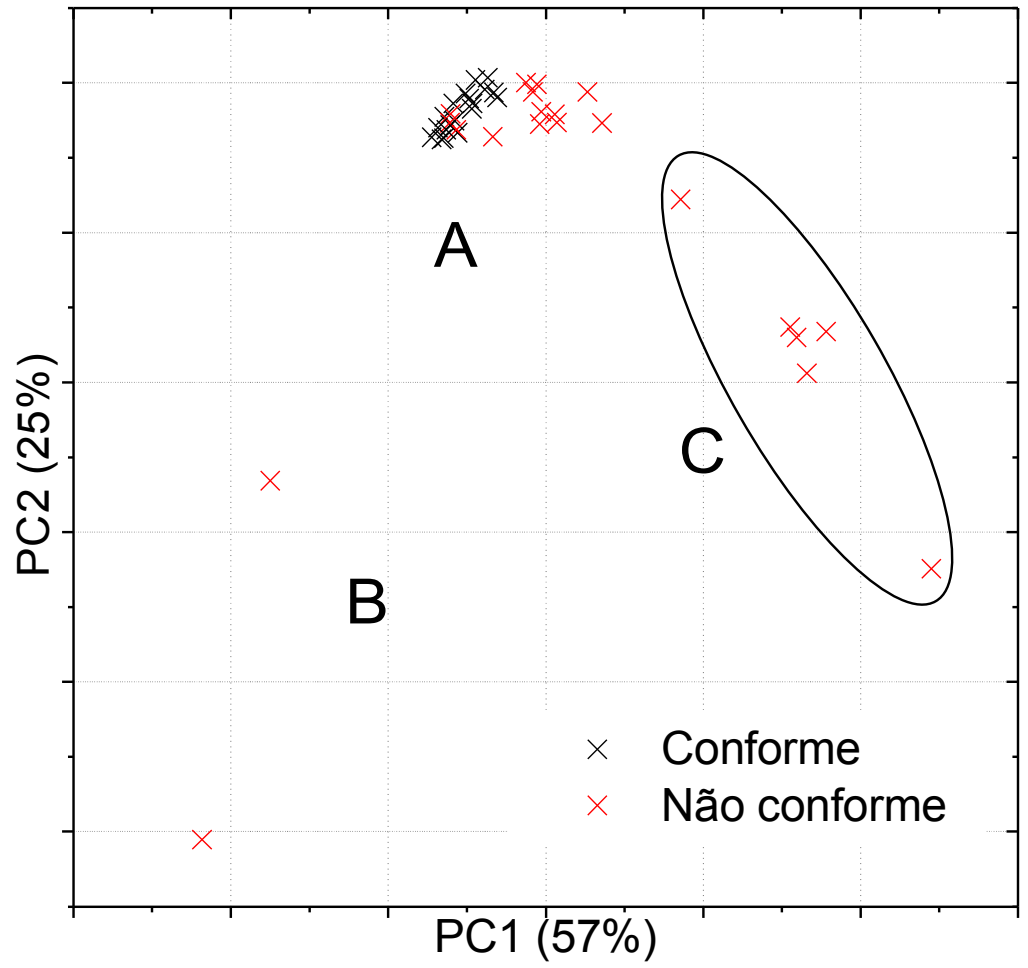

b) Análise de Componentes Principais

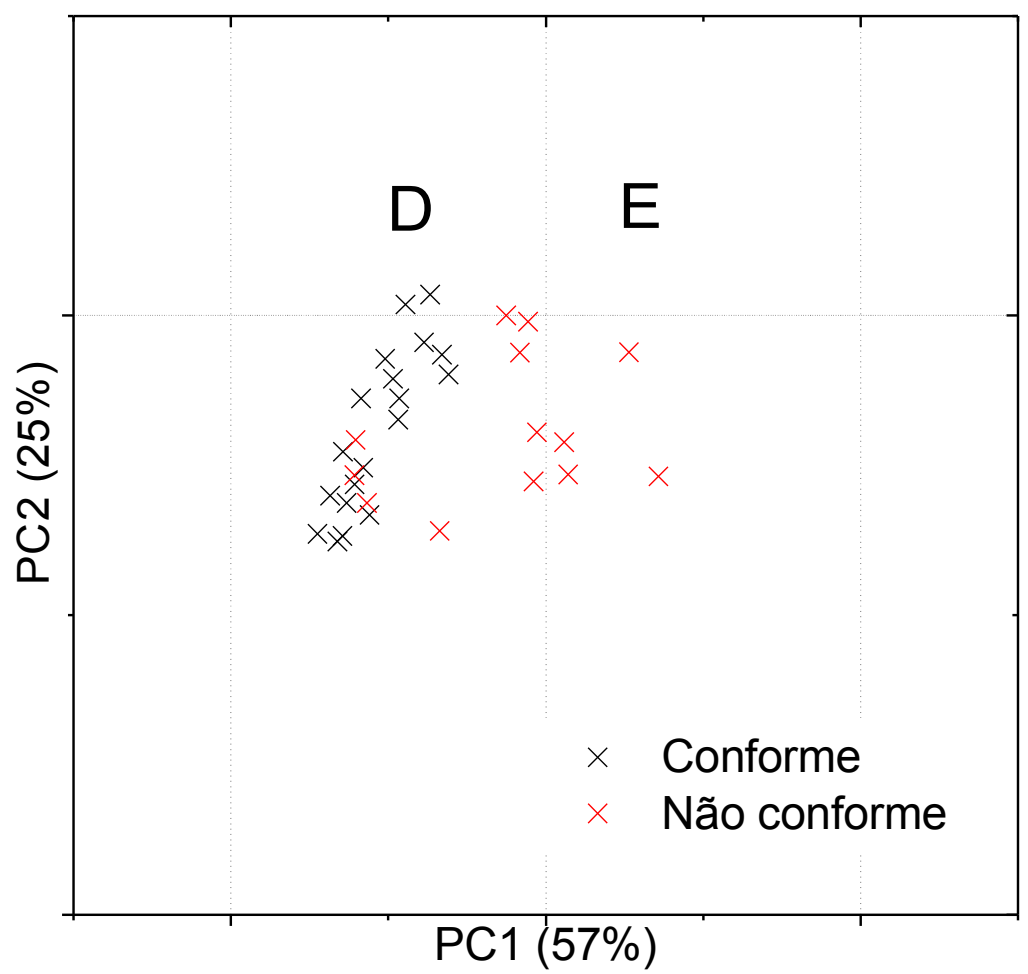

Figura 3.36 - (a) Análise PCA de gasolinas comerciais. (b) Região A ampliada. B: amostra com Temperatura de 90\% evaporado inferior ao especificado. C: amostras com teor alcoólico acima de 40\%. D: Amostras conformes. E: Amostras com teor alcoólico alto ou com elevado ponto final de ebulição. 
Tabela 3.6 Amostras comerciais de gasolina com respectivos valores de análise físico-química e limites de conformidades vigentes no período de medição ${ }^{4}$

\begin{tabular}{|c|c|c|c|c|c|c|c|}
\hline $\begin{array}{l}\text { Grupos } \\
\text { PCA }\end{array}$ & $\begin{array}{l}\text { T10\% } \\
\left({ }^{\circ} \mathrm{C}\right)\end{array}$ & $\begin{array}{l}\text { T50\% } \\
\left({ }^{\circ} \mathrm{C}\right)\end{array}$ & $\begin{array}{l}\text { T90\% } \\
\left({ }^{\circ} \mathrm{C}\right)\end{array}$ & $\begin{array}{l}\text { PFE } \\
\left({ }^{\circ} \mathrm{C}\right)\end{array}$ & $\begin{array}{l}\text { Res } \\
(\% \mathrm{ov})\end{array}$ & $\begin{array}{l}\text { AEAC } \\
(\% v)\end{array}$ & Conformidade \\
\hline & $<65$ & $<80$ & 145 a 190 & $<220$ & $<2$ & 22 a 24 & Especificado \\
\hline \multirow[t]{22}{*}{$\mathrm{D}$} & 54,2 & 72,9 & 161,5 & 205,5 & 0,9 & 24 & Conforme \\
\hline & 51,3 & 72,2 & 164,8 & 209,3 & 1 & 24 & Conforme \\
\hline & 53 & 72,4 & 158,7 & 205,9 & 1 & 24 & Conforme \\
\hline & 48,8 & 71,8 & 162,6 & 197,9 & 0,8 & 24 & Conforme \\
\hline & 50,5 & 72,3 & 163,4 & 196,9 & 1 & 23 & Conforme \\
\hline & 53,7 & 72 & 152,5 & 188,7 & 0,8 & 24 & Conforme \\
\hline & 53,4 & 72,2 & 151 & 192,2 & 0,9 & 23 & Conforme \\
\hline & 50,7 & 71,8 & 162,1 & 209,6 & 0,7 & 23 & Conforme \\
\hline & 53,6 & 72,6 & 159,1 & 202,8 & 0,9 & 24 & Conforme \\
\hline & 53,8 & 72,6 & 157,8 & 202,1 & 0,8 & 24 & Conforme \\
\hline & 58,9 & 73,1 & 166,6 & 206,8 & 0,6 & 24 & Conforme \\
\hline & 52,4 & 72,6 & 154,8 & 194,8 & 0,8 & 23 & Conforme \\
\hline & 58,4 & 72,7 & 155,9 & 190,3 & 0,7 & 24 & Conforme \\
\hline & 53,7 & 72,3 & 152,3 & 188,4 & 0,6 & 24 & Conforme \\
\hline & 68,7 & 71,6 & 106,1 & 133,6 & 0,2 & 23 & Não conforme \\
\hline & 53,1 & 72,1 & 166,6 & 210,4 & 0,8 & 23 & Conforme \\
\hline & 66,2 & 71,1 & 113 & 165,9 & 0,8 & 23 & Não conforme \\
\hline & 54,5 & 72,6 & 156,8 & 203 & 1 & 23 & Conforme \\
\hline & 59,2 & 69,6 & 149,2 & 199,2 & 0,6 & 31 & Não conforme \\
\hline & 49,9 & 72,1 & 159,6 & 205,5 & 0,8 & 23 & Conforme \\
\hline & 53 & 72,8 & 160,5 & 204,7 & 1,1 & 23 & Conforme \\
\hline & 54,8 & 72,7 & 157,8 & 201,6 & 0,7 & 24 & Conforme \\
\hline \multirow[t]{10}{*}{$\mathrm{E}$} & 51,4 & 66,4 & 168,3 & 261,2 & 3,6 & 24 & Não conforme \\
\hline & 53,6 & 69,3 & 156,4 & 221,4 & 1,6 & 24 & Não conforme \\
\hline & 51,8 & 68,9 & 171 & 259,9 & 2,6 & 23 & Não conforme \\
\hline & 48,9 & 65,8 & 159 & 249,9 & 0,3 & 23 & Não conforme \\
\hline & 49,1 & 65,7 & 162,4 & 302,2 & 1,5 & 24 & Não conforme \\
\hline & 49,7 & 64 & 165,6 & 237,7 & 1,5 & 24 & Não conforme \\
\hline & 69,9 & 74,7 & 129,9 & 163,2 & 0,8 & 30 & Não conforme \\
\hline & 55,8 & 72,6 & 150,1 & 189,9 & 1 & 29 & Não conforme \\
\hline & 64,2 & 70,8 & 76,9 & 176,8 & 1 & 43 & Não conforme \\
\hline & 56 & 69,2 & 146,7 & 204,3 & 0,8 & 25 & Não conforme \\
\hline \multirow[t]{6}{*}{$\overline{\mathrm{C}}$} & 62,4 & 73 & 78,6 & 79,7 & 1,5 & 55 & Não conforme \\
\hline & 66,9 & 71,6 & 78 & 137 & 0,3 & 55 & Não conforme \\
\hline & 62,7 & 73,5 & 78,2 & 79,2 & 0,8 & 58 & Não conforme \\
\hline & 60,1 & 73,6 & 79,5 & 193,8 & 1,1 & 49 & Não conforme \\
\hline & 59,9 & 69,4 & 78 & 176,7 & 1,2 & 44 & Não conforme \\
\hline & 69,5 & 77,7 & 79,2 & 192 & 0,8 & 75 & Não conforme \\
\hline \multirow[t]{2}{*}{$\mathrm{B}$} & 65 & 71,7 & 117,3 & 192,3 & 0,7 & 22 & Não conforme \\
\hline & 55,8 & 63,6 & 109,8 & 153,1 & 0,7 & 24 & Não conforme \\
\hline
\end{tabular}

${ }^{4} \mathrm{~T} 10 \%$, T50\%, T90\%, PFE e Res. Referem-se à analise da curva de destilação e significam, respectivamente, temperatura de $10 \%$ evaporado, de $50 \%$, de $90 \%$, ponto final de ebulição e Resíduo.

AEAC refere-se ao teor de álcool etílico anidro combustível 


\subsubsection{Ensaio de álcool combustível comercial}

Vinte e duas amostras de fornecidas pelo IPT (Tabela 3.7) foram analisadas com o mesmo sistema sensorial utilizado nos ensaios com gasolina: sensores de PMTh1,5V, PMTh-1,0mA, PHTh-1,5V, PHTh-1,0mA, todos com geometria T10, além de sensores com geometria T50 e N10 sem filme. Tomando-se amostras nas freqüências $10 \mathrm{~Hz}, 100 \mathrm{~Hz}, 1 \mathrm{kHz}, 10 \mathrm{kHz}, 100 \mathrm{kHz}$ e $1 \mathrm{MHz}$ obteve-se o gráfico PCA, análise de componentes principais, (CIOSEK et al, 2006) apresentado na. Neste gráfico, foram visualmente agrupados 3 regiões principais: $A, B$ e $C$.

As análises laboratoriais e suas as condições para sua conformidade seguiram as especificações da ANP resumidas no Anexo B.

A única amostra do grupo $A$, apresenta uma condutividade elétrica e um $\mathrm{pH}$ extremamente elevados e por isso aparece bastante destacada na Figura 3.37 a.

Na Figura 3.37 b, são mostradas as regiões B e C ampliadas. Neste gráfico é possível observar com alguma dificuldade estas duas regiões, sendo que a mais à direita (C) concentra a grande maioria das amostras conformes. A única amostra não conforme presente nesta região é uma com condutividade elétrica relativamente baixa $(151 \mu \mathrm{S} / \mathrm{m})$ e $\mathrm{pH}$ um pouco abaixo do permitido $(5,5)$.

Em contrapartida na região B possui tipicamente amostras com teor alcoólico reduzido, porém com $\mathrm{pH}$ e condutividade elétrica dentro do conforme. Entretanto, três amostras conformes aparentemente sem grande variação em relação às amostras conformes do grupo $C$ ficaram neste grupo, o que indica que a separação entre os grupos B e C é mais tênue quando comparada com os resultados da gasolina.

Ainda com relação ao grupo $\mathrm{B}$, duas amostras se destacaram mais à esquerda, mesma direção da amostra A (com condutividade elétrica elevada). Estas também apresentaram condutividade elétrica elevada, com 418 e $64.1 \mu \mathrm{S} / \mathrm{m}$.

Dentro deste universo de 22 amostras, 1 amostra fora da especificação seria classificada com conforme e 3 amostras conforme seriam classificadas com não conforme, ou seja, um índice falso-negativo de 4,5\% e falso-positivo de $13.7 \%$, totalizando uma porcentagem de erro de $18,2 \%$. 
a)
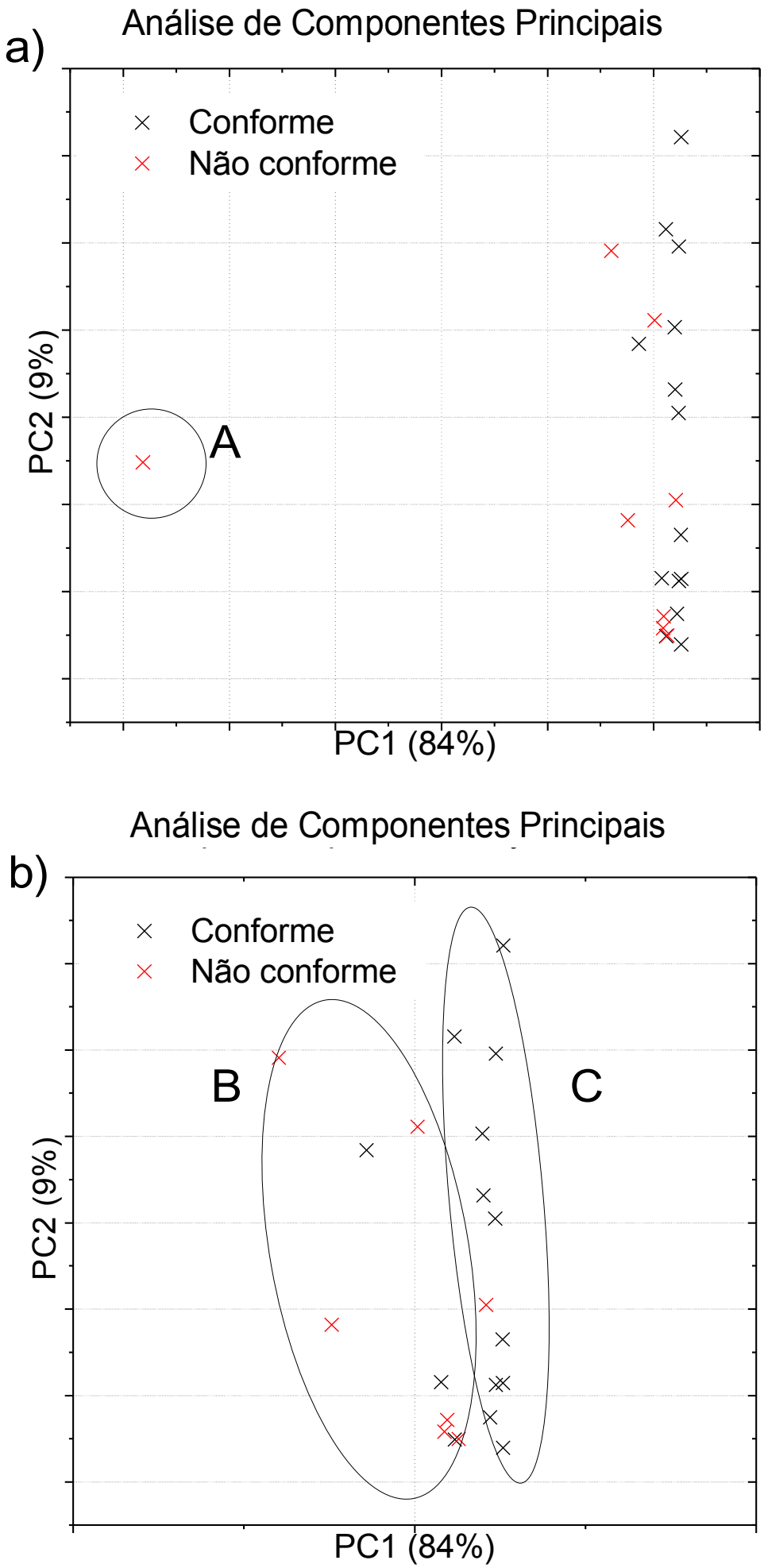

Figura 3.37 - (a) Análise PCA de etanol combustível comercial. (b) Ampliação da região esquerda do gráfico. Aproximadamente, região A: mostra uma amostra com elevada CE. B: amostras conformes e não-conformes. C: amostras conformes. 
Tabela 3.7 Amostras comerciais de álcool etílico hidratado combustível e suas respectivas análises físico-químicas e limites de conformidade vigentes no período. ${ }^{5}$

\begin{tabular}{|c|c|c|c|c|c|}
\hline $\begin{array}{c}\text { Grupo } \\
\text { PCA }\end{array}$ & $\mathbf{p H}$ & $\mathrm{CE}(\underline{\mu} \mathrm{S} / \mathrm{m})$ & ME (kg/m3) & TA $\left({ }^{\circ}\right.$ INPM) & Status \\
\hline & 6 a 8 & $<500$ & 807,6 a 811 & 92,6 a 93,8 & Especificado \\
\hline \multirow[t]{12}{*}{$\mathrm{C}$} & 6.7 & 171 & 809.7 & 93 & Conforme \\
\hline & 6.8 & 157 & 809.7 & 93 & Conforme \\
\hline & 7.2 & 120 & 809.4 & 93.1 & Conforme \\
\hline & 7.2 & 119 & 809.7 & 93 & Conforme \\
\hline & 7.5 & 152 & 809.5 & 93.1 & Conforme \\
\hline & 6.6 & 152 & 809.5 & 93.1 & Conforme \\
\hline & 7.4 & 217 & 810 & 92.9 & Conforme \\
\hline & 6.9 & 168 & 809.8 & 93 & Conforme \\
\hline & 6.9 & 131 & 809.8 & 93 & Conforme \\
\hline & 7 & 147 & 809.8 & 93 & Conforme \\
\hline & 6.9 & 144 & 809.7 & 93 & Conforme \\
\hline & 5.5 & 151 & 809.5 & 93.1 & Não conforme \\
\hline \multirow[t]{9}{*}{ B } & 6.9 & 220 & 809.7 & 93 & Conforme \\
\hline & 6.8 & 199 & 809.6 & 93 & Conforme \\
\hline & 7 & 164 & 809.6 & 93 & Conforme \\
\hline & 7.1 & 178 & 812.4 & 92 & Não conforme \\
\hline & 6.6 & 180 & 812.3 & 92.1 & Não conforme \\
\hline & 4.8 & 242 & 808.6 & 93.4 & Não conforme \\
\hline & 6.8 & 418 & 815 & 91.1 & Não conforme \\
\hline & 7.3 & 148 & 805.1 & 94.7 & Não conforme \\
\hline & 6.9 & 641 & 810.6 & 92.7 & Não conforme \\
\hline $\mathrm{A}$ & 10.2 & 2050 & 813.1 & 91.8 & Não conforme \\
\hline
\end{tabular}

3.3. REDES NEURAIS ARTIFICIAIS

\subsubsection{Validação do algoritmo da rede}

A rede neural desenvolvida foi validada utilizando-se o problema glass do conjunto de dados para comparação Proben 1 (Prechelt L., 1994). Este conjunto contém dados das análises químicas de vidros com respeito a oito elementos químicos e o índice de refração. A tarefa é classificar as amostras em seis grupos diferentes de acordo com o tipo de utilização do vidro: janela (dois tipos), veículo, recipientes, material de cozinha e lâmpadas.

\footnotetext{
${ }^{5} \mathrm{CE}$ refere-se à condutividade elétrica, ME à massa específica e TA o teor alcoólico.
} 
Há, portanto, 9 entradas e seis saídas de um total de 214 exemplos divididos em seis classes com 70, 76, 17, 13, 9 e 29 instâncias cada. Todas as entradas são contínuas. Este universo se adéqua bastante ao universo das medidas elétricas e das adulterações dos combustíveis sob análise.

$\mathrm{Na}$ Tabela 3.8, estão os resultados da RNA treinada com algoritmo RPROP apresentado no trabalho Proben1 e o algoritmo de bissetriz para a rede modular, desenvolvida neste trabalho. Particularmente, nesta rede não há camada intermediária, ou seja, essa rede somente é capaz de realizar separações lineares dos sinais de entrada.

Observamos que tanto os erros quanto o desempenho no conjunto de testes é similar, com porcentagem de erros de classificação: 46,04\%, 55,28\% e 60,57\% para o algoritmo RPROP e 43,21, 56,60 e 50,00 para o algoritmo de Bissetriz. Para se chegar neste foram realizados 10 testes com 10 diferentes pesos iniciais.

Tabela 3.8 Comparação do algoritmo com resultado do proben1 para rede neural sem camada intermediária. ${ }^{6}$

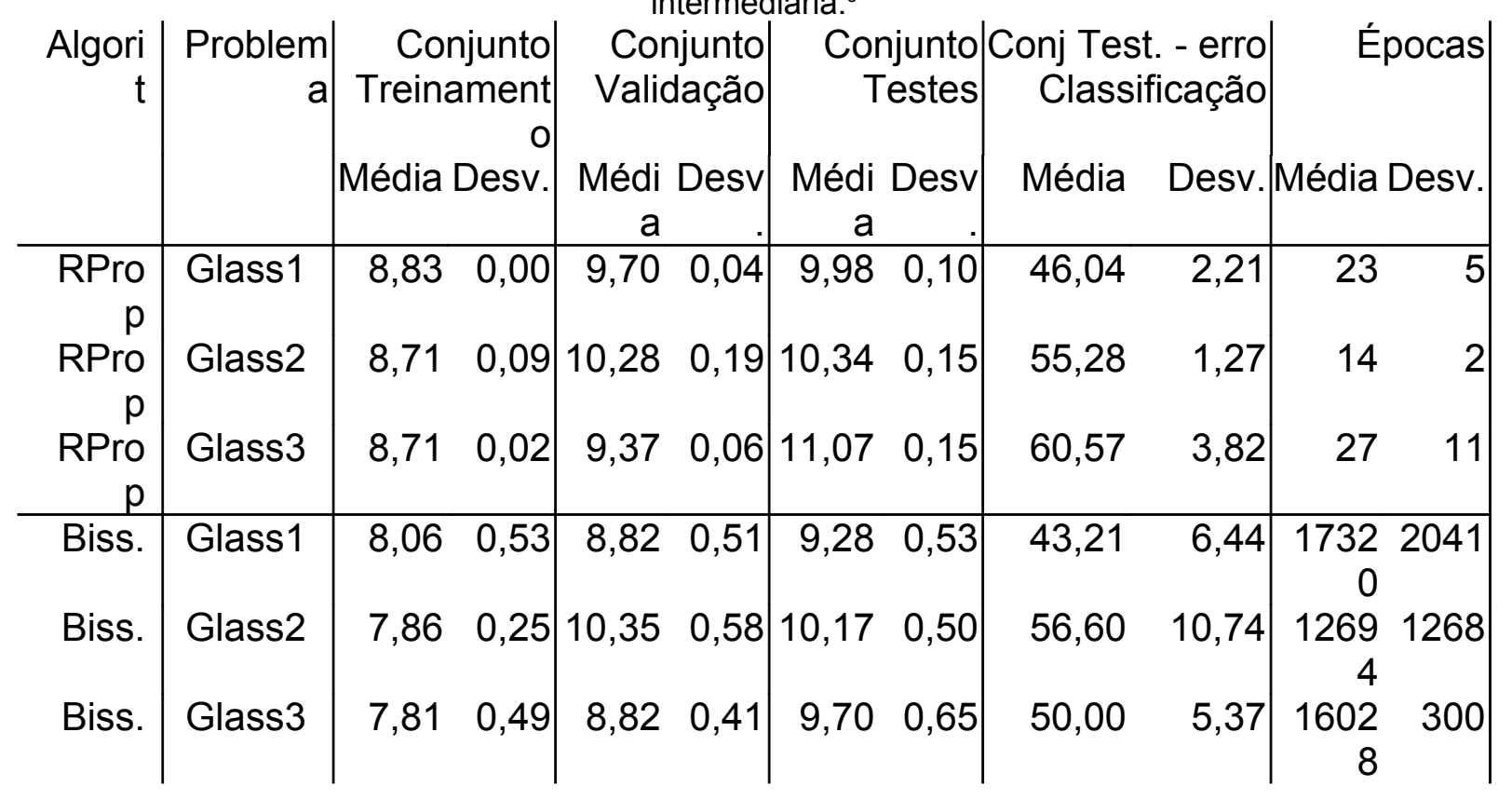

\footnotetext{
${ }^{6}$ Algorit: algoritmo de treinamento - RPROP do proben e Biss (Bissetriz) deste trabalho Problema: problema glass do Proben1 com suas 3 divisões de conjuntos de treinamento Conjunto treinamento: média e desvio padrão do erro quadrático em porcentagem no conjunto de treinamento Conjunto Validação: similar ao Conjunto Treinamento Conjunto Testes: similar ao Conjunto Treinamento Conj Test. - erro classificação: Média e desvio padrão da porcentagem de erros de classificação no conjunto de testes calculado a partir do menor erro quadrático em porcentagem do conjunto de validação.

Épocas: número de épocas de treinamento para atingir menor erro quadrático segundo o conjunto de validação
} 
$\mathrm{Na}$ Tabela 3.9, mesmo experimento calculado agora com camadas intermediárias. Foram testadas as seguintes configurações de camadas intermediárias: [2],[4],[8],[16],[32],[2,2],[4,2],[4,4],[8,4],[8,8] e[16,8]. Por exemplo, [4] significa uma rede neural com uma camada intermediária de 4 neurônios e [4,2] significa uma rede neural com duas camadas intermediárias, sendo que a mais próxima às entradas possui 4 neurônios e a seguinte apenas 2 .

Para cada módulo da rede foram testadas estas seguintes configurações 10 vezes cada. A melhor configuração foi então escolhida para compor o módulo resultado em seis redes neurais com as seguintes configurações de camada intermediária [32],[16], [16], [2, 2], [32] e [8]; [16],[ ],[8, 4],[4, 2],[8],[2, 2]; e [32], [ ], [2, 2], [4, 2], [8] e [] para os conjuntos glass1, glass2 e glass3 respectivamente. Para cada uma destas configurações, foram realizados 10 testes para determinar seu desempenho. Novamente, os resultados são bastante próximos, porém na prática foram necessários muito mais nós e iterações para se atingir o resultado.

Porém, a pesar disto, a RNA se comporta de maneira correta, habilitando-a para os testes com os combustíveis reais.

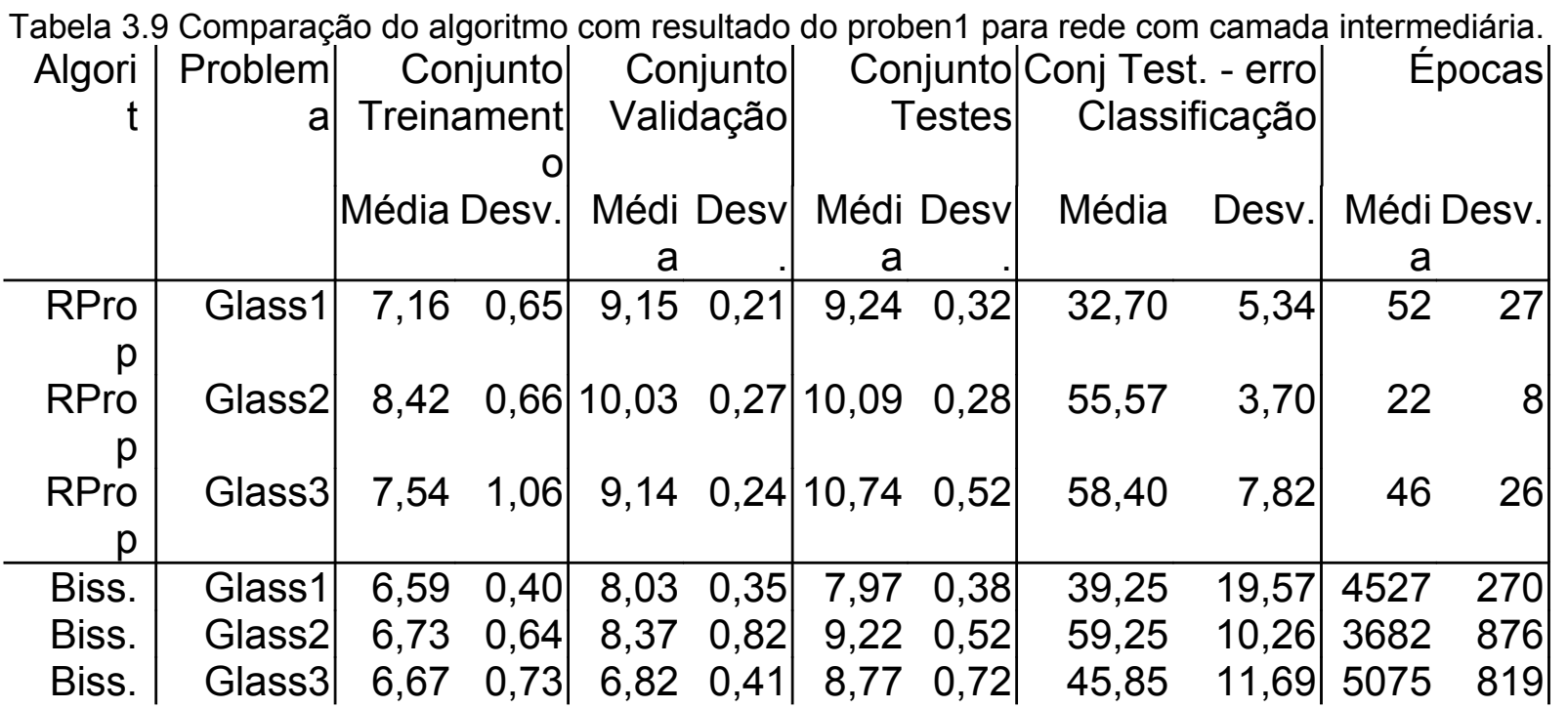

\subsubsection{Desempenho com combustíveis comerciais}

Baseados nas análises físico-químicas dos combustíveis e nos gráficos PCA do capítulo anterior as mostras de combustíveis serão divididos em grupos. 
No caso do $\mathrm{AEHC}$, serão criadas 5 classes, amostras conformes, com baixo teor alcoólico $(\mathrm{TA}<), \mathrm{pH}$ baixo $(\mathrm{PH})$, com alta condutividade elétrica $(\mathrm{CE})$ e com alto teor alcoólico (TA>).

No caso da gasolina, foram criadas 4 classes, amostras conformes, com elevado teor alcoólico (AEAC), com baixo ponto final de ebulição (PFE) e com baixa temperatura de 90\% evaporado da curva de destilação (T90).

Tabela 3.8Tabela 3.9Tabela 3.10Tabela 3.11Tabela 3.12Tabela 3.13Tabela 3.14Tabela 3.15Tabela 3.16Tabela 3.17

De forma semelhante ao item anterior foram feitos os testes da rede neural sem neurônios na camada intermediária (Tabela 3.10) e com as configurações [], [2],[4],[8],[16],[32],[2,2],[4,2],[4,4],[8,4],[8,8] e[16,8] (Tabela 3.11).

No último caso as melhores configurações foram [8, 4], [16, 8], [], [] e [32]; [32], [2, 2], [], [32] e [16, 8]; [], [16], [], [] e [32]; [8], [16], [8, 4] e [32]; [4, 2], [32], [8, 4] e []; e [8], [], [] e [32].

É possível observar que as redes com neurônios intermediário possuem um desempenho um pouco superior ao das redes sem neurônios intermediários. 1,43\%, $42,86 \%$ e $28,57 \%$ foram a porcentagens de erros de classificação encontradas para o álcool e 8,00\%, 4,00\% e 10,00\%, para a gasolina.

\begin{tabular}{|c|c|c|c|c|c|c|c|c|c|}
\hline \multirow[t]{2}{*}{$\begin{array}{c}\text { Problema } \\
\text { Etanol 1 }\end{array}$} & \multicolumn{2}{|c|}{\begin{tabular}{|r} 
Conjunto \\
Treinamento \\
Média Desv.
\end{tabular}} & \multicolumn{2}{|c|}{$\begin{array}{r}\text { Conjunto } \\
\text { Validação } \\
\text { Média Desv. }\end{array}$} & \multicolumn{2}{|c|}{$\begin{array}{r}\text { Conjunto } \\
\text { Testes } \\
\text { Média Desv. } \\
\end{array}$} & \multicolumn{2}{|c|}{$\begin{array}{l}\text { Classificação } \\
\text { Média Desv. }\end{array}$} & \\
\hline & 3,74 & 0,12 & 5,04 & 0,04 & 3,79 & 0,02 & & 0,00 & 9335 \\
\hline & 7,59 & 0,10 & 14,21 & 1,07 & 12,06 & 0,49 & 42 , & 0,00 & 720 \\
\hline Eta & 6,96 & 0,34 & 7,62 & 0,08 & 5,92 & 0,02 & 28,57 & 0,00 & 27652,1 \\
\hline & 6,08 & 0,48 & 7,51 & & 5,33 & 0,57 & & 0,00 & \\
\hline Jaso & 5,68 & 0,47 & 7,64 & 0,36 & 7,42 & 0,29 & 0,00 & 0,00 & 8564 \\
\hline Sasol & 4,20 & 0,58 & 7,66 & 0,43 & 7,70 & 0,27 & 20,00 & 0,00 & 7545 \\
\hline
\end{tabular}

\begin{tabular}{|c|c|c|c|c|c|}
\hline Problema & $\begin{array}{r}\text { Conjunto } \\
\text { Treinamento } \\
\text { Média Desv. }\end{array}$ & $\begin{array}{r}\text { Conjunto } \\
\text { Validação } \\
\text { MédiaDesv. }\end{array}$ & $\begin{array}{r}\text { Conjunto } \\
\text { Testes } \\
\text { Média Desv. }\end{array}$ & $\begin{array}{l}\text { Classificação } \\
\text { Média Desv. }\end{array}$ & Média D \\
\hline Etanol 1 & \begin{tabular}{|ll}
2,41 & 0,64
\end{tabular} & $2,41 \quad 0,43$ & $\begin{array}{ll}2,32 & 0,46\end{array}$ & $1,43 \quad 8,13$ & 57492522 \\
\hline Etá & 6,28 & 10,08 & 8,53 & 0,00 & 979 \\
\hline & 6,14 & 6,11 & 5,41 & 28,57 & 13934 \\
\hline & 39 & 4,74 & 3,14 & & 4906 \\
\hline iasolin & $3,40 \quad 3,91$ & $4,51 \quad 2,50$ & 4,41 & $4,0020,24$ & 4746 \\
\hline
\end{tabular}


Gasolina $3|1,531,21| \quad 5,19 \quad 1,31|\quad 5,93 \quad 1,04| 10,00 \quad 0,00|68951368|$

Além das tabelas de desempenho, também serão mostrada as tabelas Tabela 3.12, Tabela 3.13, Tabela 3.14, Tabela 3.15, Tabela 3.16 e Tabela $3.17 \mathrm{com}$ as matrizes de confusão para cada classe segundo o desempenho das RNAs com neurônios intermediários.

A partir delas pode-se notar que as redes neurais nos resultados, as taxas de Falsopositivos são zero para todos os conjuntos. Isto quer dizer que quando a rede predisser que a amostra está adulterada, ela realmente estará.

No etanol, as taxas de verdadeiro positivo são baixas, com exceção do conjunto 1 , que é de $97 \%$. Nos outros dois testes foram de $0 \%$ e $33 \%$. Isto quer dizer, que a rede não acerta praticamente nenhuma predição.

Já para a gasolina, estas taxas são de 100\%, 93\% e $83 \%$, o que diz que acertará uma predição de combustível adulterado em mais de $80 \%$ dos casos.

\begin{tabular}{|c|c|c|c|c|c|c|c|c|c|c|c|c|c|c|c|c|}
\hline \multirow[b]{3}{*}{ Classe } & & \multicolumn{15}{|c|}{$\begin{array}{r}\text { Tabela 3.12 Matriz de confusão para conjunto Etanol } 1 \\
\text { Classificado como: }\end{array}$} \\
\hline & & \multicolumn{5}{|c|}{ Conj. Treinamento } & \multicolumn{5}{|c|}{ Conj. Valid. } & \multicolumn{5}{|c|}{ Conj. Testes } \\
\hline & & $\mathbf{A}$ & B & C & D & $\mathbf{E}$ & A & B & C & D & E & $\mathbf{A}$ & B & C & D & E \\
\hline Conforme & A & 7 & 0 & 0 & 0 & 0 & 3 & 0 & 0 & 0 & 0 & 4 & 0 & 0 & 0 & 0 \\
\hline $\mathbf{T A}<$ & B & 0 & 1 & 0 & 0 & 0 & 0 & 1 & 0 & 0 & 0 & 0.1 & 0.9 & 0 & 0 & 0 \\
\hline $\mathbf{P H}$ & C & 0 & 0 & 1 & 0 & 0 & 0 & 0 & 1 & 0 & 0 & 0 & 0 & 1 & 0 & 0 \\
\hline $\mathbf{C E}$ & D & 0 & 0 & 0 & 1 & 0 & 0 & 0 & 0 & 1 & 0 & 0 & 0 & 0 & 1 & 0 \\
\hline $\mathbf{T A}>$ & $\mathbf{E}$ & 1 & 0 & 0 & 0 & 0 & 0 & 0 & 0 & 0 & 0 & 0 & 0 & 0 & 0 & 0 \\
\hline
\end{tabular}

\begin{tabular}{|c|c|c|c|c|c|c|c|c|c|c|c|c|c|c|c|c|}
\hline \multirow[b]{3}{*}{ Classe } & & \multicolumn{15}{|c|}{ Classificado como: } \\
\hline & & \multicolumn{5}{|c|}{ Conj. Treinamento } & \multicolumn{5}{|c|}{ Conj. Valid. } & \multicolumn{5}{|c|}{ Conj. Testes } \\
\hline & & A & B & C & D & E & A & B & C & D & $\mathbf{E}$ & A & B & C & D & $\mathbf{E}$ \\
\hline Conforme & $\mathbf{A}$ & 7 & 0 & 0 & 0 & 0 & 3 & 0 & 0 & 0 & 0 & 4 & 0 & 0 & 0 & 0 \\
\hline $\mathbf{T A}<$ & B & 0.9 & 0 & 0.1 & 0 & 0 & 1 & 0 & 0 & 0 & 0 & 1 & 0 & 0 & 0 & 0 \\
\hline PH & C & 0 & 0 & 1 & 0 & 0 & 1 & 0 & 0 & 0 & 0 & 1 & 0 & 0 & 0 & 0 \\
\hline $\mathbf{C E}$ & D & 0 & 0 & 0 & 1 & 0 & 1 & 0 & 0 & 0 & 0 & 1 & 0 & 0 & 0 & 0 \\
\hline $\mathbf{T A}>$ & $E$ & 1 & 0 & 0 & 0 & 0 & 0 & 0 & 0 & 0 & 0 & 0 & 0 & 0 & 0 & 0 \\
\hline
\end{tabular}




\begin{tabular}{|c|c|c|c|c|c|c|c|c|c|c|c|c|c|c|c|c|}
\hline \multirow[b]{3}{*}{ Classe } & & \multicolumn{15}{|c|}{ Classificado como: } \\
\hline & & \multicolumn{5}{|c|}{ Conj. Treinamento } & \multicolumn{5}{|c|}{ Conj. Valid. } & \multicolumn{5}{|c|}{ Conj. Testes } \\
\hline & & A & B & C & D & $\mathbf{E}$ & A & B & C & D & $\mathbf{E}$ & A & B & C & D & $\mathbf{E}$ \\
\hline Conforme & $\mathbf{A}$ & 7 & 0 & 0 & 0 & 0 & 3 & 0 & 0 & 0 & 0 & 4 & 0 & 0 & 0 & 0 \\
\hline $\mathbf{T A}<$ & B & 0 & 1 & 0 & 0 & 0 & 0 & 1 & 0 & 0 & 0 & 1 & 0 & 0 & 0 & 0 \\
\hline PH & C & 0 & 0 & 1 & 0 & 0 & 1 & 0 & 0 & 0 & 0 & 1 & 0 & 0 & 0 & 0 \\
\hline $\mathbf{C E}$ & D & 0 & 0 & 0 & 1 & 0 & 0 & 0 & 0 & 1 & 0 & 0 & 0 & 0 & 1 & 0 \\
\hline $\mathbf{T A}>$ & $\mathbf{E}$ & 1 & 0 & 0 & 0 & 0 & 0 & 0 & 0 & 0 & 0 & 0 & 0 & 0 & 0 & 0 \\
\hline
\end{tabular}

Tabela 3.15 Matriz de confusão para conjunto Gasolina 1

\begin{tabular}{cc|llllllllllllll} 
& & \multicolumn{18}{c}{ Classificado como: } \\
Classe & & A & B & C & D & A & B & C & D & A & B & C & D \\
\hline Conforme & A & 10 & 0 & 0 & 0 & 5 & 0 & 0 & 0 & 4 & 0 & 0 & 0 \\
PFE & B & 0 & 2.9 & 0.1 & 0 & 0 & 2 & 0 & 0 & 0 & 1 & 0 & 0 \\
AEAC & C & 2 & 0 & 4 & 0 & 0 & 1 & 1 & 0 & 0 & 0.8 & 2.2 & 0 \\
T90 & D & 0 & 0 & 0 & 2 & 0 & 0 & 0 & 2 & 0 & 0 & 0 & 2
\end{tabular}

Tabela 3.16 Matriz de confusão para conjunto Gasolina 2

\begin{tabular}{|c|c|c|c|c|c|c|c|c|c|c|c|c|c|}
\hline \multirow[b]{3}{*}{ Classe } & & \multicolumn{12}{|c|}{ Classificado como: } \\
\hline & & \multicolumn{4}{|c|}{ Conj. Treinamento } & \multicolumn{4}{|c|}{ Conj. Valid. } & \multicolumn{4}{|c|}{ Conj. Testes } \\
\hline & & $\mathbf{A}$ & B & C & D & $\mathbf{A}$ & B & C & D & $\mathbf{A}$ & B & C & D \\
\hline Conforme & $\bar{A}$ & 10 & 0 & 0 & 0 & 5 & 0 & 0 & 0 & 4 & 0 & 0 & 0 \\
\hline PFE & B & 0 & 3 & 0 & 0 & 0 & 1.9 & 0.1 & 0 & 0 & 1 & 0 & 0 \\
\hline AEAC & C & 2 & 0 & 4 & 0 & $\begin{array}{l}0 . \\
2\end{array}$ & 0.3 & 1.5 & 0 & $\begin{array}{l}0 . \\
4\end{array}$ & 0 & 2.6 & 0 \\
\hline T90 & D & 0 & 0 & 0 & 2 & 0 & 0 & 0 & 2 & 0 & 0 & 0 & 2 \\
\hline
\end{tabular}


Tabela 3.17 Matriz de confusão para conjunto Gasolina 3

\begin{tabular}{|c|c|c|c|c|c|c|c|c|c|c|c|c|c|}
\hline \multirow[b]{3}{*}{ Classe } & & \multicolumn{12}{|c|}{ Classificado como: } \\
\hline & & \multicolumn{4}{|c|}{ Conj. Treinamento } & \multicolumn{4}{|c|}{ Conj. Valid. } & \multicolumn{4}{|c|}{ Conj. Testes } \\
\hline & & A & B & C & D & A & B & C & D & $\mathbf{A}$ & B & C & D \\
\hline Conforme & $\mathbf{A}$ & 10 & 0 & 0 & 0 & 5 & 0 & 0 & 0 & 4 & 0 & 0 & 0 \\
\hline PFE & B & 0 & 3 & 0 & 0 & 0 & 1 & 1 & 0 & 0 & 1 & 0 & 0 \\
\hline AEAC & C & 1 & 0 & 5 & 0 & 0 & 0 & 2 & 0 & 1 & 0 & 2 & 0 \\
\hline T90 & D & 0 & 0 & 0 & 2 & 0 & 0 & 0 & 2 & 0 & 0 & 0 & 2 \\
\hline
\end{tabular}




\section{DISCUSSÕES}

Durante as análises dos combustíveis, os sensores para a fase gasosa não apresentaram bons resultados. As respostas variaram muito durante os dias e, mesmo em um mesmo dia, variava de acordo com o período e a umidade. Isto associado à baixa sensibilidade que encontramos ao variarmos as concentrações de etanol e água entre $50 \%, 75 \%$ e $100 \%$ em volume, grandes comparadas as adulterações habituais onde o teor alcoólico varia alguns pouco por cento.

Talvez com uma montagem experimental adequada se consiga atingir uma estabilidade suficiente. Entretanto, os tempos de estabilização das respostas e medidas para os gases tornam proibitivos a utilização em aplicações que requeiram grande capacidade de medida.

Por outro lado, nos ensaios com combustível na fase líquida, se observou boas respostas. Com grandes intensidades que prevalecem frente a oscilações dos sinais e permitem boa sensibilidade a diversos tipos de adulteração.

$\mathrm{Na}$ caracterização dos sensores, também foi observado que a diferença de condutividade e dielétrico prevalece, quando comparamos etanol, gasolina e água. No entanto, é possível notar há contribuição do filme polimérico que interfere na dupla camada dielétrica entre o filme e o combustível e que parece diminuir a capacitância e aumentar a resistência do filme num efeito contrário ao do observado pelas propriedades acima mencionadas do líquido.

Sendo assim, o resultado com redes neurais corrobora o sucesso na classificação das gasolinas com as RNAs.

Talvez o pior resultado com as RNAs para o álcool se dê pela quantidade reduzida de amostras e pelo fato de que o método de determinação do teor alcoólico seja mais preciso do que aqueles empregados na gasolina. Sendo o limite de detecção mais tênue, os sensores talvez não sejam suficientemente estáveis e sensíveis para a detecção de adulterações, a pesar de que em um dos casos, houve uma capacidade muito boa de detecção de adulteração. 
Como sugestão de atividades, poderia ser realizado um estudo das misturas de gasolina com outros adulterantes além do álcool, por exemplo, solventes como o tolueno, o xileno e o benzeno, e mapeá-los de acordo com as respostas dos sensores e as análises físico-químicas.

No caso do álcool, poderiam ser realizados outros estudos de materiais sensíveis e de adulteração por outras substâncias, por exemplo, o metanol, a fim de se obter uma avaliação do arranjo de sensores mais completa para este combustível.

Além disso, há campo para se melhorar nos aspectos de precisão nas medidas de impedância deste tipo de sensor e desenvolver equipamentos portáteis de medição para viabilizar a utilização dos sensores em campo. 


\section{CONCLUSÕES}

Neste trabalho foi possível classificar com sucesso adulterações gasolina agrupando as adulterações em três grupos, gasolinas com teor alcoólico elevado, com ponto final de ebulição baixo e com temperatura de $90 \%$ evaporado na destilação baixo.

No caso do etanol, foram agrupadas adulterações no teor alcoólico, pH baixo e Condutividade elétrica alta.

Os filmes de poli(3-metiltiofeno) e poli(3-hexiltiofenos) são sensíveis à variação de misturas de etanol, gasolina e água.

As redes neurais artificiais são capazes de processar os dados de impedância destes sensores e separá-los de acordo com classes de adulteração. 


\section{REFERÊNCIAS}

ACEVEdo,F.J. MALdONAdO, DOMínNGuEZ, S. E. NARVÁEZ, A. LÓPEZ , F.Probabilistic support vector machines for multi-class alcohol identification. Sensors and Actuators B, v. 122, p. 227-235, 2007.

ANAND, R.; MEHROTRA, K.; MOHAN, C. K.; RANKA, S. Efficient Classification for Multiclass Problems Using Modular Neural Networks. IEEE Transactions on Neural Networks, v. 6, n. 1, Janeiro, 1995.

ANTUNES P. A., SANTANA C. M., AROCA R. F., OLIVEIRA O. N., CONSTANTINO C. J. L., RIUL Jr. A. The use of Langmuir-Blodgett films of a perylene derivative and polypyrrole in the detection of trace levels of Cu2+ ions . Synthetic Metals , v. 148, n. 1, p. 21-24, 2005.

ARTURSSON, T.; EKLÖV, T.; LUNDSTRÖM, I.; MARTENSSON, P.; SJÖSTRÖM, M.; HOLMBERG, M. Drift correction for gas sensors using multivariate methods. Journal of Chemometrics, v. 14, p. 711-723, 2000.

BAI, Hua e SHI, Gaoquan. Gas Sensors Based on Conducting Polymers. Sensors, v7, p. 267-307, 2007

BARSOUKOV, E.; MacDONALD, J. R. Impedance Spectroscopy: Theory, Experiment, and Applications, 2.ed. Wiley, 2005, 616 p.

BEVENHO, A.R.V.; LI, R.W.C.; GRUBER, J. Polymeric electronic gas sensor for determining alcohol content in automotive fuels. Sensors and Actuators B, 2008. No prelo.

BRAGA, G. S.; PATERNO, L.G.; LIMA, J.P.H.; FONSECA, F.J.; ANDRADE, A. M. Influence of the deposition parameters on the morphology and electrical conductivity of PANI/PSS self-assembled films. Materials Science and Engineering C, v. 28, p. 555-562, 2008.

BURRI, J.; CROCKETT, R.; HANY, R.; RENTSCH, D. Gasoline composition determined by 1H NMR spectroscopy. Fuel, v. 83, n. 2, p. 187-193, 2004.

CAMPOS A. C.; LEONTSINIS, E. Petróleo e derivados: Capítulo 6 (Gasolina e Derivados). Rio de Janeiro: JR Editora Técnica Idta, 1990.

CANO, A. I. Electrical impedance for living tissue ischemia injury monitoring. 2005 Tese (doutorado) - Universidad Politècnica de Catalunya, Barcelona, 2005. 
CHIANG C.K.; FINGER, C.R.; PARK, Y.W.; HEEGER, A.J.; SHIRAKAWA, H.; LOUIS, E.J.; GRAU , S. C.; MACDIARMID, A.G. Electrical conductivity in doped polyacetylene. Phys. Rev. Let, v. 39, p. 1098, 1977.

CHIARI, M; et al. Advanced polymers for molecular recognition and sensing at the interface. Journal of Chromatography B, v. 866, n. 1-2, p. 89-103, 2008.

Chromatography. J. Braz. Chem. Soc., v. 16, n. 2, p. 139-146, $2005 a$.

CIOSEK,P.; WROBLEWSKI, W. The analysis of sensor array data with various pattern recognition techniques. Sensors and Actuators B, v. 114, p. 85-93, 2006.

CONSTANTINO C. J. L., ANTUNES P. A., VENÂNCIO E. C., CONSOLIN N., FONSECA F. J., MATTOSO L. H. C., AROCA R. F., OLIVEIRA Jr O. N., RIUL Jr. a Nanostructured films of perylene derivatives: High performance materials for taste sensor applications. Sensor Letters , v. 2, n. 2, p. 95-101, 2004.

CYBENKO, G. 1989. Approximation by superpositions of a single function. Math. Control, Signals Syst. 2, 303-314.

DECHER, Gero. Fuzzy Nanoassemblies: Toward Layered Polymeric Multicomposites. Science 277, 1232, 1997.

Di NATAle, C.; PAOlesse, R.; BURGIO, M.; MARTINELLI, E.; PENNAZZA, G.; D'AMICO, A. Application of metalloporphyrins-based gas and liquid sensor arrays to the analysis of red wine. Analytica Chimica Acta, v. 513, n.1, p. 49-56, 2004.

EMBRAPA - Empresa Brasileira de Pesquisa Agropecuária (BR/DF): Mattoso, L.H.C.M.; Fonseca, F. J.; Riul Junior, A., Martin Neto, L.; Venâncio E. C. Sensor para análise de misturas por seletividade global e seu uso em sistema sensorial. BR PI0200409-7, 30 jan. 2002.

FERMINO, L. P. CASTRO, H. F. GIORDANI, D. S. Determinação da Origem de Biodiesel e da sua Quantidade em Mistura com`Petrodiesel Usando Nariz Eletrônico e Redes Neurais Artificiais

FERREIRA M., RIUL Jr. A., WOHNRATH K., FONSECA F. J., OLIVEIRA Jr. O. N., MATTOSO, L. H. C. High-Performance Taste Sensor Made from Langmuir-Blodgett Films of Conducting Polymers and a Ruthenium Complex. Analytical Chemistry. v. 75, p. 953-955, 2003.

dos SANTOS, D. S., RIUL A., MALMEGRIM R. R., FONSECA F. J., OLIVEIRA O. N., MATTOSO L. H. C. A Layer-by-Layer Film of Chitosan in a Taste Sensor Application. Macromolecular Bioscience. v. 3, n. 10, p.I 591-595, 2003. 
FORNER, A. A. C. Magnetismo a temperatura ambiente em polímeros derivados de tiofeno sintetizados eletroquimicamente. 2003. 149p. Tese (doutorado) Departamento de Química da Universidade Federal de São Carlos (UFSCar), São Carlos, 2003.

FU, Jun; LI, Guang; QUIN, Yugi; FREEMAN, W.J. A pattern recognition method for electronic noses based on an olfactory neural network Sensors and Actuators B: Chemical, v. 125, n. 2, p. 489-497, 2007

GARCIA-BELMONTE, G.; BISQUERT, J. Anomalous transport on polymeric porous film electrodes in the dopant-induced insulator-to-conductor transition analyzed by electrochemical impedance. Applied Physics Letters, v. 78, n. 13, p. 1885-1887, 2001.

GARDNER J.W.; BARTLETT P.N. (Ed.). Sensors and Sensory Systems for an Electronic Nose. NATO ASI Series E: Applied Sciences, vol 212. Springler, 1992, $327 p$.

HAUGEN, J.E.; TOMIC, O.; KVAAL, K. A calibration method for handling the temporal drift of solid state gas-sensors. Analytica Chimica Acta, v. 407, p. 23-39, 2000.

HAYKIN, Simmon. Neural Networks: a comprehensive foundation. MacMillan HOFMANN, T.; SCHRÖDER, K.; ZACHEJA, J.; BINDER, J. Fluid characterization using sensor elements based on interdigitated electrodes. Sensors and Actuators B: Chemical, v. 37, n. 1-2, p. 37-42, 1996.

HOLMBERG, M.; WINQUIST, F.; LUNDSTR, I.; DAVIDE, F.; DiNATALE C.; D'AMICO, A. Drift counteraction for an electronic nose. Sensors and Actuators B, v. 35, n. 36, p. 528-535, 2006.

Klingbeil, A.E.; Jeffries, J.B.; Hanson, R.K. Temperature- and composition-dependent mid-infrared absorption spectrum of gas-phase gasoline: Model and measurements. FUEL, v. 87, n. 17-18, p. 3600-3609, 2008.

LOVEDAY, D.; PETERSON, P.; RODGERS, B. Evaluation of Organic coatings with electrochemical impedace spectroscopy: Part II - Application of EIS to coatings. Journal of coatings technology, v. 1/8, 2004.

MacDIARMID, A. G. Synthetic metals: a novel role for organic polymers. Synthetic Metals, v. 125, n. 1, p. 11-22, 2001.

MARCO, S.; ORTEGA, A.; PARDO, A.; SAMITIER, J. Gas Identification with Tin Oxide Sensor Array and Self-Organizing Maps: Adaptive Correction of Sensor Drifts. 
IEEE TRANSACTIONS ON INSTRUMENTATION AND MEASUREMENT, v. 47, n. 1, p. 316-321, 1998

MATTOSO L.H.C.; MANOHAR S.K.; MACDIARMID A.G.; EPSTEIN A.J;.. Studies on the chemical syntheses and on the characteristics of polyaniline derivatives. Journal of Polymer Science Part A: Polymer Chemistry, v. 33, n. 8, p. 1227-1234, 1995.

MEDEIROS, E. S.; PATERNO, L. G.; MATTOSO, L. H. C. . Sensing Applications of Conjugated Polymers. In: Craig Grimes; E. C. Dickey; M. V. Pishko. (Org.). Encyclopedia of Sensors. 1 ed. Stevenson Ranch: American Scientific Publishers, 2006, v. 10, p. 01-36.

MENDONÇA, M. A. Classificação de gasolinas comerciais através de métodos estatísticos multivariados. Dissertação (Mestrado) - Escola Politécnica da Universidade de São Paulo, 2005.

MENDONÇA, M. A. Classificação de gasolinas comerciais através de métodos estatísticos multivariáveis. Dissertação (Mestrado) - Escola Politécnica, Universidade de São Paulo, São Paulo, 2005.

OLIVEIRA, C. S.; HERNANDEZ, E. M. Experimentos com arquiteturas neurais clássicas para o desenvolvimento de arquiteturas neurais híbridas. Produção em iniciação científica da EPUSP. São Paulo, 2002.

OLIVEIRA, F.S.; TEIXEIRA, L.S.G.; ARAUJO, M.C.U.; KORN, M. Screening analysis to detect adulterations in Brazilian gasoline samples using distillation curves. Fuel, v. 83, n. 7-8, p. 917-923, 2004.

PEREIRA, R.C.C; SKROBOT, V.L.; CASTRO, E.V.R.; FORTES, I.C.P.; PASA, V.M.D. Determination of Gasoline Adulteration by Principal Components AnalysisLinear Discriminant Analysis Applied to FTIR Spectra. Energy \& Fuels, v. 20, n. 3, p. 1097-1102, 2006.

PERSAUD, K; DODD, G. Analysis of discrimination mechanisms in the mammalian olfactory system using a model nose. NATURE, v. 299, n. 5881, p. 352-355, 1982.

Publishing Company, 1994.

PRECHELT, L. PROBEN1--A standardized benchmark collection for neural network training algorithms, 1994 . Anonymous FTP: ftp:// ftp.ira.uka.de/pub/neuron/proben1.tar.gz or ftp://ftp.cs.cmu.edu/afs/cs/ project/connect/bench/contrib/prechelt/proben1.tar.gz 
RIUL Jr. A, MALMEGRIM R. R., FONSECA F. J., MATTOSO L. H. C. An artificial taste sensor based on conducting polymers. Biosensors Bioelectronics, v. 18, p. 1365-1369, 2003b.

RIUL Jr. A.; GALLARDO Soto A.M.; MELLO S.V.; BONE S.; TAYLOR D.M.; MATTOSO L.H.C.An electronic tongue using polypyrrole and polyaniline. Synthetic Metals, v. 132, p. 109-116, 2003a.

RIUL Jr. A; SOUSA H.C.; MALMEGRIN R.R.; dos SANTOS D.S.; CARVALHO C.P.L.F.; FONSECA F.J.; OLIVEIRA Jr. O.N, MATTOSO L.H.C. Wine classification by taste sensors made from ultra-thin films and using neural networks Sensors and Actuators B, v. 98, p. 77-83, 2004.

ROCHA, M.S.; SIMÕES-MOREIRA, J.R. A simple impedance method for determining ethanol and regular gasoline mixtures mass contents. Fuel, v. 84 , p. 447-452, 2005.

SANTOS, J.C.B. Estudo de camadas transportadoras de cargas em diodos emissores de luz poliméricos: Revisão bibliográfica. Dissertação (Mestrado) - Escola Politécnica, Universidade de São Paulo, São Paulo, 2007.

SKROBOT, V. L.; CASTRO, E. V. R.; PEREIRA, R. C. C.; PASA, V. M. D.; FORTES, I. C. P. Identification of Adulteration of Gasoline Applying Multivariate Data Analysis Techniques HCA and KNN in Chromatographic Data. Energy \& Fuels, v. 19, p. 23502356, 2005.

SOBÁNSKI, T.; SZCZUREK, A.; NITSCH, K.; LICZNERSKI, B.W.; RADWAN, W. Electronic nose applied to automotive fuel qualification. Sensors and Actuators B, v. 116, n. 1-2, p. 207-212, 2006

TAYLOR, D. M.; MACDONALD, A. G. AC admitance of the metal/insulator/electrolyte interface. J. Phys. D: Appl. Phys, v. 20, p. 1277-1283, 1987.

TOKO, K. A taste sensor. Measurement Science \& Technology, v. 9, n. 12, p. 19191936, 1998.

TOMIC, O.; EKLÖV, T.; KVAAL, K.; HAUGEN, J.E. Recalibration of a gas-sensor array system related to sensor replacement. Analytica Chimica Acta, v. 512, p. 199206, 2004.

WIEDEMANN, L. S. M.; D'AVILA, L. A.; AZEVEDO, D. A. Adulteration detection of Brazilian gasoline samples by statistical analysis. Fuel, v. 84, n. 4, p. 467-473, $2005 b$. 
WIEDEMANN, L. S. M.; d'AVILA, L. A.; AZEVEDO, D. A. Brazilian Gasoline Quality: Study of Adulteration by Statistical Analysis and Gas Chromatography. J. Brazilian Chemistry Society, v. 16, n. 2, p 139-145, 2005.

WIEDEMANN, L. S. M.; D’AVILA, L. A.; AZEVEDO, D. A. Brazilian Gasoline Quality: Study of Adulteration by Statistical Analysis and Gas

WIZIACK, N.K.L. Estudo do Desempenho de uma língua eletrônica baseada em materiais nanoestruturados. 2005 Dissertação (Mestrado) - Departamento de Sistemas eletrônicos da Escola Politécnica da USP, São Paulo, 2005.

WIZIACK, N.K.L. Integração de uma Língua Eletrônica e de um Nariz Eletrônico fabricados com filmes nanoestruturados de polímeros condutores para análise de combustíveis. Qualificação (Doutorado) - Escola Politécnica da Universidade de São Paulo, 2007. 


\section{APÊNDICE A - Resumo de ensaios de conformidade}

Nesta seção brevemente mencionamos os principais ensaios realizados na detecção de adulteração de combustíveis. Para a gasolina os principais são a curva de destilação e o teor alcoólico. Para o álcool etílico hidratado combustível, são os testes de massa específica/teor alcoólico, condutividade e $\mathrm{pH}$.

Curva de destilação - gasolina

O ensaio de destilação, efetuado de acordo como método MB-45, propicia uma medida em termos de volatilidade, das proporções relativas de todos os hidrocarbonetos componentes de uma gasolina.

Consiste o ensaio em destilar $100 \mathrm{ml}$ de gasolina, condensar o destilado e registrar as temperaturas nas quais as várias porcentagens destilam.

Plotando-se em gráfico as porcentagens de destilado e as temperaturas correspondentes, obtém-se a chamada curva de destilação (figura 1), de grande utilidade para prever o desempenho da gasolina no motor. 


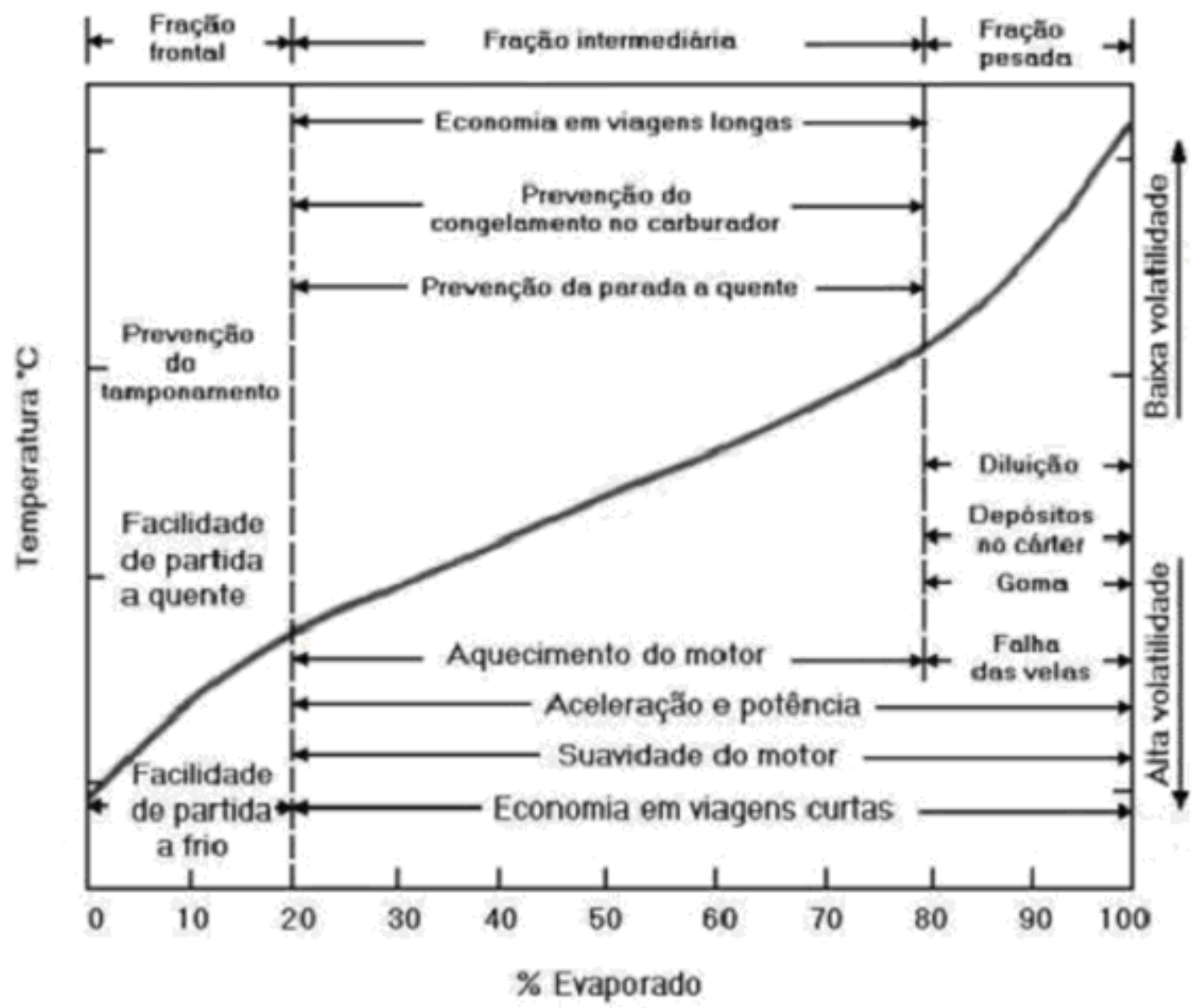

Figura 1 - Curva de destilação da gasolina e sua função de acordo com a volatilidade (CAMPOS, 1990).

A especificação da gasolina assinala as temperaturas nas quais $10 \%, 50 \%$ e $90 \%$ do combustível é evaporado, o ponto final de ebulição, que é a temperatura máxima observada durante a destilação, e a porcentagem do resíduo.

Estas características da destilação, juntamente com a pressão de vapor e a relação V/L, definem e controlam a partida do motor, seu aquecimento, aceleração, tendência ao tamponamento e diluição do óleo do cárter, a economia, em parte, de combustível, e a tendência a provocar o congelamento no carburador, fenômeno que ocorre a baixas temperaturas em determinadas condições de umidade. A destilação tem aplicação, também, no que se refere à verificação de contaminações entre produtos de características diferentes, bem como de adulterações propositais.

A temperatura de evaporação dos $10 \%$ deve ser suficientemente baixa para assegurar uma partida fácil sob condições normais de temperatura ambiente. 
Geralmente, o 'ponto de 10\%'deve ser mais baixo no inverno do que no verão. Da volatilidade dos primeiros $10 \%$ vai depender uma vaporização adequada do produto, a fim de que o motor frio entre pleno funcionamento com menor número de rotações possível, favorecendo, desse modo, uma partida fácil e rápida. Entretanto, um ponto de $10 \%$ demasiado baixo pode contribuir para o congelamento no carburador e ocasionar o fenômenol do tamponamento (vapor-lock). Quando duas gasolinas possuem a mesma pressão de vapor, aquela que tem o ponto $10 \%$ da destilação mais baixo, usualmente apresenta maior tendência ao tamponamento.

O excesso de frações leves em uma gasolina favorece a interrupção do fluxo líquido ou o torna descontínuo, podendo provocar a parada do motor ou as falhas conhecidas como 'engasgue'. Uma volatilidade exagerada também aumenta as perdas por evaporação durante o armazenamento e manipulação do produto. Por outro lado, quando a porcentagem de frações leves de uma gasolina é baixa, a partida do motor em tempo frio será mais difícil.

O 'ponto 50\%'da curva de destilação da gasolina indica sua capacidade de suprir uma mistura adequada de combustível durante o período de aquecimento, particularmente durante as acelerações nesse período de aquecimento. Quanto mais baixa a temperatura do 'ponto 50\%', mais rapidamente o motor se aquecerá; entretanto, também aumentará a tendência ao congelamento no carburador, com a conseqüente possível paralisação do motor. As características de aquecimento rápido são desejáveis tanto para um bom desempenho do veículo, como para evitar o desperdício de combustível que ocorre quando o afogador está em operação. Em resumo, as características de aquecimento e aceleração dependem das frações intermediárias controladas pela temperatura dos $50 \%$ evaporados, que, nas gasolinas atuais, se situa em torno dos $100^{\circ} \mathrm{C}$.

A temperatura correspondente aos $90 \%$ evaporados e ao 'ponto final de ebulição', assim como a porcentagem do resíduo, indicam a quantidade de componentes da gasolina que possuem ponto de ebulição relativamente elevado. Com o motor trabalhando na temperatura normal de operação, estes componentes contribuem para uma economia de combustível, mas, por outro lado, eles têm tendência a causar uma distribuição deficiente da mistura no coletor de admissão, bem como a propiciar a diluição do óleo lubrificante no cárter. A diluição do óleo cárter e a lavagem do óleo lubrificante nas paredes dos cilindros ocorrem sempre que a 
gasolina atinge os cilindros em forma líquida e tem oportunidade de fluir para o cárter, passando pelos anéis de segmento.

Além dos inconvenientes citados, uma temperatura de $90 \%$ evaporados muito alta provocará depósitos excessivos na câmara de combustão, formação de vernizes e borra no motor.

Teor alcoólico - gasolina

No Brasil, a adição de álcool etílico anidro combustível (AEAC) à gasolina é feita há muitos anos. Atualmente, adiciona-se $25 \%$ + ou - $1 \%$ de álcool anidro na mistura com gasolina. A adição de oxigenados à gasolina deveria ter somente a finalidade de reduzir as emissões tóxicas, porém esta quantidade pode ser alterada pelo Ministério da Agricultura devido a vários fatores, como por exemplo, a baixa ou alta produção de álcool pelas usinas açucareiras.

A adição de álcool na gasolina já foi muito discutida há alguns anos atrás e existem duas fortes correntes: uma favorável e outra desfavorável. Acredita-se que, em proporções até a faixa de $15 \%$ a $20 \%$ de álcool em volume, a utilização de misturas de gasolina-álcool traz vantagens apreciáveis. Embora, o problema do uso do álcool anidro é mais uma questão de preço (Campos, 1990).

Uma das vantagens de se misturar álcool à gasolina é que o álcool proporciona o aumento de sua octanagem. E esse aumento depende da composição da gasolina e, principalmente do nível de octanagem dela. Nos baixos níveis de octanagem, o álcool tem excelente valor de mistura. O álcool tem elevado calor latente de vaporização (205 cal/g) comparado com a gasolina $(80 \mathrm{cal} / \mathrm{g})$, o que aumenta o esfriamento do motor, influenciando favoravelmente a resistência à detonação. Outra vantagem é o aproveitamento do excesso de produção de álcool-anidro produzido pelas usinas açucareiras e ainda a redução de poluição ambiental provocada pelas emissões do escape dos veículos (Campos, 1990).

As desvantagens desta adição é que com um teor muito elevado de álcool a eficiência do motor diminui. $E$ se a relação ar/combustível necessária para combustão completa do álcool é de 9:1, e da gasolina é de 15:1, com porcentagens elevadas de álcool na mistura, faz-se necessário ajustar e regular o carburador (ou bico injetor) para operar com a mistura. Até um teor de $15 \%$ de álcool não há necessidade de nova regulagem (Campos, 1990).

Método Proveta: 
O método da proveta (NBR 13992) é o principal ensaio utilizado para se determinar o teor alcoólico da gasolina. Ele consiste em colocar $50 \mathrm{ml}$ da amostra de gasolina na proveta de vidro, adicionar solução aquosa de $\mathrm{NaCl}(10 \% \mathrm{p} / \mathrm{v})$ até completar o volume de $100 \mathrm{ml}$, tampar a proveta e inverter cuidadosamente por dez vezes. Deixar em repouso e aguardar por 15 minutos até a separação completa das duas camadas. Anotar o volume final $(\mathrm{ml})$ da camada aquosa. O teor de álcool presente na gasolina é calculado conforme a equação abaixo:

\%álcool $=[(\mathrm{A}-50) \times 2]+1$,

sendo que A é o volume final da camada aquosa.

Teor alcoólico e massa específica - Álcool

O teor alcoólico e a massa específica são determinados pelo teste NBR9552. Esta medida considera a característica de que o teor alcoólico e a massa específica estão intimamente relacionados.

A massa específica é dada em $\mathrm{kg} / \mathrm{m} 3$ e o teor alcoólico é dado em graus INPM, ambos à 20oC. O grau INPM é a porcentagem em massa de álcool contido em um sistema hidro-alcoólico. Para encontrá-lo, é preciso determinar a quantidade em gramas de álcool contidos em 100 mg de combustível.

Os limites para o álcool anidro são de densidade máxima de 791,5 kg/m3 e teor alcoólico mínimo de 93INPM. Já para o álcool hidratado, a densidade deve estar entre 807,6 e $811,0 \mathrm{~kg} / \mathrm{m} 3$ e o teor alcoólico deve estar entre 92,6 e 93,8ㅇNPM.

$\mathrm{pH}-$ Álcool

O pH deve ser medido de acordo com a norma NBR10891 e deve estar entre 6 e 8.

$\mathrm{pH}-$ Condutividade elétrica

A condutividade elétrica deve ser medida pela norma NBR10547 e deve ser de no máximo de $500 \mathrm{mS} / \mathrm{m}$.

Referências bibliográficas 
CAMPOS A. C.; LEONTSINIS, E. Petróleo e derivados: Capítulo 6 (Gasolina e Derivados). Rio de Janeiro: JR Editora Técnica Idta, 1990.

MENDONÇA, M. A. Classificação de gasolinas comerciais através de métodos estatísticos multivariados. Dissertação (Mestrado) - Escola Politécnica da Universidade de São Paulo, 2005. 


\section{APÊNDICE B - Software de automação do Solartron1260A e multiplexador}

Abaixo estão as telas do Software desenvolvido em LabView® de automação do medidor de impedância Solartron e do multiplexador de sensores Embrapa.

Este módulo permite maior flexibilidade no ajuste de parâmetros de medida em comparação ao Software da Embrapa, no qual este foi baseado.

Ele permite configurar o Tipo de medida (Tensão, corrente, impedância), as grandezas lidas e os modos de integração do sinal (Tensão ou corrente) na Tela 1

Tela 1

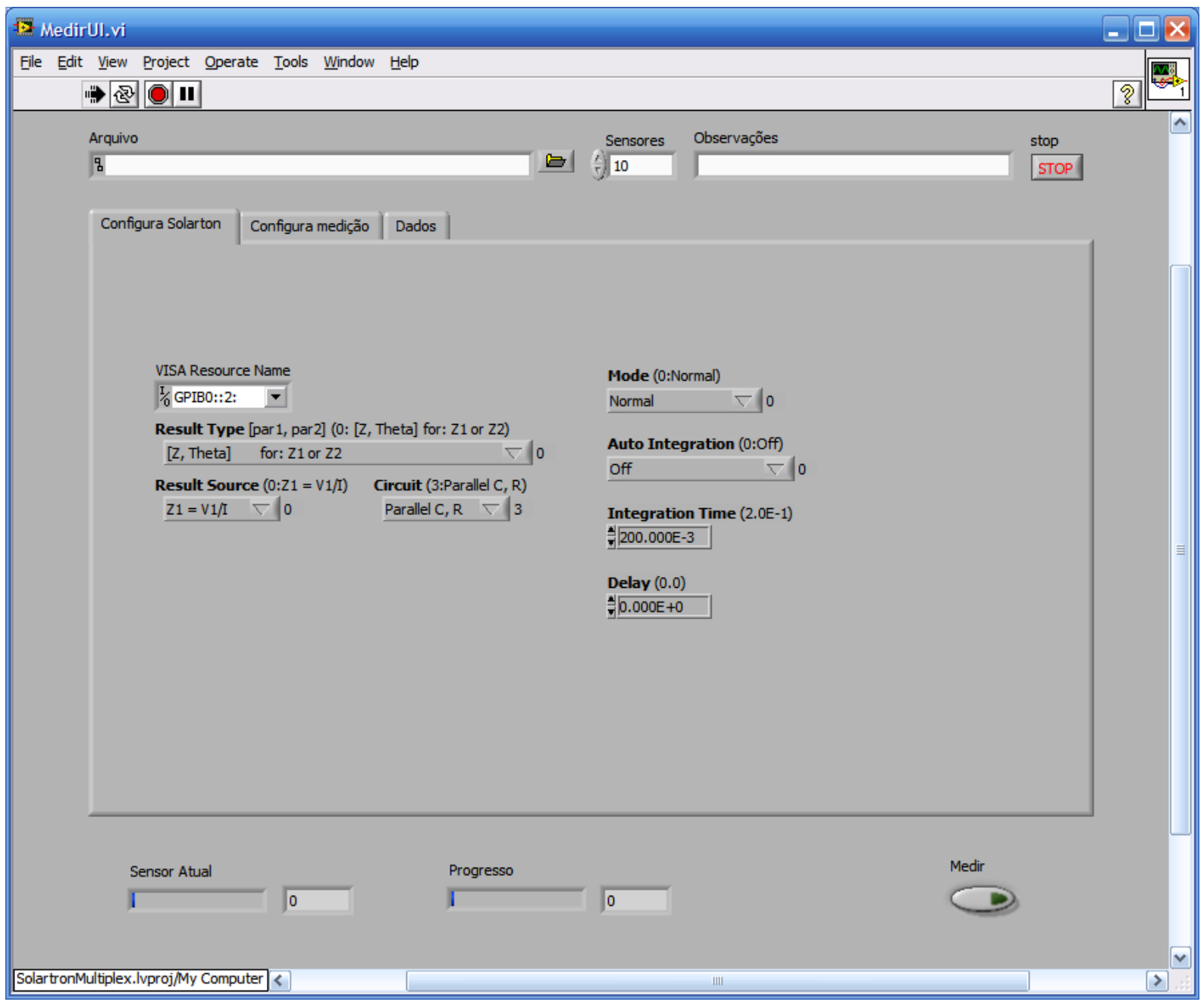


Além disso, ele permite configurar na Tela 2 varreduras de freqüência (especificando o número de pontos por década), varreduras na amplitude do sinal e na tensão de bias, que não eram permitidas anteriormente, bem como apenas medir repetidamente o sensor sem varredura.

Tela 2

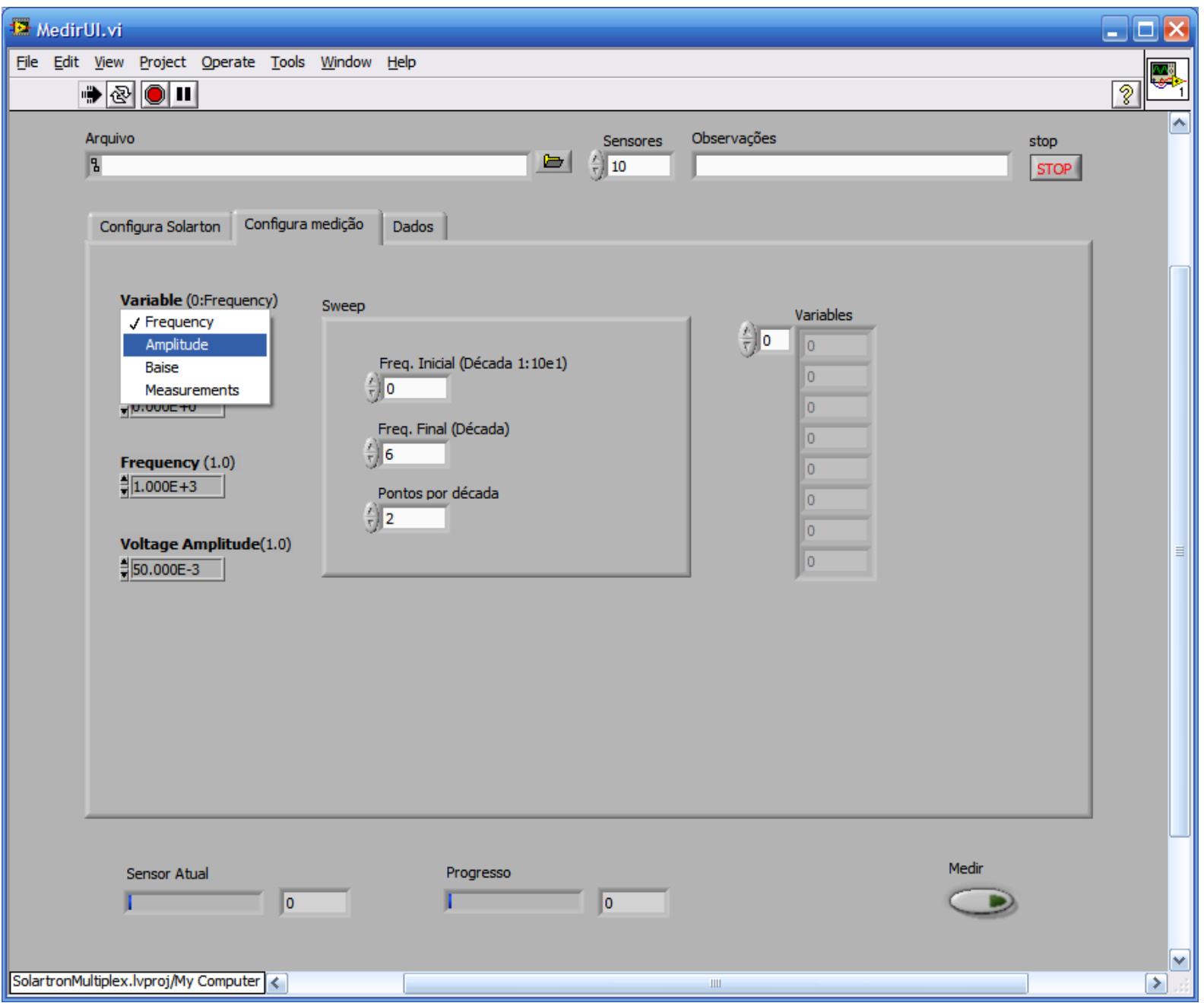




\title{
ANEXO A - PORTARIA ANP № 309 (Regulamento técnico)
}

\author{
REGULAMENTO TÉCNICO ANP N 5/2001
}

\section{Objetivo}

Este Regulamento Técnico aplica-se às gasolinas automotivas comercializadas em todo o território nacional e estabelece suas especificações.

\section{Normas aplicáveis}

A determinação das características dos produtos será realizada mediante o emprego de Normas Brasileiras (NBR) e Métodos Brasileiros (MB) da Associação Brasileira de Normas Técnicas (ABNT) ou de normas da American Society for Testing and Materials (ASTM).

Os dados de precisão, repetitividade e reprodutibilidade, fornecidos nos métodos relacionados a seguir, devem ser usados somente como guia para aceitação das determinações em duplicata do ensaio e não devem ser considerados como tolerância aplicada aos limites especificados neste Regulamento.

A análise do produto deverá ser realizada em amostra representativa do mesmo, obtida segundo método ASTM D 4057 - Practice for Manual Sampling of Petroleum and Petroleum Products.

As características constantes da Tabela de Especificação deverão ser determinadas de acordo com a publicação mais recente dos seguintes métodos de ensaio:

\begin{tabular}{|c|c|}
\hline Método ABNT & TÍTULO \\
\hline MB 424 & $\begin{array}{l}\text { Produtos líquidos de petróleo - Determinação dos tipos de hidrocarbonetos pelo } \\
\text { indicador de absorção por fluorescência }\end{array}$ \\
\hline MB 457 & $\begin{array}{l}\text { Combustível - Determinação das características antidetonantes - Índice de octano - } \\
\text { Método motor }\end{array}$ \\
\hline NBR 4149 & $\begin{array}{l}\text { Gasolina e misturas de gasolina com produtos oxigenados - Determinação da pressão } \\
\text { de vapor - Método seco }\end{array}$ \\
\hline NBR 6563 & $\begin{array}{l}\text { Gás Liqüefeito de Petróleo e Produtos Líquidos de Petróleo - Determinação de } \\
\text { enxofre - Método da lâmpada }\end{array}$ \\
\hline NBR 7148 & $\begin{array}{l}\text { Petróleo e Produtos de Petróleo - Determinação da massa específica, densidade } \\
\text { relativa }{ }^{\circ} \mathrm{API} \text { - Método do densímetro }\end{array}$ \\
\hline NBR 9619 & Produtos de Petróleo - Determinação das propriedades de destilação \\
\hline NBR 13992 & $\begin{array}{l}\text { Gasolina Automotiva - Determinação do teor de álcool etílico anidro combustível } \\
\text { (AEAC) }\end{array}$ \\
\hline
\end{tabular}




\begin{tabular}{|l|l||} 
NBR 14065 & $\begin{array}{l}\text { Destilados de Petróleo e Óleos Viscosos - Determinação da massa específica e da } \\
\text { densidade relativa pelo densímetro digital. }\end{array}$ \\
\hline \hline NBR 14156 & Produtos de Petróleo - Determinação da pressão de vapor - Minimétodo \\
\hline NBR 14359 & Produtos de Petróleo - Determinação da corrosividade - Método da lâmina de cobre \\
\hline NBR 14478 & $\begin{array}{l}\text { Gasolina - Determinação da estabilidade à oxidação pelo método do período de } \\
\text { indução }\end{array}$ \\
\hline \hline NBR 14525 & Combustíveis - Determinação de goma por evaporação \\
\hline NBR 14533 & $\begin{array}{l}\text { Produtos de Petróleo - Determinação do enxofre por Espectrometria de Fluorescência } \\
\text { de Raios X (Energia Dispersiva) }\end{array}$ \\
\hline
\end{tabular}

\begin{tabular}{|c|c|}
\hline Método ASTM & TÍTULO \\
\hline D 86 & Distillation of Petroleum Products \\
\hline D 130 & $\begin{array}{l}\text { Detection of Copper Corrosion from Petroleum Products by the Copper Strip Varnish } \\
\text { Test }\end{array}$ \\
\hline D 381 & Existent Gum in Fuels by Jet Evaporation. \\
\hline D 525 & Oxidation Stability of Gasoline (Induction Period Method). \\
\hline D 1266 & Sulfur in Petroleum Products (Lamp Method) \\
\hline D 1298 & $\begin{array}{l}\text { Density, Relative Density (Specific Gravity), of API Gravity of Crude Petroleum and } \\
\text { Liquid Petroleum Products by Hydrometer Method }\end{array}$ \\
\hline D 1319 & Hydrocarbons Types in Liquid Petroleum Products by Fluorescent Indicator Adsorption \\
\hline D 2622 & $\begin{array}{l}\text { Sulfur in Petroleum Products by Wavelenght Dispersive X-Ray Fluorescence } \\
\text { Spectrometry }\end{array}$ \\
\hline D 2699 & Knock Characteristics of Motor and Aviation Fuels by the Research Method \\
\hline D 2700 & Knock Characteristics of Motor and Aviation Fuels by the Motor Method \\
\hline D 3120 & $\begin{array}{l}\text { Trace Quantities of Sulfur in Light Liquid Petroleum Hydrocarbons by Oxidative } \\
\text { Microcoulometry }\end{array}$ \\
\hline D 3237 & Lead In Gasoline By Atomic Absorption Spectroscopy \\
\hline D 3606 & $\begin{array}{l}\text { Benzene and Toluene in Finished Motor and Aviation Gasoline by Gas } \\
\text { Chromatography }\end{array}$ \\
\hline D 4052 & Density and Relative Density of Liquids by Digital Density Meter \\
\hline D 4294 & Sulfur in Petroleum Products by Energy Dispersive X-Ray Fluorescence Spectroscopy \\
\hline D 4953 & Vapor Pressure of Gasoline and Gasoline-oxygenate Blends (Dry Method) \\
\hline D 5190 & Vapor Pressure of Petroleum Products (Automatic Method) \\
\hline D 5191 & Vapor Pressure of Petroleum Products (Mini Method) \\
\hline D 5443 & $\begin{array}{l}\text { Paraffin, Naphthene, and Aromatic Hydrocarbon Type Analysis in Petroleum Distillates } \\
\text { Through } 200^{\circ} \mathrm{C} \text { by Multi-Dimensional Gas Chromatography }\end{array}$ \\
\hline D 5453 & Sulphur in light hydrocarbons, motor fuels and oils by ultraviolet fluorescence \\
\hline D 5482 & Vapor Pressure of Petroleum Products (Mini Method - Atmospheric) \\
\hline
\end{tabular}



Spectroscopy.

\section{Tabela de Especificação}

\begin{tabular}{|c|c|c|c|c|c|c|c|}
\hline \multirow{3}{*}{ CARACTERÍSTICA } & \multirow[t]{3}{*}{ UNIDADE } & \multicolumn{4}{|c|}{ ESPECIFICAÇÃO } & \multirow{2}{*}{\multicolumn{2}{|c|}{ MÉTODO }} \\
\hline & & \multicolumn{2}{|c|}{ Gasolina Comum } & \multicolumn{2}{|c|}{ Gasolina Premium } & & \\
\hline & & Tipo A & Tipo C & Tipo A & Tipo C & ABNT & ASTM \\
\hline Cor & - & (1) & $(2)$ & (1) & $(2)$ & \multirow{2}{*}{\multicolumn{2}{|c|}{ visual (3) }} \\
\hline Aspecto & - & $(4)$ & $(4)$ & (4) & $(4)$ & & \\
\hline $\begin{array}{l}\text { Álcool Etílico Anidro } \\
\text { Combustível - AEAC }\end{array}$ & $\%$ vol & $\begin{array}{l}1 \text { máx } \\
(5) .\end{array}$ & $(6)$ & $\begin{array}{l}1 \\
(5)\end{array}$ & $(6)$ & \multicolumn{2}{|l|}{ NBR 13992} \\
\hline $\begin{array}{|lll|}\text { Massa } & \text { específica } & \text { a } \\
20^{\circ} \mathrm{C} & & \end{array}$ & $\mathrm{kg} / \mathrm{m} 3$ & anotar & anotar & anotar & anotar & $\begin{array}{l}\text { NBR } 7148 \\
\text { NBR } 14065\end{array}$ & $\begin{array}{l}\text { D } 1298 \\
\text { D } 4052\end{array}$ \\
\hline Destilação & & & & & & NBR 9619 & D 86 \\
\hline $10 \%$ evaporado, máx. & ${ }^{\circ} \mathrm{C}$ & 65,0 & 65,0 & 65,0 & 65,0 & & \\
\hline $50 \%$ evaporado, máx. & ${ }^{\circ} \mathrm{C}$ & 120,0 & 80,0 & 120,0 & 80,0 & & \\
\hline $\begin{array}{ll}90 \% & \text { evaporado, } \\
\text { máx.(7) } & \end{array}$ & ${ }^{\circ} \mathrm{C}$ & 190,0 & 190,0 & 190,0 & 190,0 & & \\
\hline PFE, máx. & ${ }^{\circ} \mathrm{C}$ & 220,0 & 220,0 & 220,0 & 220,0 & & \\
\hline Resíduo, máx. & $\%$ vol & 2,0 & 2,0 & 2,0 & 2,0 & & \\
\hline $\begin{array}{l}\text { No de Octano Motor - } \\
\text { MON, mín. }\end{array}$ & - & (8) (9) & $82,0(9)$ & - & - & MB 457 & D 2700 \\
\hline $\begin{array}{l}\text { Índice Antidetonante - } \\
\text { IAD, mín.(10) }\end{array}$ & - & (8) & 87,0 & (8) & 91,0 & MB 457 & $\begin{array}{l}\text { D } 2699 \\
\text { D } 2700 \\
\end{array}$ \\
\hline $\begin{array}{l}\text { Pressão de Vapor } \\
\text { a } 37,8^{\circ} \mathrm{C}(11)\end{array}$ & $\mathrm{kPa}$ & $\begin{array}{ll}45,0 & a \\
62,0 & \end{array}$ & 69,0 máx. & $\begin{array}{ll}45,0 & a \\
62,0 & \end{array}$ & 69,0 máx. & $\begin{array}{l}\text { NBR } 4149 \\
\text { NBR } 14156\end{array}$ & $\begin{array}{l}\text { D } 4953 \\
\text { D } 5190 \\
\text { D } 5191 \\
\text { D } 5482\end{array}$ \\
\hline $\begin{array}{l}\text { Goma Atual Lavada, } \\
\text { máx. }\end{array}$ & $\begin{array}{l}\mathrm{mg} / 100 \\
\mathrm{ml}\end{array}$ & 5 & 5 & 5 & 5 & NBR 14525 & D 381 \\
\hline $\begin{array}{l}\text { Período de Indução a } \\
100^{\circ} \mathrm{C} \text {, mín. }\end{array}$ & $\min$ & $(12)(13)$ & 360 & $(12)(13)$ & 360 & NBR 14478 & D 525 \\
\hline \begin{tabular}{|lr} 
Corrosividade & ao \\
Cobre a $50^{\circ} \mathrm{C}$, & $3 \mathrm{~h}$,
\end{tabular} & - & 1 & 1 & 1 & 1 & NBR 14359 & D 130 \\
\hline
\end{tabular}




\begin{tabular}{|c|c|c|c|c|c|c|c|}
\hline máx. & & & & & & & \\
\hline Enxofre, máx. (14) & $\%$ massa & 0,12 & 0,10 & 0,12 & 0,10 & $\begin{array}{l}\text { NBR } 6563 \\
\text { NBR } 14533\end{array}$ & $\begin{array}{l}\text { D } 1266 \\
\text { D } 2622 \\
\text { D } 3120 \\
\text { D } 4294 \\
\text { D } 5453\end{array}$ \\
\hline Benzeno, máx. (14) & $\%$ vol & 1,2 & 1,0 & 1,9 & 1,5 & - & $\begin{array}{l}\text { D } 3606 \\
\text { D } 5443 \\
\text { D } 6277\end{array}$ \\
\hline Chumbo, máx. (5) & $g / L$ & 0,005 & 0,005 & 0,005 & 0,005 & - & D 3237 \\
\hline Aditivos (15) & - & - & - & - & - & - & - \\
\hline $\begin{array}{l}\text { Hidrocarbonetos: (14) } \\
\text { (16) }\end{array}$ & $\%$ vol & & & & & MB 424 & D 1319 \\
\hline Aromáticos, máx. (17) & & 57 & 45 & 57 & 45 & & \\
\hline Olefínicos, máx. (17) & & 38 & 30 & 38 & 30 & & \\
\hline
\end{tabular}

(1) De incolor a amarelada, isenta de corante.

(2) De incolor a amarelada se isenta de corante cuja utilização é permitida no teor máximo de 50ppm com exceção da cor azul, restrita à gasolina de aviação

(3) A visualização será realizada em proveta de vidro, conforme a utilizada no Método NBR 7148 ou ASTM D 1298.

(4) Límpido e isento de impurezas.

(5) Proibida a adição. Deve ser medido quando houver dúvida quanto à ocorrência de contaminação.

(6) O AEAC a ser misturado às gasolinas automotivas para produção da gasolina $C$ deverá estar em conformidade com o teor e a especificação estabelecidos pela legislação em vigor.

(7) No intuito de coibir eventual presença de contaminantes o valor da temperatura para $90 \%$ de produto evaporado não poderá ser inferior à $155^{\circ} \mathrm{C}$ para gasolina $\mathrm{A} e$ $145^{\circ} \mathrm{C}$ para gasolina $\mathrm{C}$.

(8) A Refinaria, a Central de Matérias-Primas Petroquímicas, o Importador e o Formulador deverão reportar o valor das octanagem MON e do IAD da mistura de gasolina A, de sua produção ou importada, com AEAC no teor mínimo estabelecido pela legislação em vigor. 
(9) Fica permitida a comercialização de gasolina automotiva com MON igual ou superior a 80 até 30/06/2002.

(10) Índice antidetonante é a média aritmética dos valores das octanagens determinadas pelos métodos MON e RON.

(11) Para os Estados do Rio Grande do Sul, Santa Catarina, Paraná, São Paulo, Rio de Janeiro, Espírito Santo, Minas Gerais, Mato Grosso, Mato Grosso do Sul, Goiás e Tocantins, bem como para o Distrito Federal, admite-se, nos meses de abril a novembro, um acréscimo de 7,0kPa ao valor máximo especificado para a Pressão de Vapor.

(12) A Refinaria, a Central de Matérias-Primas Petroquímicas, o Importador e o Formulador deverão reportar o valor do Período de Indução da mistura de gasolina $A$, de sua produção ou importada, com AEAC no teor máximo estabelecido pela legislação em vigor.

(13) O ensaio do Período de Indução só deve interrompido após 720 minutos, quando aplicável, em pelo menos $20 \%$ das bateladas comercializadas. Neste caso, e se interrompido antes do final, deverá ser reportado o valor de 720 minutos.

(14) Os teores máximos de Enxofre, Benzeno, Hidrocarbonetos Aromáticos e Hidrocarbonetos Olefínicos permitidos para a gasolina $A$ referem-se àquela que transformar-se-á em gasolina $C$ através da adição de $22 \% \pm 1 \%$ de álcool. No caso de alteração legal do teor de álcool na gasolina os teores máximos permitidos para os componentes acima referidos serão automaticamente corrigidos proporcionalmente ao novo teor de álcool regulamentado.

(15) Utilização permitida conforme legislação em vigor, sendo proibidos os aditivos a base de metais pesados.

(16) Fica permitida alternativamente a determinação dos hidrocarbonetos aromáticos e olefínicos por cromatografia gasosa. Em caso de desacordo entre resultados prevalecerão os valores determinados pelos ensaios MB424 e D1319.

(17) Até 30/06/2002 os teores de Hidrocarbonetos Aromáticos e Olefínicos podem ser apenas informados. 


\title{
ANEXO B - RESOLUÇÃO ANP NNo 36 (Regulamento técnico)
}

\author{
REGULAMENTO TÉCNICO ANP No 7/2005
}

\section{Objetivo}

Este Regulamento Técnico aplica-se ao Álcool Etílico Anidro Combustível (AEAC) e ao Álcool Etílico Hidratado Combustível (AEHC), nacional ou importado, para uso como combustível e estabelece as suas especificações.

\section{Normas complementares}

A determinação das características do produto far-se-á mediante o emprego de Normas Brasileiras (NBR) da Associação Brasileira de Normas Técnicas (ABNT) ou das Normas da American Society for Testing and Materials (ASTM).

Os dados de exatidão, repetitividade e reprodutibilidade fornecidos nos métodos relacionados a seguir devem ser usados somente como guia para aceitação das determinações em duplicata do ensaio e não devem ser considerados como tolerância aplicada aos limites especificados neste Regulamento.

A análise do produto deverá ser realizada em amostra representativa do mesmo, coletada segundo as normas ASTM D4057 - Practice for Manual Sampling of Petroleum and Petroleum Products ou ASTM E300 - Practice for Sampling Industrial Chemicals.

3. As características constantes da Tabela das Especificações deverão ser determinadas de acordo com a publicação mais recente dos seguintes métodos de ensaio:

\begin{tabular}{|l|l||}
\hline MÉTODO & TÍTULO \\
\hline NBR 5992 & Determinação da massa específica e do teor alcoólico do Álcool Etílico e suas misturas com água \\
\hline NBR 8644 & Álcool Etílico Combustível - Determinação do resíduo por evaporação \\
\hline NBR 9866 & Álcool Etílico - Verificação da alcalinidade e determinação da acidez total \\
\hline NBR 10422 & Álcool Etílico - Determinação do teor de sódio por fotometria de chama \\
\hline NBR 10547 & Álcool Etílico - Determinação da condutividade elétrica \\
\hline NBR 10891 & Álcool Etílico Hidratado - Determinação do pH \\
\hline NBR 10893 & Álcool Etílico - Determinação do teor do cobre por espectrofotometria de absorção atômica \\
\hline
\end{tabular}




\begin{tabular}{|l|l||}
\hline NBR 10894 & Álcool Etílico - Determinação dos íons cloreto e sulfato por cromatografia iônica \\
\hline NBR 10895 & Álcool Etílico - Determinação do teor de íon cloreto por técnica potenciométrica \\
\hline NBR 11331 & Álcool Etílico - Determinação do teor de ferro por espectrofotometria de absorção atômica \\
\hline NBR 12120 & Álcool Etílico - Determinação do teor de sulfato por volumetria \\
\hline NBR 13993 & Álcool Etílico - Determinação do teor de hidrocarbonetos \\
\hline ASTM D512 & Chloride Ion in Water \\
\hline \hline ASTM D1125 & Electrical Conductivity and Resistivity of Water \\
\hline ASTM D1613 & Acidity in Volatile Solvents and Chemical Intermediates Used in Paint, Varnish, Lacquer and \\
\hline $\begin{array}{l}\text { ASTM D4052 } \\
\text { ASTM D5501 }\end{array}$ & Density and Relative Density of Liquids by Digital Density Meter \\
\hline ASTMination of Ethanol Content of Denatured Fuel Ethanol by Gas Chromatography \\
\hline
\end{tabular}


Tabela I - Especificações do AEAC e do AEHC

\begin{tabular}{|c|c|c|c|c|c|}
\hline \multirow[t]{2}{*}{ CARACTERÍSTICA } & \multirow[t]{2}{*}{ UNIDADE } & \multicolumn{2}{|c|}{ ESPECIFICAÇÕES } & \multicolumn{2}{|l|}{ MÉTODO } \\
\hline & & AEAC & AEHC & ABNT/NBR & ASTM (1) \\
\hline Aspecto & - & (2) & (2) & \multicolumn{2}{|l|}{ Visual } \\
\hline Cor & - & (3) & (4) & \multicolumn{2}{|l|}{ Visual } \\
\hline $\begin{array}{l}\text { Acidez total (como ácido } \\
\text { acético), máx. }\end{array}$ & $\mathrm{mg} / \mathrm{L}$ & 30 & 30 & 9866 & D 1613 \\
\hline Condutividade elétrica, máx & $\mu \mathrm{S} / \mathrm{m}$ & 500 & 500 & 10547 & D 1125 \\
\hline Massa específica a $20^{\circ} \mathrm{C}$ & $\mathrm{kg} / \mathrm{m} 3$ & 791,5 máx. & $\begin{array}{l}807,6 \text { a } 811,0 \\
(5)\end{array}$ & 5992 & D 4052 \\
\hline Teor alcoólico & INPM & 99,3 mín. & 92,6 a $93,8(5)$ & 5992 & - \\
\hline Potencial hidrogeniônico $(\mathrm{pH})$ & - & - & 6,0 a 8,0 & 10891 & - \\
\hline $\begin{array}{l}\text { Resíduo por evaporação, máx. } \\
\text { (6) }\end{array}$ & $\mathrm{mg} / 100 \mathrm{Ml}$ & - & 5 & 8644 & - \\
\hline $\begin{array}{l}\text { Teor de hidrocarbonetos, } \\
\text { máx.(6) }\end{array}$ & $\%$ vol. & 3,0 & 3,0 & 13993 & - \\
\hline Íon Cloreto, máx. (6) & $\mathrm{mg} / \mathrm{kg}$ & - & 1 & 10894 / 10895 & D 512(7) \\
\hline Teor de etanol, mín. (8) & $\%$ vol. & 99,6 & 95,1 & - & D 5501 \\
\hline Íon Sulfato, máx.(9) & $\mathrm{mg} / \mathrm{kg}$ & - & 4 & $10894 / 12120$ & - \\
\hline Ferro, máx. (9) & $\mathrm{mg} / \mathrm{kg}$ & - & 5 & 11331 & - \\
\hline Sódio, máx. (9) & $\mathrm{mg} / \mathrm{kg}$ & - & 2 & 10422 & - \\
\hline Cobre, máx. (9) (10) & $\mathrm{mg} / \mathrm{kg}$ & 0,07 & - & 10893 & - \\
\hline
\end{tabular}

(1) Poderão ser utilizados como métodos alternativos para avaliação das características nos casos de importação do álcool, com exceção do método ASTM D4052, que poderá ser sempre utilizado como método alternativo para a determinação da massa específica.

(2) Límpido e isento de impurezas.

(3) Incolor antes da adição de corante, segundo especificação constante da Tabela II deste Regulamento Técnico, que deverá ser adicionado no teor de $15 \mathrm{mg} / \mathrm{L}$ proporcionando ao produto a cor laranja. 
(4) Incolor.

(5) Aplicam-se na Importação, Distribuição e Revenda os seguintes limites para massa específica e teor alcoólico do AEHC: 805,0 a 811,0 e 92,6 a 94,7 respectivamente.

(6) Limite requerido na Importação, Distribuição e Revenda, não sendo exigida esta análise para emissão do Certificado da Qualidade pelos Produtores.

(7) Procedimento C e modificação constante na ASTM D4806.

(8) Requerido quando o álcool não for produzido por via fermentativa a partir da cana-deaçúcar ou em caso de dúvida quando da possibilidade de contaminação por outros tipos de álcool.

(9) O produtor deverá transcrever no Certificado da Qualidade o resultado obtido na última determinação quinzenal, conforme previsto no $\S 1^{\circ}$ do Art. $5^{\circ}$ da presente Resolução.

(10) Deverá ser determinado no AEAC que tiver sido transportado ou produzido em local que possua equipamentos ou linhas de cobre, ou ligas que contenham este metal.

Tabela II - Especificação do corante a ser adicionado ao álcool etílico anidro combustível (AEAC)

\begin{tabular}{|c|c|c|}
\hline Característica & Especificação & Método \\
\hline \multirow{2}{*}{$\begin{array}{l}\text { Aspecto líquido visual Família } \\
\text { química (\&quot;Color index\&quot;) }\end{array}$} & Solvent Red 19 ou Solvent Red 164 & - \\
\hline & Solvent Yellow 174 & - \\
\hline Cor & laranja & visual \\
\hline Absorvância a 420 nm & 0,150 a 0,190 & \multirow[t]{2}{*}{$(*)$} \\
\hline Absorvância a $530 \mathrm{~nm}$ & 0,100 a 0,135 & \\
\hline Solubilidade & solúvel em AEAC e insolúvel em água & visual $(* *)$ \\
\hline
\end{tabular}

(*) A absorbância deve ser determinada em amostra contendo $15 \mathrm{mg} / \mathrm{L}$ do corante em AEAC, medida em célula de caminho ótico de $1 \mathrm{~cm}$, no valor especificado para o comprimento de onda.

(**) A solubilidade deve ser avaliada em amostra contendo $15 \mathrm{mg} / \mathrm{L}$ do corante em AEAC. 
Anexo B 


\section{ANEXO C - Boletim Mensal de Qualidade}

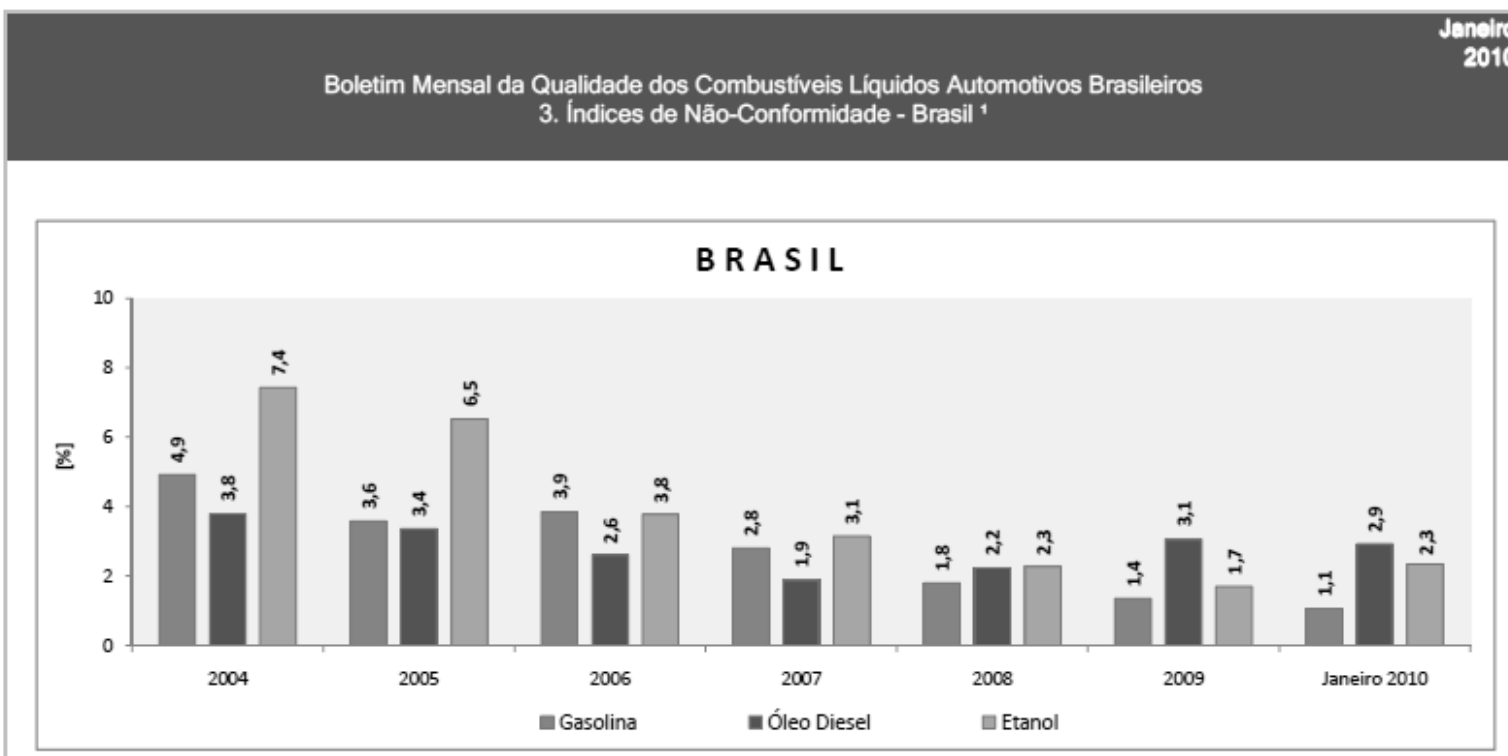

\begin{tabular}{|c|c|c|c|c|c|c|c|c|c|c|c|c|c|c|c|}
\hline Perlodo & & & & & & & & & 20 & & & & & eiro 20 & \\
\hline Produtas & NT & NC & NT & NC & NT & NC & NT & NC & NT & NC & NT & NC & NT & NC & $\%$ \\
\hline Gasolna & 90.236 & 4.434 & 96.146 & 3.442 & 77.656 & 2.991 & 68.086 & 1.913 & 70.555 & 1.268 & 74.934 & 1.012 & 6.237 & 66 & 1,1 \\
\hline Óleo Diesel & 27.926 & 1.059 & 31.300 & 1.050 & 51.223 & 1.335 & 58.172 & 1.099 & 60.124 & 1.347 & 67.535 & 2.065 & 5.718 & 167 & 2,9 \\
\hline Elanol & 14.822 & 1.100 & 20.781 & 1.354 & 60.807 & 2.297 & 42.792 & 1.343 & 43.833 & 996 & 41.350 & 702 & 3.286 & 77 & 2,3 \\
\hline TOTAIS & 132.984 & 6.593 & 148.227 & 5.846 & 189.686 & 6.623 & 169.050 & 4.355 & 174.512 & 3.611 & 183.819 & 3.779 & 15.241 & 310 & 2,0 \\
\hline
\end{tabular}

Grdfico mensal de ndo-conformidades por natureza'. Dados Brasll - Janelro 2010

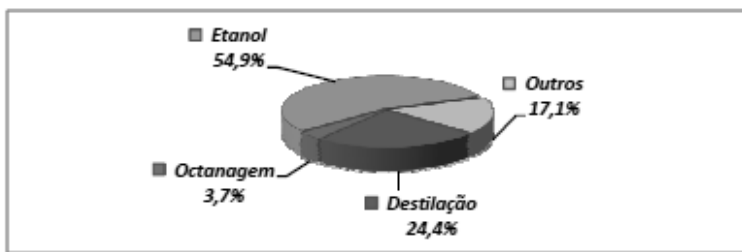

\begin{tabular}{|l|r|r|}
\hline Gasolina & NC & \multicolumn{1}{|c|}{$\boldsymbol{\%}$} \\
\hline Destilaçăo & 20 & 24,4 \\
\hline Octanagem & 3 & 3,7 \\
\hline Etanol & 45 & 54,9 \\
\hline Outros & 14 & 17,1 \\
\hline NC Totais & 82 & 100,0 \\
\hline
\end{tabular}
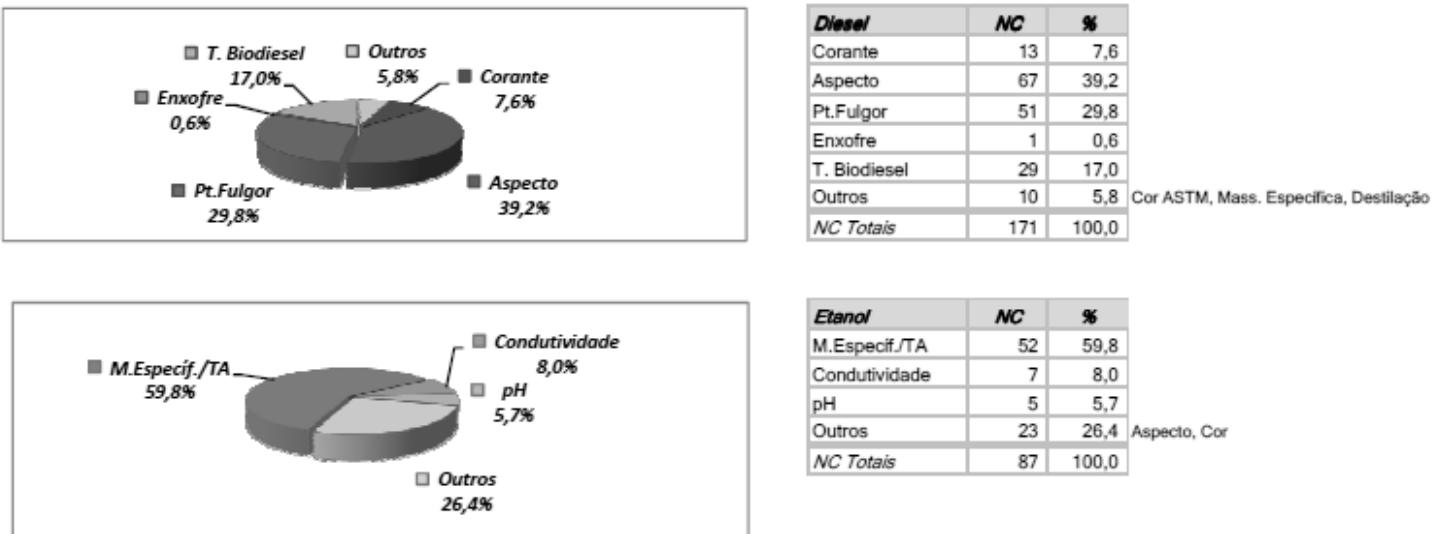

Nota:

' Dados de monitoramento obtidos no ano corrente até o mês de referência deste boletim.

${ }^{2}$ Cada amostra analisada pode conter uma ou mais nâo-conformidades.

NT= Número total de amostras coletadas

NC= Número de amostras năo-conformes de acordo com às especficaçб̃es da ANP 